INSTITUTO DE PESQUISAS ENERGÉTICAS E NUCLEARES Autarquia Associada à Universidade de São Paulo

ESTUDOS DA UTILIZAÇÃO DA CINZA DE CASCA DE ARROZ COMO CARGA EM MATRIZ DE POLIPROPILENO E DO EFEITO DA RADIAÇÃO IONIZANTE SOBRE ESTE COMPÓSITO

EDUARDO DE FARIA ALFARO

Dissertação apresentada como parte dos requisitos para obtenção do Grau de Mestre em Ciências na Área de Tecnologia Nuclear Aplicações.

Orientador:

Dr. Leonardo Gondim de Andrade e Silva 
Dedico este trabalho a Deus que sempre me deu forças para continuar. Aos meus pais José Romero (in memoriam) e Odete Alfaro pelo dom da vida. A minha esposa Edina Maria e a minha filha Beatriz Alfaro pelo incentivo, compreensão e carinho. 


\section{AGRADECIMENTOS}

Ao Dr. Leonardo Gondim de Andrade e Silva pela orientação nas diversas fases percorridas na realização do trabalho.

Ao Instituto de Pesquisas Energéticas e Nucleares pela oportunidade a mim concedida para a realização deste trabalho.

À Universidade Mackenzie e à Prof. Dra. Leila Figueiredo de Miranda pela autorização na utilização do laboratório de Processamento de Materiais.

Aos técnicos Luiz Henrique da Silveira, Abner Cabral Neto, Maria Lioba Luciancencov Crespo e também ao estagiário Sergio Ciampolini Nogueira de Lima pela cooperação na realização dos testes.

Ao MSc. Hiroshi Oikawa pela realização dos testes de infravermelho.

Ao Prof. Dr. Mauro Terence pela ajuda na interpretação dos testes de microscopia eletrônica de varredura e espectroscopia de absorção na região do infravermelho.

Aos engenheiros Carlos Gaia e Elizabeth Somessari pela irradiação das amostras.

Aos colegas Djalma Batista e Alex Correia pela ajuda nos ensaios térmicos.

A Mariana Machado da Basell Poliolefinas pela ajuda nos testes da primeira parte do trabalho.

Ao MSc. Delmo Amari Nishitsuji e Lea Sarita Montagna pelas análises de microscopia eletrônica de varredura .

Aos colegas do Hospital Cachoeirinha Maria Eudocia R. Muricy, Carla de Fátima Machado e Maria Christina Godoy pelo apoio e compreensão ao longo de todo o trabalho.

A todos que direta ou indiretamente contribuíram na realização deste trabalho. 


\title{
ESTUDOS DA UTILIZAÇÃO DA CINZA DE CASCA DE ARROZ COMO \\ CARGA EM MATRIZ DE POLIPROPILENO E DO EFEITO DA RADIAÇÃO IONIZANTE SOBRE ESTE COMPÓSITO
}

\author{
Eduardo de Faria Alfaro
}

\begin{abstract}
RESUMO
Na primeira etapa deste trabalho foi avaliada a potencialidade do uso da cinza de casca de arroz como carga em polipropileno (PP) comparando-a com o talco que é a carga mineral mais utilizada em polímeros. Esta comparação foi feita utilizando os compósitos formados por polipropileno com $20 \%$ da cinza de casca de arroz assim como, os formados por polipropileno com $20 \%$ de talco, determinando as suas propriedades. Apesar das propriedades do compósito de PP com a carga de $20 \%$ de cinza de casca de arroz apresentarem resultados inferiores em relação àqueles quando se utilizou o talco como carga, pode-se dizer que a cinza de casca de arroz pode ser usada como carga para outros usos menos nobres do PP. Desta forma se está dando um destino para esse resíduo que hoje é descartado no meio ambiente contribuindo assim, para a preservação do mesmo, além de reduzir o custo do produto. Este trabalho também teve como objetivo estudar o efeito da radiação ionizante nas propriedades destes compósitos de PP com $20 \%$ de cinza de casca de arroz. Utilizou-se o agente de acoplagem, anidrido maleico, para verificar se houve melhora na homogeneização das amostras. Em virtude do PP ser um polímero semicristalino, quando exposto ao processo de irradiação, tem sua morfologia modificada devido aos mecanismos de cisão das cadeias poliméricas. Este fato é atribuído aos mecanismos de cisão das cadeias poliméricas, que está de acordo com a literatura.
\end{abstract}




\title{
STUDY OF THE RICE HUSK ASH UTILIZATION AS FILLER IN POLYPROPYLENE MATRIX AND IONIZATION RADIATION EFFECT ON THIS COMPOSITE
}

\author{
Eduardo de Faria Alfaro
}

\begin{abstract}
In the first step of this work, it was evaluated the possibility of using rice husk ash as a filler in polypropylene (PP) making a comparison with talc which is the most used mineral filler in polymers. This comparison was made by using polypropylene with $20 \%$ rice husk ash as well as polypropylene with $20 \%$ talc measuring their properties. Despite the properties of the PP with $20 \%$ rice husk ash decreased compared with the composite of polypropylene with $20 \%$ talc it can be said that the rice husk ash can be used as filler for or other utilization less noble of PP. This way it is being given a destination for this residue that it is disposable in the environment contributing to its preservation, moreover reducing the product cost. This work had also as an aim to study the ionizing radiation effect in the properties of these composites. It was used the coupling agent, maleic anhydride, to verify a best sample homogenization. According to the results it can be said that PP is a semicrystalline polymer, and so it has its morphology modified when exposed to the irradiation process. This fact is due to the scission mechanisms of the polymeric chains which it is in compliance to the literature.
\end{abstract}




\section{SUMÁRIO}

\section{Página}

1 INTRODUÇÃO

2 OBJETIVOS E FINALIDADE

3 PARTE EXPERIMENTAL

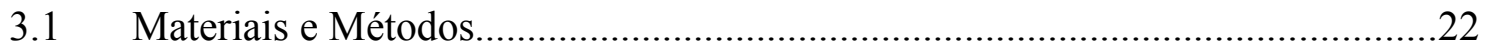

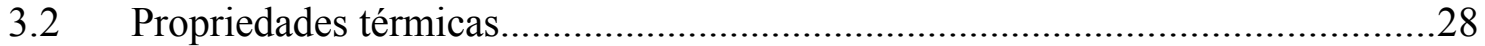

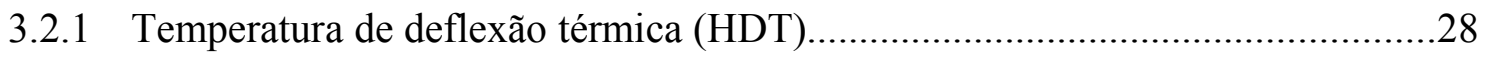

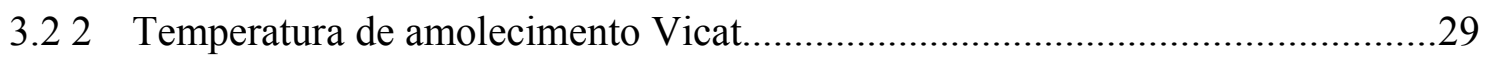

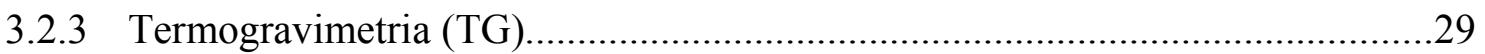

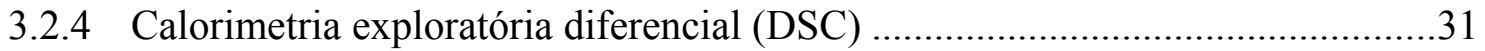

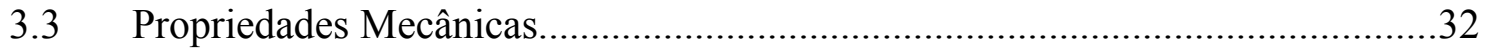

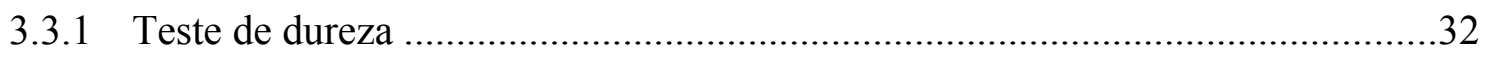

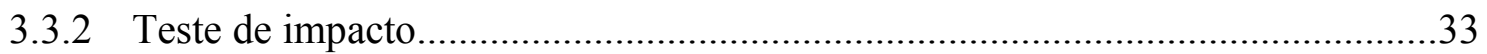

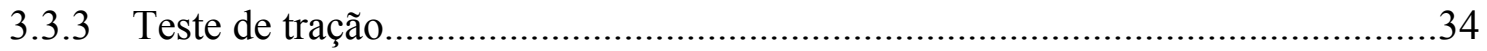

3.4 Microscopia eletrônica de varredura (MEV) ................................................... 35

3.5 Espectroscopia de absorção na região do infravermelho (IV)......................... 35

$4 \quad$ RESULTADOS E DISCUSSÃO

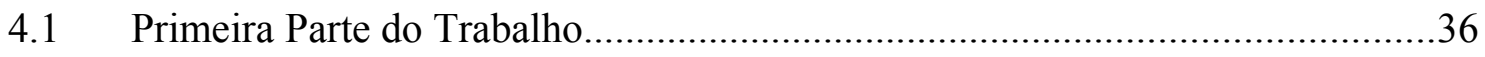

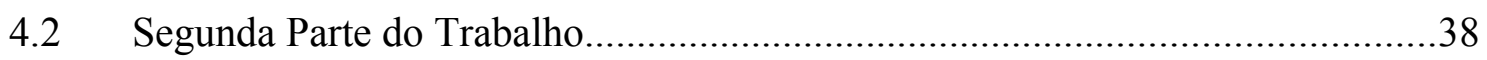

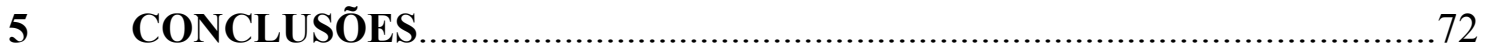

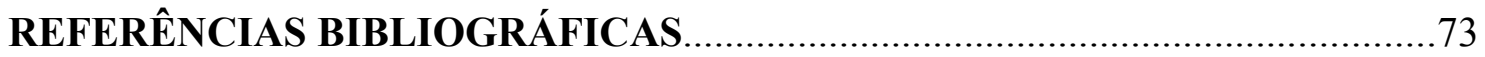




\section{LISTA DE TABELAS}

\section{Página}

TABELA 1 Parâmetros da extrusão dos compostos estudados........................22

TABELA 2 Informações técnicas do polipropileno HP-500N.........................23

TABELA 3 Composição da cinza de casca de arroz...........................................36

TABELA 4 Propriedades do PP com $20 \%$ de talco e do PP com $20 \%$ de cinza

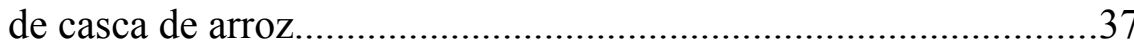

TABELA 5 Resultados de temperatura de deflexão térmica de amostrasde PP submetidas a diferentes doses de radiação

TABELA 6 Resultados de temperatura de deflexão térmica de amostras de PP com cinza de casca de arroz submetidas a diferentes doses de radiação

TABELA 7 Resultados de temperatura de deflexão térmica de amostras de PP com cinza de casca de arroz e agente de acoplagem submetidas a diferentes doses de radiação. .42

TABELA 8 Resultados de temperatura de amolecimento Vicat de amostras de PP submetidas a diferentes doses de radiação 44

TABELA 9 Resultados de temperatura de amolecimento Vicat de amostras de PP com cinza de casca de arroz submetidas a diferentes doses de radiação . .45

TABELA 10 Resultados de temperatura de amolecimento Vicat de amostras de PP com cinza de casca de arroz e agente de acoplagem submetidas a diferentes doses de radiação. 
TABELA 11 Resultados de análises DSC de amostras de PP submetidas a diferentes doses de radiação

TABELA 12 Resultados de análises DSC de amostras de PP com cinza de casca de arroz submetidas a diferentes doses de radiação.

TABELA 13 Resultados de análises DSC de amostras de PP com cinza de casca de arroz e agente de acoplagem submetidas a diferentes doses de radiação

TABELA 14 Resultados de análises TG de amostras de PP submetidas a diferentes doses de radiação

TABELA 15 Resultados de análises TG de amostras de PP com cinza de casca de arroz submetidas a diferentes doses de radiação.

TABELA 16 Resultados de análises TG de amostras de PP com cinza de casca de arroz e agente de acoplagem submetidas a diferentes doses de radiação

TABELA 17 Resultados de testes de dureza Shore D de amostras de PP, PP + $\mathrm{CCA}$ e de PP + CCA + AG submetidas a diferentes doses de radiação

TABELA 18 Resultados de testes de impacto Izod com PP, PP + CCA e PP + $\mathrm{CCA}+\mathrm{AG}$ para amostras submetidas a diferentes doses de radiação

TABELA 19 Resultados de testes de tensão na ruptura de amostras de PP, PP + $\mathrm{CCA}$ e de $\mathrm{PP}+\mathrm{CCA}+\mathrm{AG}$ submetidas a diferentes doses de radiação 


\section{LISTA DE FIGURAS}

\section{Página}

FIGURA 1 Reação de formação e unidade estrutural do polipropileno 18

FIGURA 2 Reômetro marca HAAKE modelo RHEODRIVE 5000 acoplado ao acessório de extrusão de rosca simples com matriz capilar marca HAAKE modelo Rheomix 252.

FIGURA 3 Acessório de extrusão de rosca simples com matriz capilar marca HAAKE modelo Rheomix 252.

FIGURA 4 Injetora ROMI PRIMAX 65R .26

FIGURA 5 Acelerador de elétrons Dynamitron II modelo DC 1500 JOB 188......27

FIGURA 6 Equipamento da Tinius Olsen para ensaios de HDT e Vicat. .28

FIGURA 7 Balança Shimadzu Libror AEL - 40 SM .30

FIGURA 8 Equipamento marca Shimadzu TGA-50 para termogravimetria 30

FIGURA 9 Equipamento marca Shimadzu DSC 50 para análise de calorimetria exploratória diferencial.

FIGURA 10 Equipamento de dureza ShoreD 32

FIGURA 11 Equipamento de impacto da Tinius Olsen para ensaios do tipo Izod ..33 
FIGURA 12 Equipamento universal de ensaios da marca MTS, modelo Q TEST..34

FIGURA 13 Resultados de temperatura de deflexão térmica de amostras de PP submetidas a diferentes doses de radiação

FIGURA 14 Resultados de temperatura de deflexão térmica de amostras de PP com cinza de casca de arroz irradiadas e não irradiada. 40

FIGURA 15 Resultados de temperatura de deflexão térmica de amostras de PP e de PP com cinza de casca de arroz em amostras irradiadas e não irradiadas a diferentes doses.

FIGURA 16 Resultados de temperatura de deflexão térmica de amostras de PP com cinza de casca de arroz e agente de acoplagem submetidas a diferentes doses de radiação

FIGURA 17 Resultados de temperatura de deflexão térmica de amostras de PP com cinza de casca de arroz e de PP com cinza de casca de arroz e agente de acoplagem submetidas a diferentes doses de radiação.

FIGURA 18 Resultados de temperatura de amolecimento Vicat de amostras de PP submetidas a diferentes doses de radiação

FIGURA 19 Resultados de temperatura de amolecimento Vicat de amostras de PP com cinza de casca de arroz submetidas a diferentes doses de radiação

FIGURA 20 Resultados de temperatura de amolecimento Vicat de amostras de PP e de PP com cinza de casca de arroz em amostras irradiadas e não irradiadas 46

FIGURA 21 Resultados de temperatura de amolecimento Vicat de amostras de PP com cinza de casca de arroz e agente de acoplagem em amostras irradiadas e não irradiada. 
FIGURA 22 Resultados de temperatura de amolecimento Vicat de amostras de PP com cinza de casca de arroz e de PP com cinza de casca de arroz e agente de acoplagem em amostras irradiadas e não irradiadas.

FIGURA 23 Resultados de dureza Shore D de amostras de PP em amostras irradiadas e não irradiada.

FIGURA 24 Resultados de dureza Shore D de amostras de PP com cinza de casca de arroz em amostras irradiadas e não irradiada.

FIGURA 25 Resultados de dureza Shore D de amostras de PP e de PP com cinza de casca de arroz de amostras irradiadas e não irradiadas.

FIGURA 26 Resultados de dureza Shore D de amostras de PP com cinza de casca de arroz e agente de acoplagem em amostras irradiadas e não irradiada 55

FIGURA 27 Resultados de dureza Shore D de amostras irradiadas e não irradiadas de PP e de PP com cinza de casca de arroz e agente de acoplagem ...56

FIGURA 28 Resultados de resistência ao impacto Izod de amostras de PP em amostras irradiadas e não irradiada

FIGURA 29 Resultados de resistência ao impacto Izod de amostras de PP com cinza de casca de arroz em amostras irradiadas e não irradiada. .58

FIGURA 30 Resultados de impacto Izod de amostras irradiadas e não irradiadas de PP e de PP com cinza de casca de arroz .59

FIGURA 31 Resultados de resistência ao impacto Izod de amostras de PP com cinza de casca de arroz e agente de acoplagem em amostras irradiadas e não irradiada. 
FIGURA 32 Resultados de resistência ao impacto Izod de amostras de PP com cinza de casca de arroz e de PP com cinza de casca de arroz e agente de acoplagem em amostras irradiadas e não irradiadas

FIGURA 33 Resultados de tensão máxima em amostras de PP irradiadas e não irradiada.

FIGURA 34 Resultados de tensão máxima em amostras de PP irradiadas e não irradiada . com cinza de casca de arroz.

FIGURA 35 Resultados de tensão máxima de amostras irradiadas e não irradiadas de PP e de PP com cinza de casca de arroz.

FIGURA 36 Resultados de tensão máxima de amostras de PP com cinza de casca de arroz e agente de acoplagem em amostras irradiadas e não irradiada. .64

FIGURA 37 Resultados de tensão máxima de amostras irradiadas e não irradiadas de PP com cinza de casca de arroz e de PP com cinza de casca de arroz e agente de acoplagem.

FIGURA 38 Micrografia de amostra de PP a 0 kGy..... 66

FIGURA 39 Micrografia de amostra de PP com cinza de casca de arroz a 0 kGy...67

FIGURA 40 Micrografia de amostra de PP com cinza de casca de arroz e agente de acoplagem a $0 \mathrm{kGy}$.....

FIGURA 41 Micrografia de amostra de PP a 200 kGy 68

FIGURA 42 Micrografia de amostra de PP com cinza de casca de arroz a 200 kGy

FIGURA 43 Micrografia de amostra de PP com cinza de casca de arroz e agente de acoplagem a $200 \mathrm{kGy}$ 
FIGURA 44 Espectros de absorção na região do infravermelho das amostras de PP não irradiada e submetidas a doses de radiação de 200 e 500 kGy.....70

FIGURA 45 Espectros de absorção na região do infravermelho das amostras de PP + CCA não irradiada e submetidas a doses de radiação de 200 e 500

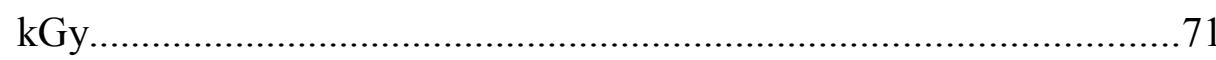




\title{
LISTA DE ABREVIAÇÕES
}

\author{
PP - Polipropileno \\ CA - Casca de arroz \\ CCA - Cinza de casca de arroz \\ $\mathrm{PE}$ - Polietileno \\ $\mathrm{PC}$ - Policarbonato \\ $\mathrm{PP}+\mathrm{CCA}+\mathrm{AG}-$ Polipropileno com cinza de arroz e agente de acoplagem \\ PP + CCA - Polipropileno com cinza de arroz \\ AG - Agente de acoplagem (anidrido maleico a $1 \%$ ) \\ HDT - Temperatura de deflexão térmica \\ $\mathrm{TG}$ - Termogravimetria \\ DSC - Calorimetria exploratória diferencial \\ CTR - Centro de Tecnologia das Radiações \\ IPEN - Instituto de Pesquisas Energéticas e Nucleares \\ CNEN - Comissão Nacional de Energia Nuclear \\ ASTM - Associação Americana de Testes de Materiais \\ NBR - Norma Brasileira \\ ABNT - Associação Brasileira de Normas Técnicas \\ ISO - Organização Internacional de Padronização \\ $\mathrm{TiCl}_{4}$ - Tetracloreto de titânio \\ $\mathrm{Al}\left(\mathrm{C}_{2} \mathrm{H}_{5}\right)_{3}$ - Tricloreto de alquil alumínio
}




\section{INTRODUÇÃO}

Inicialmente foi feita uma introdução sobre os polímeros, dando ênfase ao polipropileno que foi uma das matérias-primas utilizadas no presente trabalho, bem como sobre as cargas utilizadas em compósitos, que faz parte do tema a ser desenvolvido.

A palavra plástico se origina do idioma grego "plastikos" e significa adequado à moldagem o que define sua principal característica que é a flexibilidade (RIONIL COMPOSTOS VINÍLICOS, 2007).

Em 1862 Alexander Parkes descobriu um material orgânico, derivado da celulose (parkesina), que quando aquecido podia ser moldado e permanecia assim quando era resfriado. O tipógrafo americano John Wesley Hyatt, na tentativa de substituição do marfim, quando da fabricação de bolas de bilhar, descobriu, por acidente, um material à base de nitrato de celulose que se tornava um filme sólido e flexível (celulóide, originado de fibra de algodão com certos ácidos), isto em 12/08/1870. Leo Hendrik Baekeland obteve, em 1909, a Baquelite por meio da reação de ácido carbólico (fenol) com formaldeído. Este material foi utilizado na fabricação de pentes, botões, materiais elétricos e jóias (PLÁSTICOS CARONE LTDA, 1997).

Assim como a humanidade viveu as idades da pedra e dos metais, hoje estamos vivendo numa nova era; desde o surgimento do "nylon", em 1938, até os dias de hoje, os avanços têm sido muitos na tentativa de substituição de vários dos antigos materiais utilizados pelo homem por algum tipo de plástico (SANTOS, 2000).

Os polímeros podem ser divididos em termoplásticos e termorrígidos. Os termoplásticos podem ser fundidos várias vezes e são recicláveis, maleáveis, rígidos ou mesmo frágeis (polietileno - PE, polipropileno - PP, policarbonato - PC entre outros) e termorrígidos, sendo muito estáveis às variações de temperatura e uma vez obtidos não mais se fundem, não podem ser recicláveis, pois suas moléculas formam redes ou reticulados. Como exemplo deste tipo de material termorrígido tem-se a resina epóxi, resina fenol entre outras (GORNI, 2003). 
Os polímeros dividem-se em plásticos, fibras e elastômeros. As fibras se caracterizam por terem grande resistência e módulo, elongação boa e estabilidade térmica. Os elastômeros (borrachas) são polímeros que têm a propriedade de se alongar ou contrair rapidamente. Foram desenvolvidos elastômeros termoplásticos como o 1,4 cis poliisopreno. O estireno-butadieno, o polibutadieno e o etileno-propileno respondem por 90\% da produção total dos elastômeros (STEVENS, 1990).

Segundo alguns autores, plásticos de engenharia são polímeros que podem ser usados para substituir aplicações de engenharia como engrenagens e peças estruturais em substituição a materiais clássicos, como os metais (MANO, 1991).

As resinas termoplásticas de polipropileno são produzidas a partir do gás propileno (ponto de ebulição $=-48^{\circ} \mathrm{C}$ ) e no estado sólido são translúcidas e leitosas oferecendo bom equilíbrio em termos de propriedades térmicas, químicas e elétricas com resistência moderada a ataques de soluções ácidas, básicas ou sais inorgânicos (exceção são os compostos halogenados, ácido nítrico fumegante e outros agentes oxidantes ativos) (FISPQ, 2004). Os polipropilenos não reforçados são usados em embalagens, recipientes farmacêuticos, médicos e cosméticos. Os do tipo reforçados, com fibra de vidro, têm suas aplicações em automóveis (quase metade da produção de polipropileno), aparelhos eletrodomésticos, carcaças de baterias, motores de ventoinhas, forros de proteção e como isolantes (ALBUQUERQUE, 1990; BILLMEYER, 1986).

O polipropileno é a resina de maior demanda no país tendo apresentado, em 2005, um consumo aparente de 521 mil toneladas, 6\% de alta em relação ao mesmo período do ano passado, sendo que a produção aumentou 8,7\%. As exportações passaram de 72 mil t. para 98 mil t. (evolução de 34,9\%) (FERRO, 2005).

A polimerização do polipropileno pode ser encontrada em um dos seus três arranjos: isotático, sindiotático ou atático (MORRISON; BOYD, 1973). O PP isotático é o de maior interesse prático. É muito cristalino, tem temperatura de fusão elevada $\left(175^{\circ} \mathrm{C}-\right.$ $\left.183^{\circ} \mathrm{C}\right)$, é rígido e insolúvel $(65 \%)$ a temperatura ambiente, com solubilidade boa, acima de $80^{\circ} \mathrm{C}$ em xilol, decalina e outros hidrocarbonetos (BRYDSON, 1975). O segredo de se obter o PP isotático está no catalisador que se vai usar na reação assegurando-se a estereorregularidade das moléculas. Todos os tipos de polipropileno (homopolímeros, 
copolímeros e copolímeros heterofásicos) podem ser produzidos desde que se controle a estrutura molecular, a massa molar e a sua distribuição. O polipropileno sai do reator na forma de pequenas partículas ou esferas. Estas vão para uma extrusora onde são incorporados os aditivos, sendo processadas e posteriormente granuladas. O polipropileno pode ser usado no processo de moldagem por injeção, moldagem por sopro, extrusão e de fibras (SUZANO PETROQUÍMICA, 2007).

Por outro lado, o polipropileno possui limitações para aplicações: pouca resistência mecânica, pouca resistência a abrasão, sofre com a ação da radiação ultravioleta e agentes oxidantes e possui resistência limitada a temperaturas (VICK, 2007).

A polimerização do propileno é dita como uma reação de adição ocorrendo por mecanismos de radicais livres, catiônicos ou aniônicos dependendo da maneira como são iniciados (SOLOMONS, 1982) e pertence à família das poliolefinas e foi obtido na polimerização do monômero propileno em 1954 (FIG. 1) por Giulio Natta, porém sua aplicação industrial se tornou possível a partir de 1957 (FUNDAÇÃO DE AMPARO À PESQUISA DO ESTADO DA BAHIA, 2005) podendo ser também produzido pela polimerização em lama (MANO; MENDES, 1999). As melhorias na tecnologia de polimerização do PP, novas gerações de agentes clarificantes mais eficazes e melhorias nos processamentos fizeram com que o PP atingisse o "status" de plástico que mais cresce na indústria (JANOWITZER, 2005).

Os químicos Karl Ziegler e Giulio Natta fizeram uma revolução na produção de plásticos, usando catalisadores halogenados à base de titânio e alquil alumínio $\left(\mathrm{TiCl}_{4} \mathrm{Ou}\right.$ $\left.\mathrm{Al}\left(\mathrm{C}_{2} \mathrm{H}_{5}\right)_{3}\right)$, reduzindo parâmetros como temperatura e pressão no processo de polimerização do polipropileno (HESS ; HERRMANN, 2005). Os catalisadores e condições de processamento devem ser selecionados com cuidado para garantir que um determinado tipo de polipropileno seja produzido (INSTITUTO DE QUÍMICA - UFRGS, 2007; FELISBERTI; SILVA, 2007). 


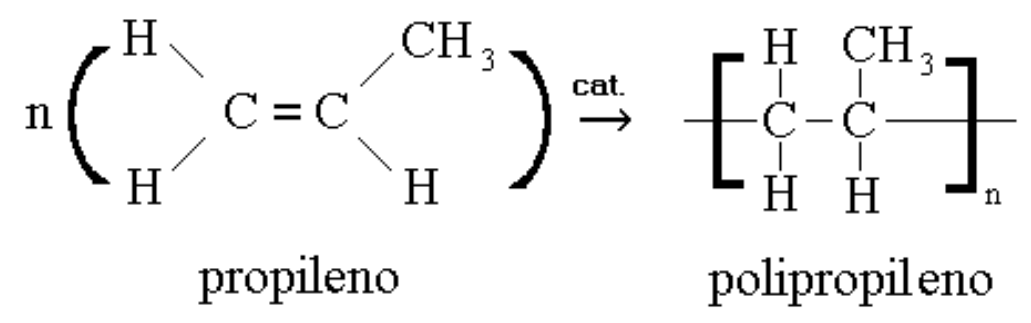

FIGURA 1 - Reação de formação e unidade estrutural do polipropileno

A combinação de partículas e fibras com matrizes poliméricas vem sendo usada rotineiramente como forma de se alterar propriedades mecânicas, ópticas, térmicas e na redução de custo. Os materiais mais utilizados para propiciar as características mencionadas anteriormente são as fibras de vidro e de carbono, as cargas minerais (CM) como o carbonato de cálcio precipitado, o talco e a micro esfera de vidro.

As cargas minerais são substâncias que alteram a resistência a temperaturas baixas e altas. Além disso, proporcionam ótima estabilidade dimensional (diminuição da contração na moldagem) e diminuição na absorção de água. Devido ao seu preço relativamente baixo, pode reduzir custos, dependendo da percentagem utilizada na composição da resina (SAECHTLING, 1996; ASCIUTTI, 1997).

O talco é uma carga mineral que tem grandes aplicações na indústria automobilística, mecânica e eletrônica conferindo estabilidade dimensional superior ao produto acabado. Além disso, reduz a absorção de água, a contração na moldagem e aumenta a resistência à temperatura de deflexão térmica sendo adicionado aos termoplásticos por simples mistura mecânica, pois existem agentes de acoplagem ( no caso, silanos ) que servem de ponte entre o talco e o polímero melhorando muito o desempenho do produto acabado; tendo como desvantagem a alteração do acabamento superficial da peça (SAECHTLING, 1996; ASCIUTTI, 1997; WIEBECK et al., 1998; BAKER; WEBER, 1989; GODLEWSKI; HEGGS, 1989). 
A casca de arroz (CA) é um revestimento ou capa protetora formada durante o crescimento dos grãos de arroz. Removida durante o refino do arroz, esta casca possui valor comercial baixo, pois o $\mathrm{SiO}_{2}$ e as fibras contidas não possuem valor nutritivo e por isso não são usadas na alimentação humana ou animal (DELLA, 2001). Há alguns anos, quase todo esse material ia parar nas lavouras e fundo de rios, num descarte prejudicial e criminoso. Preocupados com a crescente contaminação ambiental destes resíduos, alguns grupos vêm se dedicando ao estudo do aproveitamento de resíduos agrícolas como é o caso da casca de arroz para geração de energia. Contudo a queima da casca de arroz em termoelétricas gera a cinza que até pouco tempo não era aproveitada, causando um problema ambiental.

A combustão da CA gera cinzas com formas estruturais variáveis (amorfa e/ou cristalina) que dependem tanto do tipo de equipamento e queima usada, bem como do tempo e da temperatura de queima. A CA queimada em condições controladas (temperatura máxima de $1000^{\circ} \mathrm{C}$ ), ao atingir $800^{\circ} \mathrm{C}$ com um patamar de queima de duas horas, gera cinza residual constituída de sílica em forma cristalina de quartzo. Para temperaturas no intervalo de 450 a $700^{\circ} \mathrm{C}$, com patamar de três a quatro horas, obtém-se sílica no estado amorfo. A sílica amorfa é um material de fácil moagem e, quando moída tem área superficial maior e é bastante reativa. Suas propriedades principais são a condutividade térmica baixa e a resistência ao choque térmico elevada. Desta forma é um componente desejável na composição de produtos cerâmicos como refratários e isolantes térmicos, que sofrerão intensa ação do calor e variação brusca de temperatura (DELLA, 2001; SOUZA; BATISTA; LIBORIO, 1999).

Outras aplicações para a cinza da casca de arroz foram investigadas: na construção civil (JAUBERTHIE, et al., 2000; BUI; HU; STROEVEN, 2005; SERAS; SULTANA; NARAYAN SWAMY, 2006; LORIS; BERALDO, 2008), na indústria da borracha (SIRIWARDENA; ISMAIL; ISHIAKU, 2001; SEREDA et al., 2003; SAE-OUI; RAKDEE; THANMATHORN, 2002; SALMAH; ISMAIL, 2008), em material cerâmico (BONDIOLI et al., 2007) e em polímeros (FUAD et al., 1993; FUAD et al., 1995; BERA; KALE., 2006; RAZAVI-NOURI; JAFARZADEH-DOGOURI; OROMIEHIE,. 2006; TORO; QUIJADA; MURILLO, 2005; FROUCHI; DABDIN, 2007; YANG; KIM, 2007; BERA; KALE, 2008; FERRO; WIEBECK; SILVA, 2007). 
A interação da radiação ionizante com a matéria promove eventos físicos, químicos e físico-químicos. Quando certo polímero ou mesmo filme polimérico é submetido a radiação ionizante pode sofrer várias modificações em sua estrutura física e química induzidas pela radiação levando a reticulação e cisão das moléculas, fenômenos que ocorrem simultaneamente e que um deles predomina sobre o outro dependendo de vários fatores como do tipo de material, dose de radiação e atmosfera de irradiação entre outros (CLEGG; COLLYER, 1991; GOULAS; RIGHANAKOS; KONTOMINAS, 2003; CHAPIRO, 1969).

A interação da radiação ionizante com compostos orgânicos produz cátions, anions, radicais livres e espécies excitadas. Quando os polímeros são irradiados, os radicais livres e demais espécies formadas podem ficar aprisionadas por algum tempo na matriz do polímero causando transformações chamadas efeitos pós-irradiação (MIRANDA, 1999; O'DONNELL; SANGSTER, 1970).

Quando uma molécula de um polímero $\mathrm{AB}$ é submetida à radiação ionizante ocorrem transformações químicas ou eventos primários por ação da radiação ionizante (CHAPIRO, 1969; CHARLESBY, 1960; PLATZER, 1967).

Em trabalho realizado pelo grupo estudou-se a possibilidade da utilização da cinza da casca de arroz como uma carga alternativa em poliamidas 6 e 6.6 em substituição ao talco obtendo-se resultados satisfatórios (FERRO; WIEBECK; SILVA, 2007). 


\section{OBJETIVOS E FINALIDADE}

Este trabalho tem como objetivo avaliar a potencialidade de uso da cinza de casca de arroz como carga em polipropileno e compará-la com o talco que é a carga mineral mais utilizada em polímeros. Este trabalho também tem como objetivo estudar o efeito da radiação ionizante nas propriedades destes compósitos com a finalidade de verificar uma possível melhoria nas suas propriedades devido à reticulação e verificar se a interação entre o polímero e a carga (cinza de casca de arroz) melhora frente à radiação usando agente de acoplagem. Assim sendo, será dado um destino nobre a este resíduo diminuindo o seu descarte em aterros sanitários contribuindo, portanto, para a preservação do meio ambiente. 


\section{PARTE EXPERIMENTAL}

\subsection{Materiais e Métodos}

$\mathrm{Na}$ primeira etapa do trabalho foi usado polipropileno (homopolímero) fornecido pela Basell Poliolefina Ltda. O talco foi fornecido pela empresa Magnesita e a casca de arroz, para a produção da cinza, era proveniente de beneficiadores da cidade de São José do Rio Pardo (SP).

Neste trabalho inicialmente foram determinadas as porcentagens dos componentes da cinza de casca de arroz, conforme resultados mostrados na TAB. 3 , utilizando a técnica de difração de raio X.

O processo da queima da cinza de casca de arroz foi realizado em duas etapas. Na primeira etapa, a casca foi aquecida em um forno, entre $300^{\circ} \mathrm{C}$ e $350^{\circ} \mathrm{C}$, por 40 minutos, para a devida volatilização de toda a água e hidrocarbonetos. Depois a temperatura foi elevada a $600^{\circ} \mathrm{C}$, por uma hora até completa combustão. Após tratamento térmico, com objetivo de redução de matéria orgânica, a cinza foi moída para redução de tamanho das partículas e aumento da sua área superficial.

O material foi processado numa extrusora de rosca dupla da Werner \& Pfleider do tipo ZSK 25 mm, equipada com dosador Brabender. Esta extrusora tinha uma vazão máxima de $30 \mathrm{~kg} / \mathrm{h}$.

Os parâmetros de extrusão estão apresentados na TAB. 1.

TABELA 1 - Parâmetros da extrusão dos compósitos estudados

\begin{tabular}{lcc}
\hline \multicolumn{1}{c}{ Parâmetros } & PP + 20\% de Talco & PP + 20\% de CCA \\
\hline Pressão no Cabeçote (bar) & 11 & 12 \\
Potência utilizada no Torque $(\mathrm{kW})$ & 5,4 & 4,9 \\
Vazão $(\mathrm{kg} / \mathrm{h})$ & 21 & 15 \\
\hline
\end{tabular}


Ao sair da extrusora o fundido foi resfriado em água sendo transferido posteriormente para um granulador onde o material foi transformado em "pellets" e depois seco em estufa.

Posteriormente, foram injetados corpos-de-prova para caracterização dos compósitos de PP com 20\% de talco e de PP com $20 \%$ de cinza de casca de arroz.

As propriedades mecânicas analisadas foram:

- Resistência ao impacto Charpy seguindo a norma ISO 179.

- Resistência à tração e alongamento seguindo a norma ISO 527.

- Resistência à flexão e módulo de flexão seguindo a norma ISO 178.

A propriedade térmica analisada foi:

- Temperatura de deflexão térmica (HDT) de acordo com a norma ISO 75-2A.

Também foram determinados o índice de fluidez seguindo a norma ISO 1133 e o teor de carga seguindo a norma ISO 3451-1.

$\mathrm{Na}$ segunda parte do trabalho foi utilizado como matéria-prima um polipropileno cedido pela indústria Quattor, cujas características principais encontram-se na TAB.2 .

TABELA 2 - Informações técnicas do polipropileno HP-500-N (QUATTOR, 2008)

\begin{tabular}{lll}
\hline Propriedades & Valor & Método ASTM \\
\hline Físicas & & \\
\hline Índice de Fluidez $\left(230^{\circ} \mathrm{C} / 2,16 \mathrm{~kg}\right)$ & $\begin{array}{l}11,5 \mathrm{~g} / 10 \mathrm{~min} . \\
0,905 \mathrm{~g} / \mathrm{cm}^{3}\end{array}$ & $\begin{array}{l}\mathrm{D}-1138 \\
\mathrm{D}-792\end{array}$ \\
Densidade $\left(23^{\circ} \mathrm{C}\right)$ & & \\
\hline Mecânicas & $36 \mathrm{MPa}$ & $\mathrm{D}-638$ \\
\hline Resistência a tração no escoamento $(50 \mathrm{~mm} / \mathrm{min})$. & $9 \%$ & $\mathrm{D}-638$ \\
Alongamento no escoamento $(50 \mathrm{~mm} / \mathrm{min})$. & $1500 \mathrm{MPa}$ & $\mathrm{D}-790$ \\
Módulo de Flexão $(1,3 \mathrm{~mm} / \mathrm{min})$. & $30 \mathrm{~J} / \mathrm{m}$ & $\mathrm{D}-256$ \\
Resistência ao Impacto Izod a $23^{\circ} \mathrm{C}$ & 73 & $\mathrm{D}-2240$ \\
Dureza Shore D $(1 \mathrm{~s})$ & & \\
\hline Térmicas & & D-1525 \\
\hline Temperatura de Amolecimento Vicat $(10 \mathrm{~N} / \mathrm{Taxa} \mathrm{A})$ & $153^{\circ} \mathrm{C}$ & $\mathrm{D}-648$ \\
\hline Temperatura de Deflexão Térmica $(0,45 \mathrm{MPa})$ & $88^{\circ} \mathrm{C}$ & \\
\hline
\end{tabular}


Os testes de caracterização das amostras foram realizados no laboratório de Caracterização e Processamento de Materiais da Universidade Presbiteriana Mackenzie, Campus Itambé, São Paulo, Capital e no Laboratório de Caracterização de Polímeros do IPEN-CNEN / SP no Centro de Tecnologia das Radiações (CTR).

Foi utilizado o polipropileno com $20 \%$ de cinza de casca de arroz para preparação das amostras. Com o objetivo de promover uma homogeneização do compósito foi utilizado um reômetro marca HAAKE, modelo RHEODRIVE 5000 (FIG.2) que tem como acessório de extrusão o equipamento HAAKE RHEOMIX 252 (FIG.3), cuja capacidade estava acoplada ao reômetro, com temperatura máxima de trabalho de $300^{\circ} \mathrm{C}$, velocidade de fuso da ordem de $180 \mathrm{rpm}$ e pressões interna e do bico fixas.

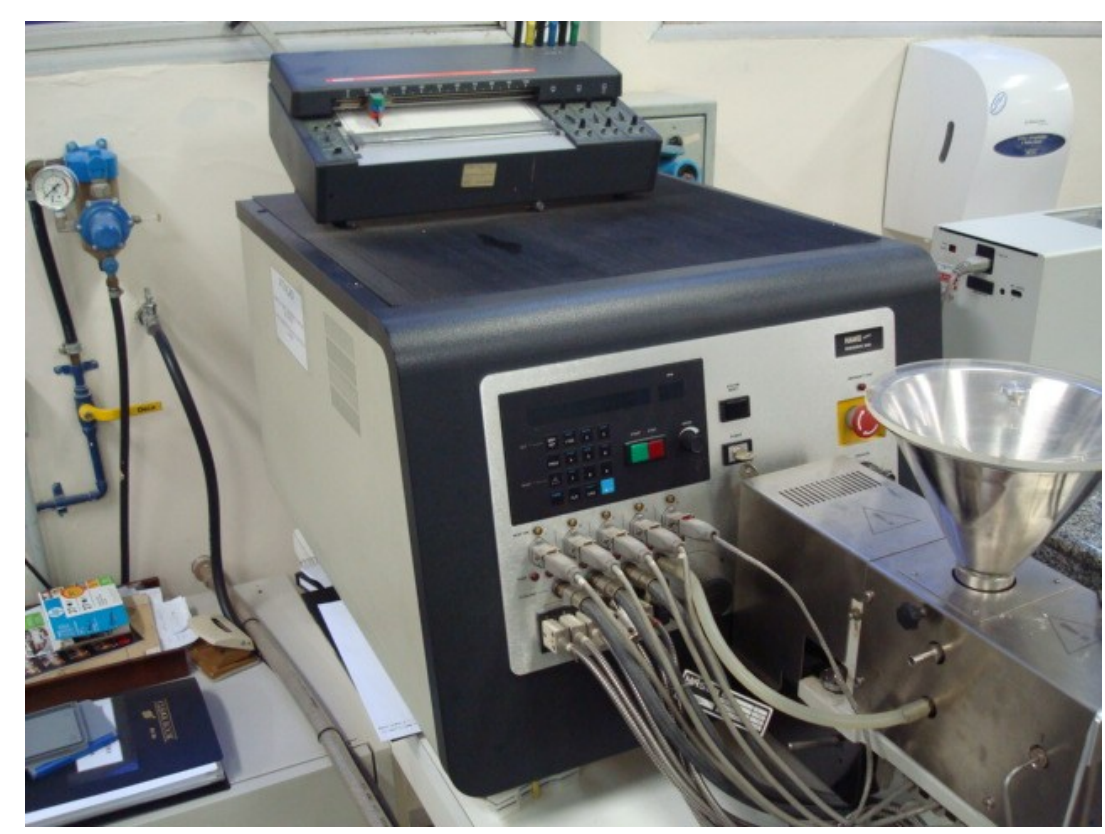

FIGURA 2 - Reômetro marca HAAKE modelo RHEODRIVE 5000 acoplado ao acessório de extrusão de rosca simples com matriz capilar modelo Rheomix 252 


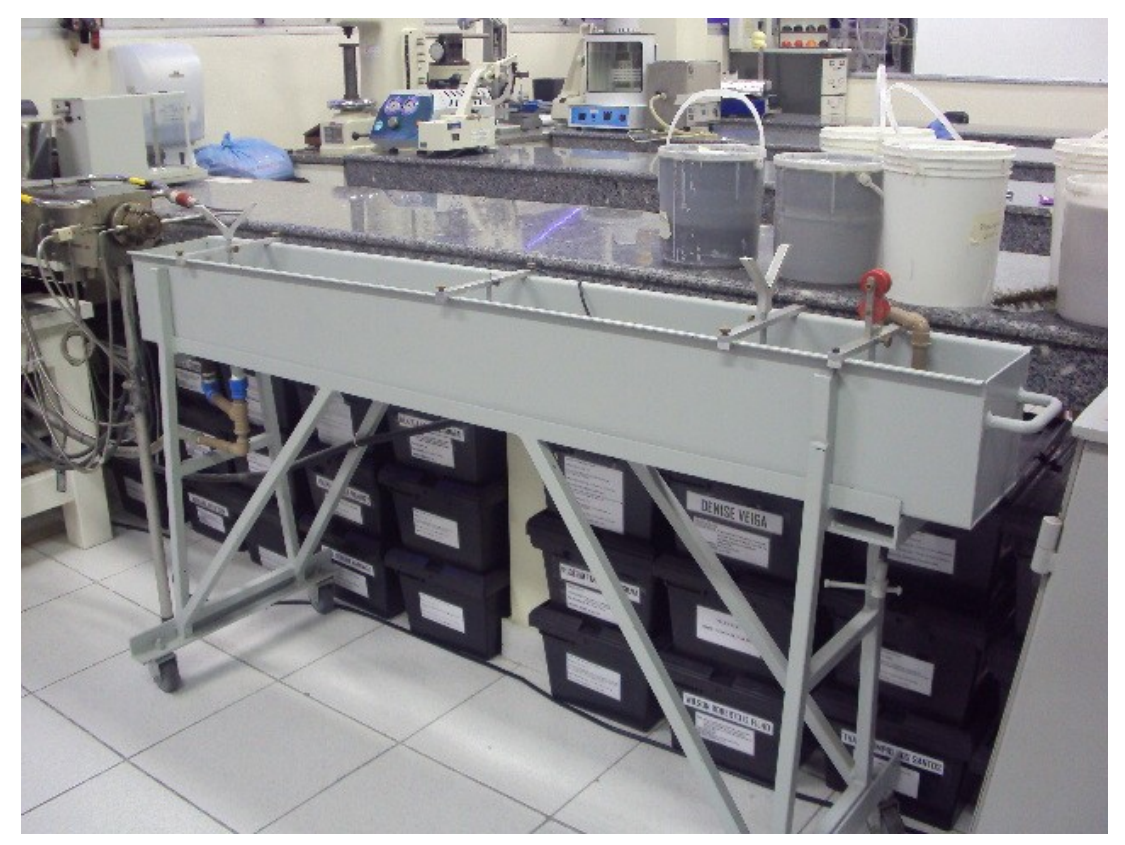

FIGURA 3 - Acessório de extrusão de rosca simples com matriz capilar marca HAAKE modelo Rheomix 252

Depois de pronto, o compósito passou por um cortador de lâmina simples, tipo faca, sendo, assim, transformado em pellets. Posteriormente, foram injetados corpos-deprova de polipropileno puro, de polipropileno com cinza de casca de arroz e polipropileno com cinza de casca de arroz associado ao agente de acoplagem (AG, anidrido maleico a 1\%) na injetora ROMI PRIMAX 65R (FIG.4) cujas características diziam respeito as zonas de temperaturas: zona 1 temperatura de $210^{\circ} \mathrm{C}$, zona 2 temperatura de $190^{\circ} \mathrm{C}$, zona 3 temperatura de $180^{\circ} \mathrm{C}$ e finalmente, zona 4 temperatura de $170^{\circ} \mathrm{C}$ próximo do canal de alimentação, volume total de dosagem da ordem de $21 \mathrm{~cm}^{3}$, pressão de injeção igual a 800 bar e vazão de $70 \mathrm{~cm}^{3} / \mathrm{s}$. 


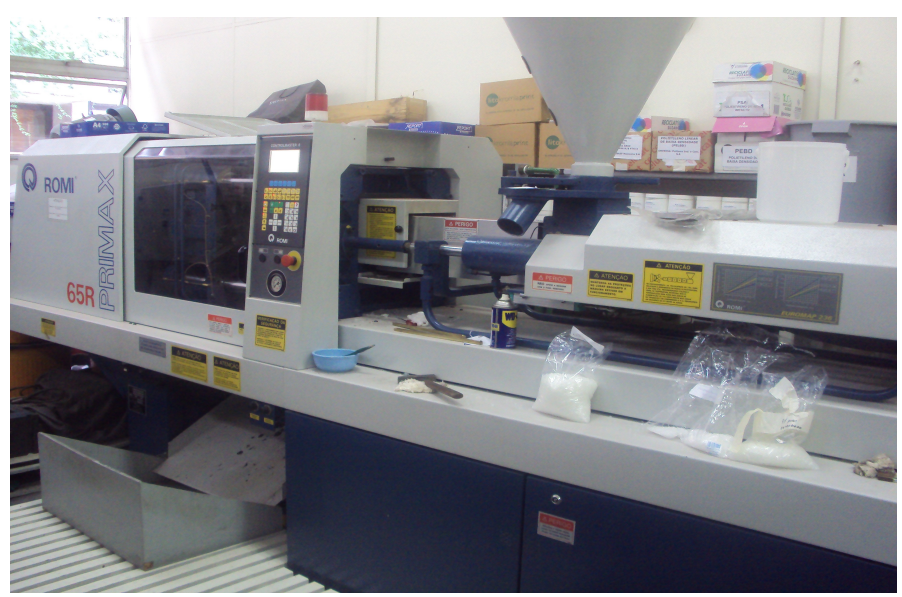

FIGURA 4 - Injetora ROMI PRIMAX 65 R

Após a preparação das amostras, as mesmas foram irradiadas para estudar o efeito da radiação ionizante nestes compósitos. Parte dos corpos-de-prova foram irradiados em um acelerador de elétrons do tipo Dynamitron II da Radiation Dynamics, modelo DC 1500 - JOB 188, com energia máxima de 1,5 MeV, corrente de feixe que varia de $0,3 \mathrm{~mA}$ a $25 \mathrm{~mA}$ e $37,5 \mathrm{~kW}$ de potência (FIG.5) no CTR do IPEN-CNEN/SP com uma taxa de dose de 11,22 kGy/s. As amostras foram colocadas em bandejas, confeccionadas em alumínio e revestidas em madeira, para minimizar o efeito de retroespalhamento dos elétrons. As doses de radiação aplicadas nas amostras foram de 0, 50, 100, 200, 300 e 500 $\mathrm{kGy}$, e as irradiações foram realizadas à temperatura ambiente e na presença de ar. 


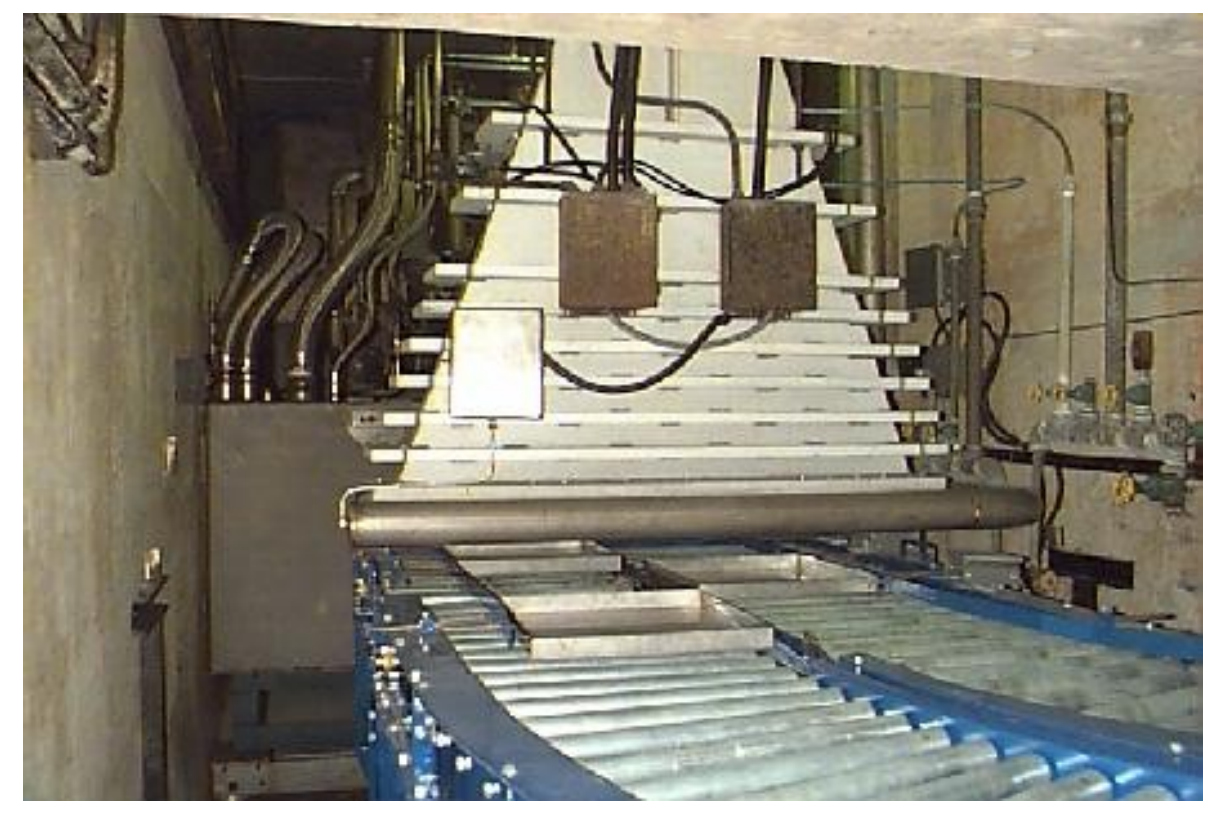

FIGURA 5 - Acelerador de elétrons Dynamitron II modelo DC 1500 JOB 188

Após as irradiações as amostras foram caracterizadas, nos laboratórios da Universidade Mackenzie e do IPEN-CNEN/SP, utilizando-se nesta segunda parte do trabalho as normas ASTM.

As propriedades mecânicas analisadas foram:

- Resistência ao impacto Izod seguindo a norma ASTM D-256.

- Resistência à tração e alongamento seguindo a norma ASTM D-638.

- Dureza seguindo a norma ASTM D-2240.

As propriedades térmicas analisadas foram:

- Temperatura de deflexão térmica (HDT) de acordo com a norma ASTM D648.

- Temperatura de amolecimento Vicat de acordo com a norma ASTM D1525.

- Termogravimetria (TG).

- Calorimetria exploratória diferencial (DSC). 


\subsection{Propriedades Térmicas}

\subsubsection{Temperatura de deflexão térmica (HDT)}

No teste de deflexão térmica (HDT, Heat Distortion Temperature) demonstrase a temperatura em que acontece a deflexão térmica $(0,25 \mathrm{~mm})$, quando sob efeito de uma carga pré-escolhida e ,também, como os materiais se comportam em condições padronizadas de temperatura e carga. O equipamento utilizado foi da marca Tinius Olsen, modelo HD 94/398 (FIG.6). O teste foi realizado segundo a norma ASTM D-648.

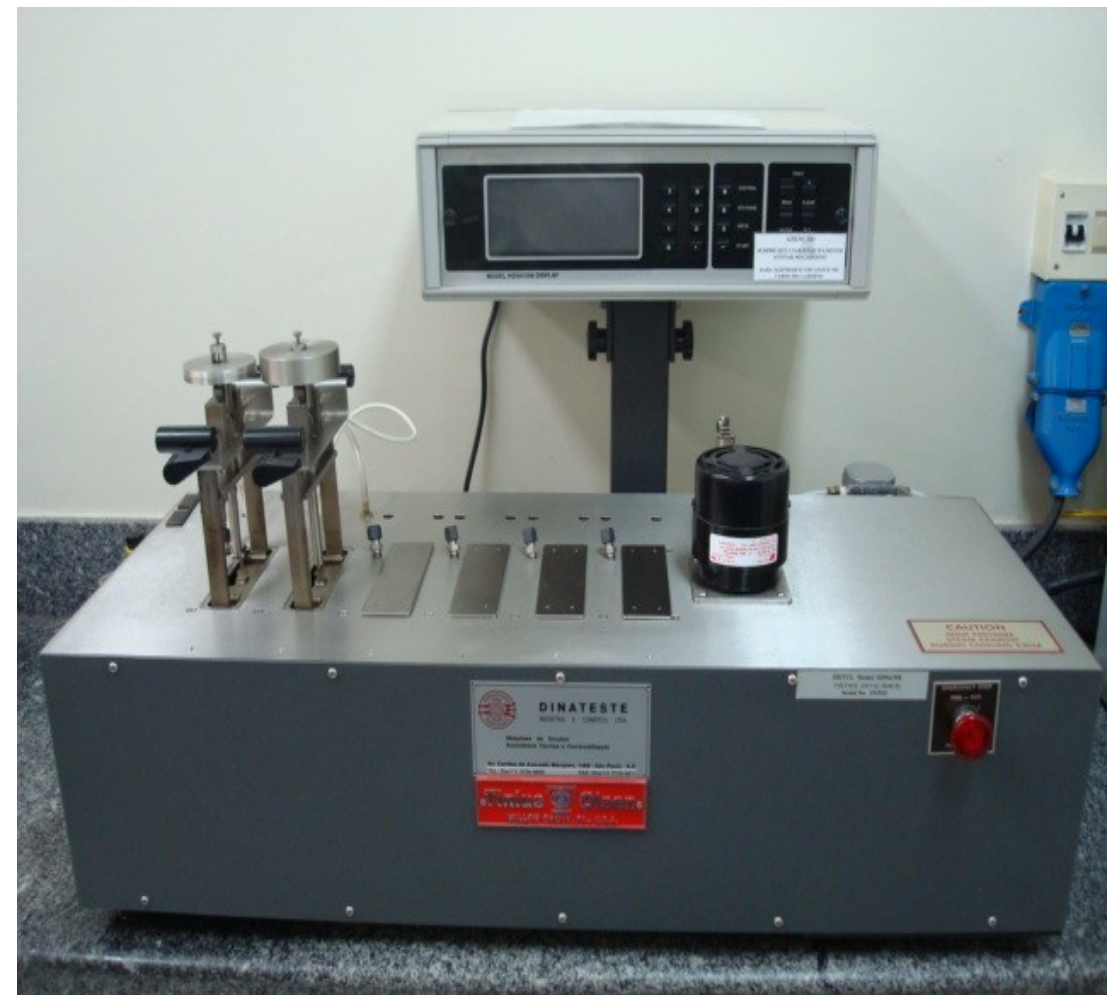

FIGURA 6 - Equipamento da Tinius Olsen para ensaios de HDT e Vicat 


\subsubsection{Temperatura de amolecimento Vicat}

Por definição, a temperatura de amolecimento Vicat é aquela onde ocorre a penetração de uma agulha, no corpo-de-prova, sob uma carga específica, até a profundidade de $1 \mathrm{~mm}$. O objetivo do teste é avaliar a resistência máxima à temperatura de uso dos materiais em estudo. $\mathrm{O}$ equipamento utilizado foi o mesmo do teste de deflexão térmica utilizando-se a norma ASTM D-1525.

\subsubsection{Termogravimetra (TG)}

Por definição, TG é uma técnica de análise térmica na qual a variação de massa da amostra (perda ou ganho) é determinada em função da temperatura e/ou tempo, enquanto a amostra é submetida a uma programação controlada de temperatura (MATOS; MACHADO; apud CANEVAROLO Jr., 2004).

As amostras de polipropileno, polipropileno com cinza de casca de arroz e polipropileno com cinza de casca de arroz combinado com agente de acoplagem possuíam massa em torno de 4,0 a 6,0 mg e foram pesadas na balança marca Shimadzu, modelo Libror AEL-40 SM, com capacidade de 42 g (FIG.7). A panela utilizada nos ensaios era de platina $(\mathrm{Pt})$. A atmosfera utilizada era de gás inerte de nitrogênio $\left(\mathrm{N}_{2}\right)$ e o fluxo de gás da ordem de $50 \mathrm{~mL} / \mathrm{min}$. A taxa de aquecimento foi de $10^{\circ} \mathrm{C} / \mathrm{min}$ até a temperatura de $600^{\circ} \mathrm{C}$ (num intervalo de tempo de 10 minutos). $\mathrm{O}$ resfriamento era da ordem de $-10^{\circ} \mathrm{C} / \mathrm{min}$. $\mathrm{O}$ equipamento utilizado para as análises foi da marca Shimadzu TGA 50 (FIG.8). 


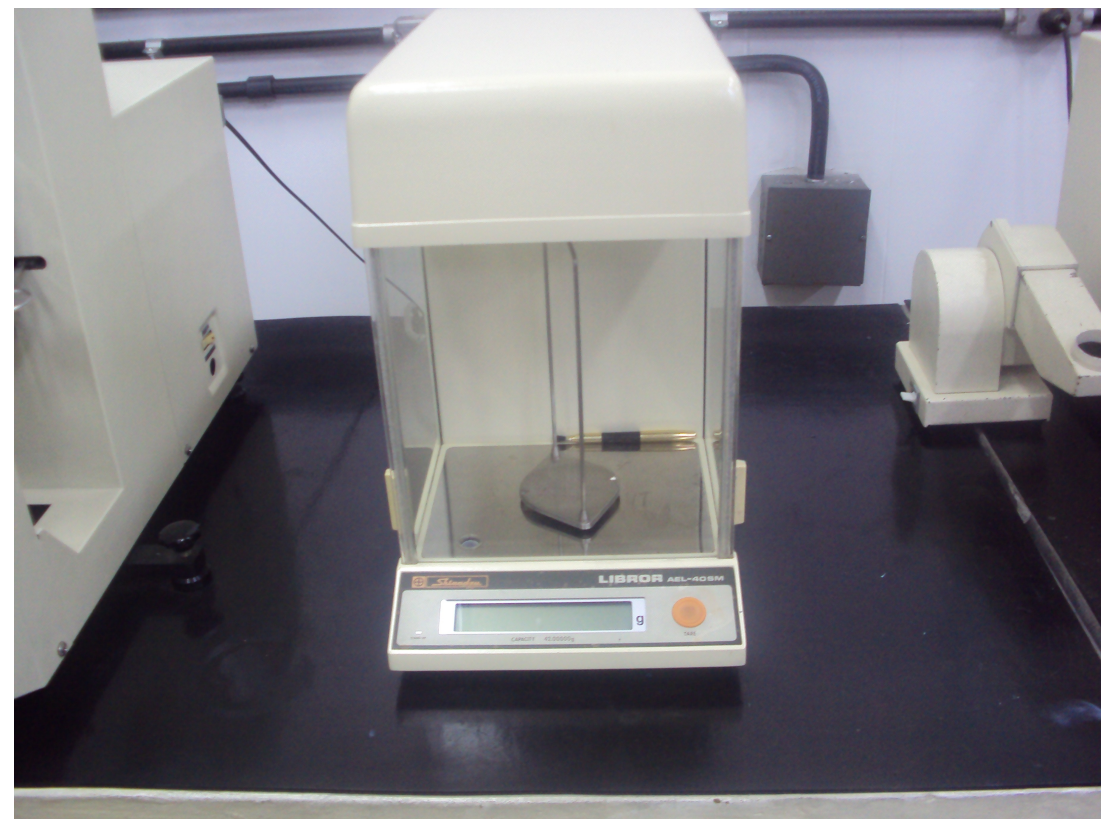

FIGURA 7 - Balança Shimadzu Libror AEL-40 SM

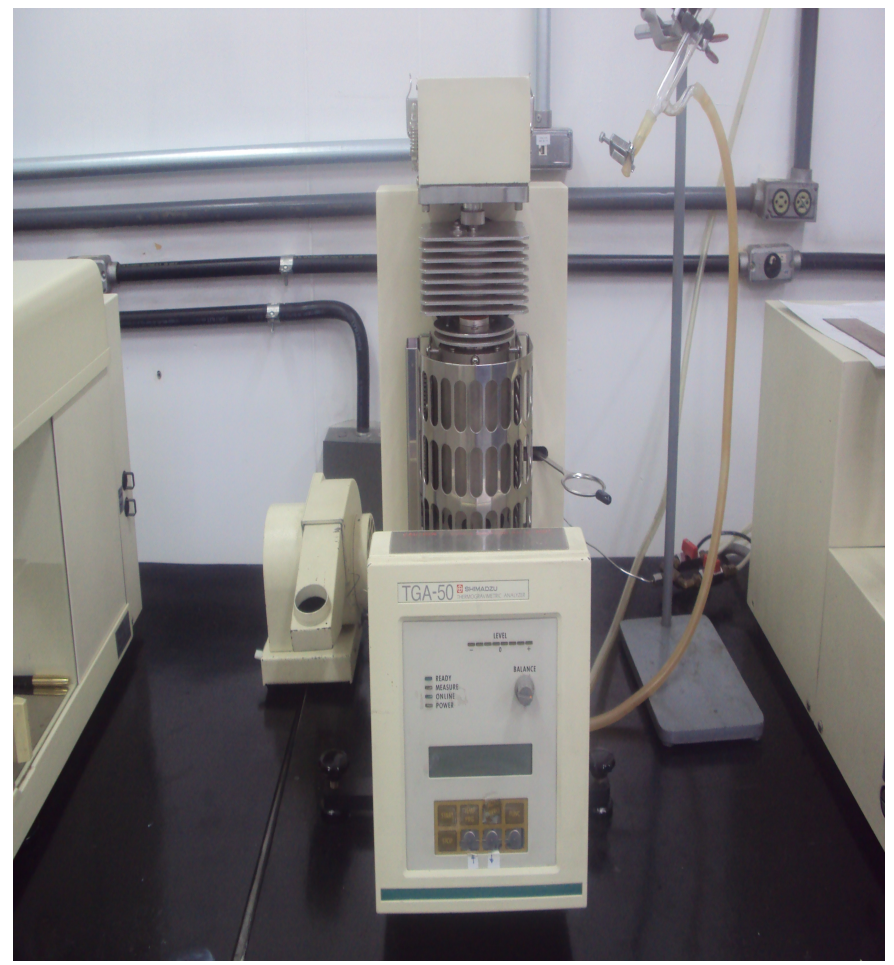

FIGURA 8- Equipamento marca Shimadzu TGA 50 para termogravimetria 


\subsubsection{Calorimetria exploratória diferencial (DSC)}

DSC é uma técnica onde se mede a diferença de energia $(\Delta \mathrm{H})$ que é fornecida à substância e o material de referência em função da temperatura que possui controle programado (MACHADO; MATOS in CANEVAROLO Jr. 2004).

As amostras de polipropileno, polipropileno com cinza de casca de arroz e polipropileno com cinza da casca de arroz e agente de acoplagem possuíam massa em torno de 4,0 a 6,0 mg e foram pesadas na balança marca Shimadzu, modelo Libror AEL-40 SM, com capacidade de 42 g (FIG.7). A panela utilizada nos ensaios era de alumínio (Al). A atmosfera utilizada era de gás inerte de nitrogênio $\left(\mathrm{N}_{2}\right)$ e o fluxo de gás da ordem de 50 $\mathrm{mL} / \mathrm{min}$. A taxa de aquecimento foi de $10^{\circ} \mathrm{C} / \mathrm{min}$ até a temperatura de $230^{\circ} \mathrm{C}$ (num intervalo de tempo de 10 minutos). $\mathrm{O}$ resfriamento foi da ordem de $-10^{\circ} \mathrm{C} / \mathrm{min}$. Posteriormente foi realizado um segundo aquecimento com temperaturas variando de $10^{\circ} \mathrm{C}$ até $230^{\circ} \mathrm{C}$. O equipamento utilizado para as análises foi da marca Shimadzu DSC 50 (FIG.9).

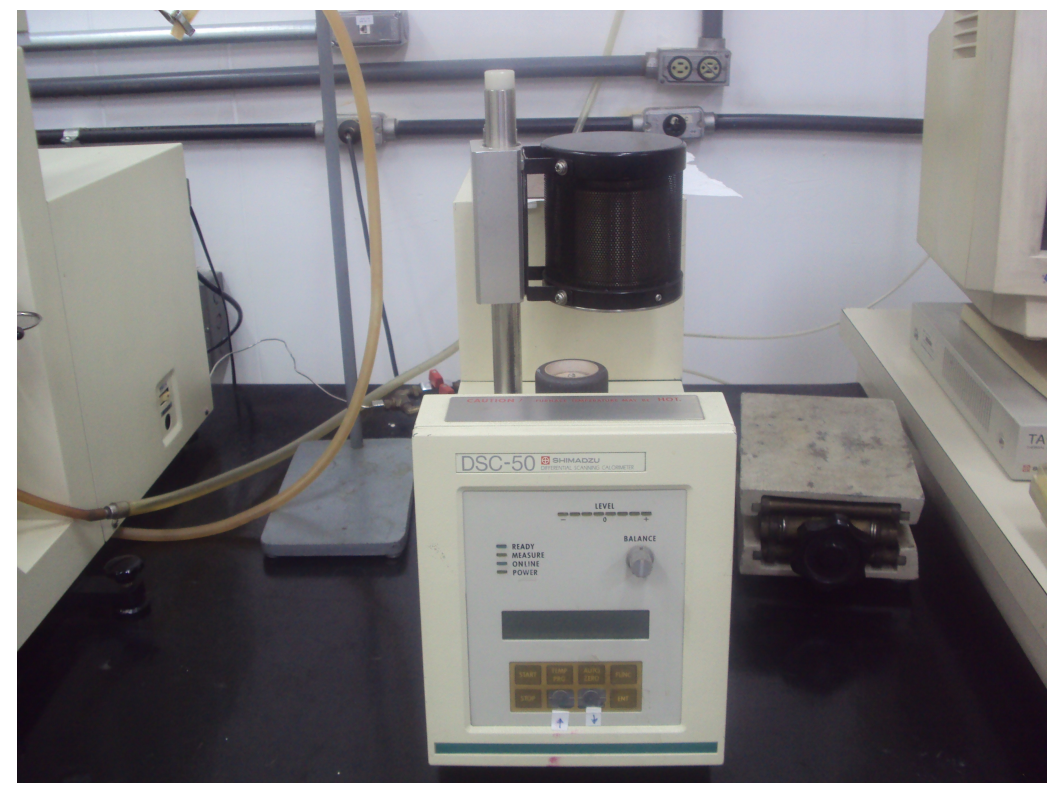

FIGURA 9 - Equipamento marca Shimadzu DSC 50 para análise de calorimetria exploratória diferencial 


\subsection{Propriedades Mecânicas}

\subsubsection{Teste de dureza}

O teste de dureza visa verificar a penetração de um indentador, quando se aplica uma força sobre uma amostra. A dureza varia de maneira inversamente proporcional à penetração e depende tanto do módulo elástico e do comportamento viscoelástico do material. A dureza medida possui unidade Shore D. O equipamento utilizado na realização deste teste foi o durômetro digital marca Mitutoyo, modelo Hardmatic HH 314 (FIG.10). Este teste foi realizado segundo a norma ASTM D - 2240 .

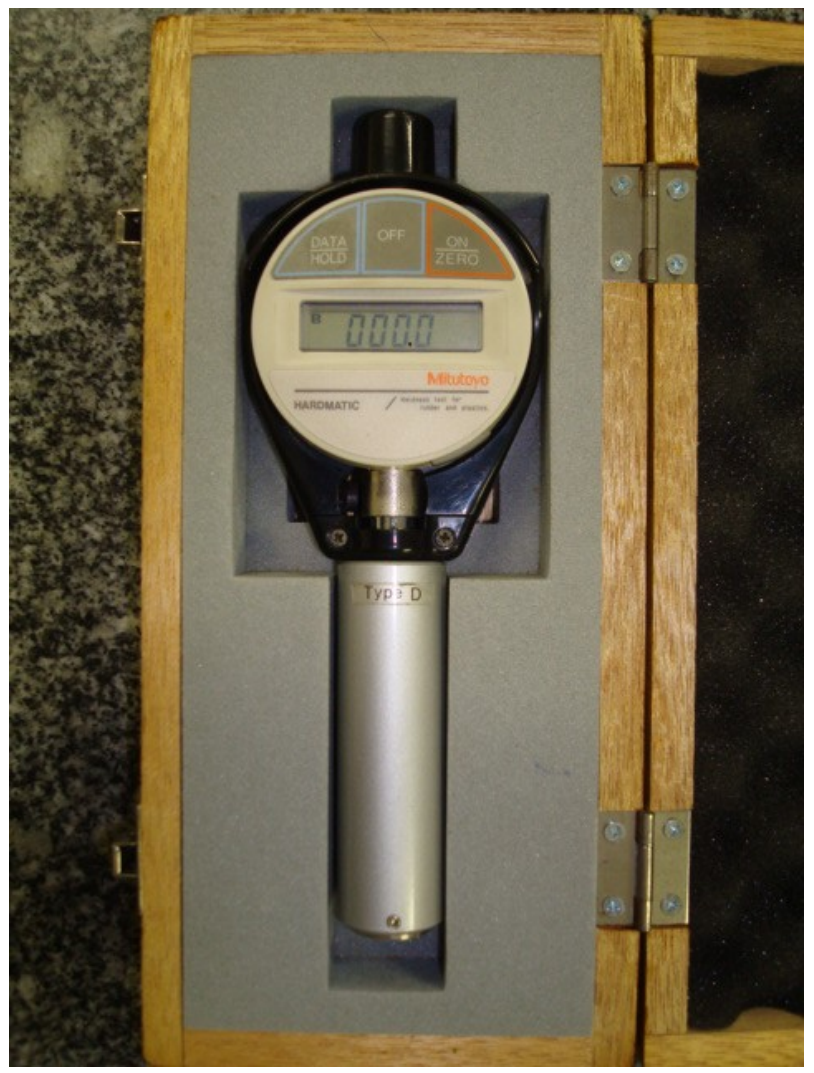

FIGURA 10 - Equipamento de dureza Shore D 


\subsubsection{Teste de impacto}

O teste de impacto visa verificar a quantidade de energia cinética envolvida desde o início da fratura até a completa ruptura do corpo- de -prova. Para a realização deste teste foi utilizada a máquina de impacto marca Tinius Olsen, modelo 892 (FIG. 11). O referido teste foi realizado pela norma ASTM D-256.

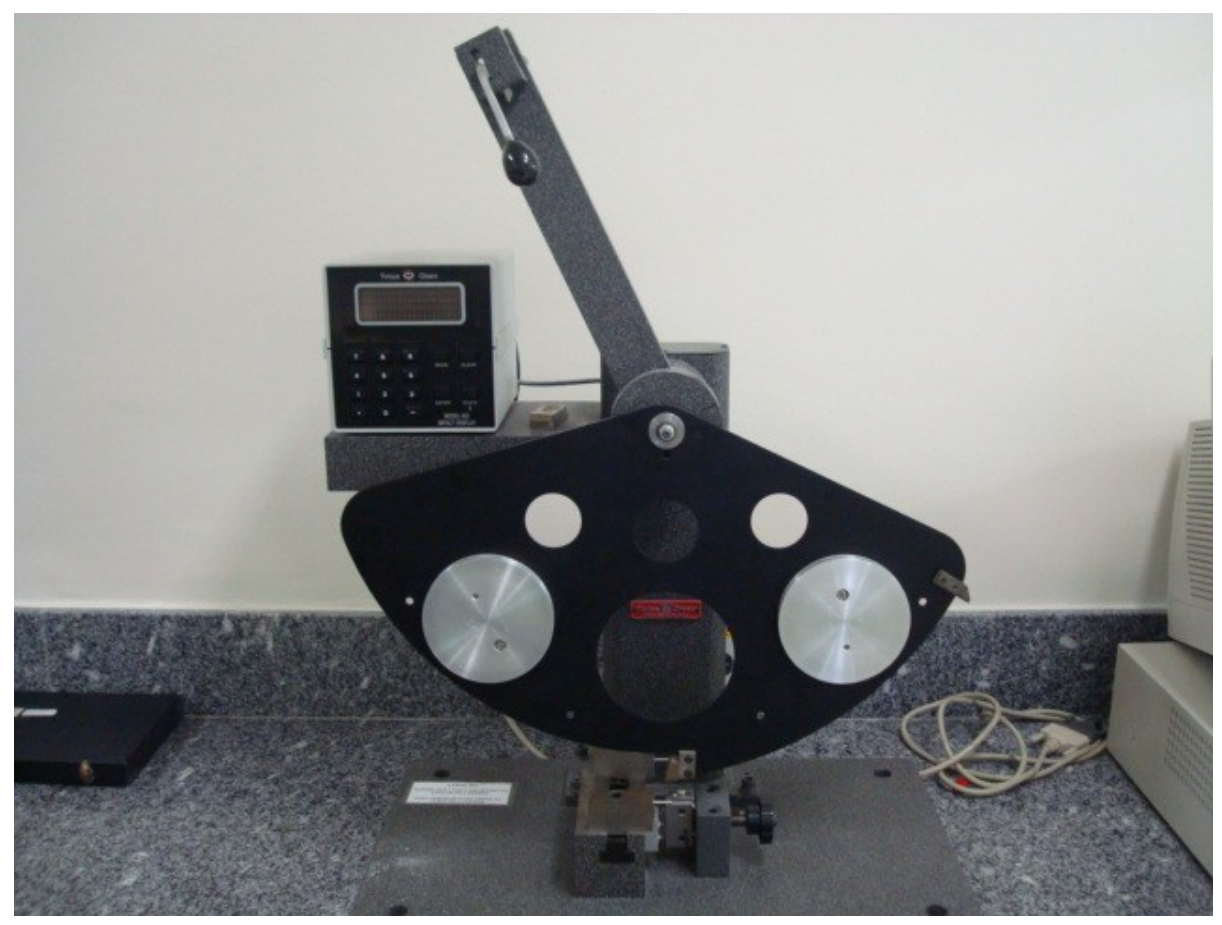

FIGURA 11 - Equipamento de impacto da Tinius Olsen para ensaios de impacto tipo Izod 


\subsubsection{Teste de tração}

O teste de tração tem como objetivo submeter o material a esforço que provoque certa elongação até que aconteça a ruptura do corpo-de-prova. $\mathrm{Na}$ realização destes testes foi utilizada a máquina universal de ensaio marca MTS, modelo QTEST (FIG. 12). O referido teste foi realizado pela norma ASTM D-638.

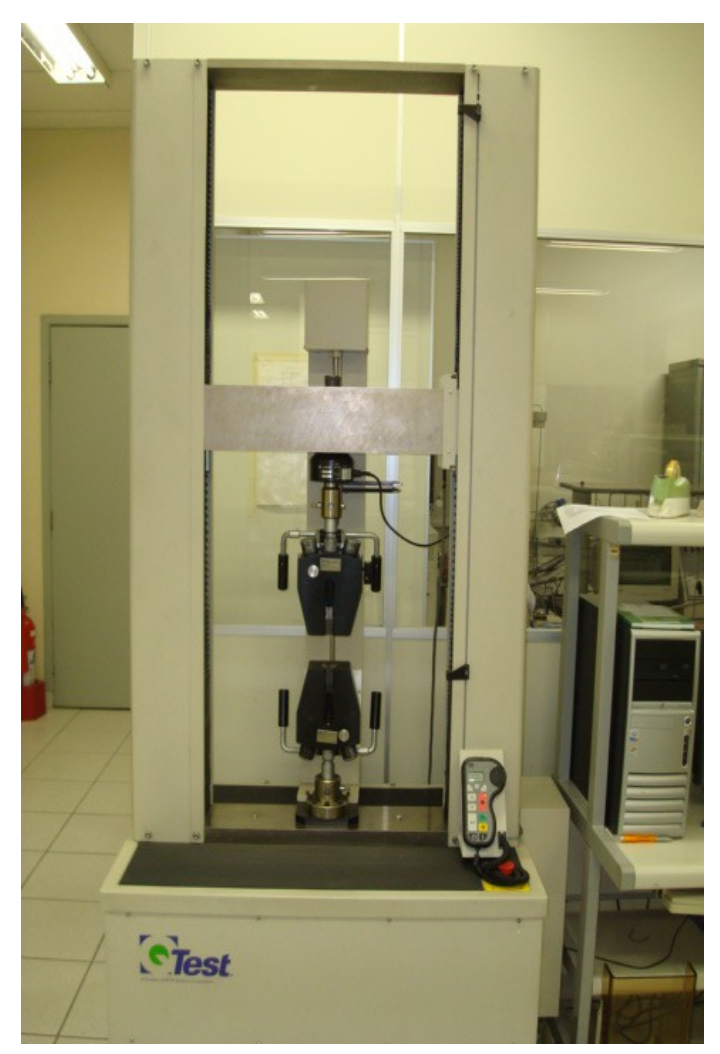

FIGURA 12 - Equipamento universal de ensaios de tração da marca MTS, modelo QTEST 


\subsection{Microscopia eletrônica de varredura (MEV)}

Foram utilizadas amostras de polipropileno, de polipropileno com cinza de casca de arroz e, também, polipropileno com cinza de casca de arroz com agente acoplante (anidrido maleico a 1\%). As amostras, não irradiadas e as irradiadas, foram previamente preparadas e usinadas na Divisão de Oficinas do IPEN - CNEN/SP. Posteriormente elas foram fraturadas em nitrogênio líquido e as superfícies de fratura foram metalizadas com ouro. As análises morfológicas foram realizadas em microscópio eletrônico de varredura, marca JEOL, modelo JXA - 6400, do Centro de Tecnologia da Marinha em São Paulo CTMSP como complemento deste trabalho com o objetivo de verificar como ocorreu a interação entre o polímero (PP, polipropileno) e a carga (cinza de casca de arroz).

\subsection{Espectroscopia de absorção na região do infravermelho (IV)}

Foram realizadas análises de espectroscopia de absorção na região do infravermelho das amostras de polipropileno e polipropileno com cinza de casca de arroz nas doses de 0, 200 e 500 kGy. Os ensaios de espectroscopia de absorção na região do infravermelho foram realizados no espectrômetro marca Perkin Elmer, modelo Spectrum 100, acoplado com dispositivo Universal ATR (“Sampling Acessory”). O equipamento possui um programa de comparação que permitiu correlacionar as diferenças espectrais ocorridas entre as amostras analisadas. 


\section{RESULTADOS E DISCUSSÃO}

\subsection{Primeira Parte do Trabalho}

$\mathrm{Na}$ TAB. 3 são apresentadas as porcentagens dos componentes da cinza de casca de arroz utilizada neste trabalho.

TABELA 3 - Composição da cinza de casca de arroz

\begin{tabular}{cc}
\hline COMPOSIÇÃO & $\begin{array}{c}\text { PORCENTAGEM } \\
\text { (\%) }\end{array}$ \\
\hline $\mathrm{SiO}_{2}$ & 91,89 \\
$\mathrm{Al}_{2} \mathrm{O}_{3}$ & 0,09 \\
$\mathrm{Fe}_{2} \mathrm{O}_{3}$ & 0,06 \\
$\mathrm{CaO}$ & 0,52 \\
$\mathrm{MgO}$ & 0,33 \\
$\mathrm{~K}_{2} \mathrm{O}$ & 1,50 \\
$\mathrm{P}_{2} \mathrm{O}_{5}$ & 0,25 \\
$\mathrm{SO}_{3}$ & 0,06 \\
$\mathrm{TiO}_{2}$ & 0,00 \\
$\mathrm{MnO} \mathrm{Cl}_{2}$ & 0,25 \\
$\mathrm{Rb}_{2} \mathrm{O}$ & 0,01 \\
$\mathrm{Co}_{3} \mathrm{O}_{4}$ & 0,01 \\
$\mathrm{PF}$ & 0,05 \\
$\mathrm{Outros}^{\text {TOTAL }}$ & 4,80 \\
\hline TOTA & 0,19 \\
\hline
\end{tabular}

De acordo com a TAB. 3 observa-se que a CCA possui na sua composição mais de $90 \%$ de $\mathrm{SiO}_{2}$.

$\mathrm{Na}$ TAB. 4 são apresentados os resultados das propriedades das amostras de polipropileno com $20 \%$ de talco e de PP com $20 \%$ de CCA estudadas neste trabalho.

Os valores apresentados na TAB. 4 representam a média dos resultados obtidos conforme o número de corpos-de-prova previstos nas normas utilizadas. 
TABELA 4 - Propriedades do PP com 20\% de talco e do PP com 20\% de cinza de casca de arroz

\begin{tabular}{lcc}
\hline \multicolumn{1}{c}{ Propriedades } & $\begin{array}{c}\text { PP com 20\% de } \\
\text { talco }\end{array}$ & $\begin{array}{c}\text { PP com 20\% de } \\
\text { CCA }\end{array}$ \\
\hline Índice de Fluidez (g/10 min) & 19,4 & 15,5 \\
Teor de Carga (\%) & 20,2 & 15,2 \\
Módulo de Flexão (MPa) & 2740 & 1941 \\
Resistência à flexão (MPa) & 49,04 & 41,7 \\
Resistência à tração no escoamento & 33,6 & 29,1 \\
(MPa) & & \\
Alongamento no escoamento $(\%)$ & 5,05 & 5,18 \\
Alongamento na ruptura $(\%)$ & 27,7 & 47,2 \\
Charpy com entalhe a $23^{\circ} \mathrm{C}\left(\mathrm{kJ} / \mathrm{m}^{2}\right)$ & 2,9 & 2,2 \\
Charpy sem entalhe a $23^{\circ} \mathrm{C}\left(\mathrm{kJ} / \mathrm{m}^{2}\right)$ & 62,7 & 46,3 \\
Temperatura de deflexão térmica & 61,6 & 56,1 \\
$\left({ }^{\circ} \mathrm{C}\right)$ & & \\
\hline
\end{tabular}

Comparando os resultados das propriedades estudadas neste trabalho (TAB. 4) para as amostras de PP com os dois tipos de carga (talco e cinza de casca de arroz), podese observar que o desempenho do material com cinza de casca de arroz foi inferior ao composto com talco em quase todas as propriedades estudadas.

Nota-se que no ensaio de flexão, os resultados para o composto de PP com $20 \%$ de cinza de casca de arroz foram inferiores ao do composto de PP com $20 \%$ de talco.

No ensaio de tração, apesar da resistência à tração no escoamento ter sido menor para as amostras de PP com $20 \%$ de cinza de casca de arroz em comparação com o talco, não houve variação significativa no alongamento no escoamento (indicando em pequeno grau a homogeneidade e dispersão do produto), mas o alongamento na ruptura foi maior devido à presença da cinza de casca de arroz que aumentou o alongamento na ruptura e interferiu na cristalinidade .

Quanto ao ensaio de resistência ao impacto, o resultado para o composto de PP com cinza de casca de arroz também foi inferior que o composto de PP com talco. 
A temperatura de deflexão térmica mostrou-se também inferior quando a carga utilizada foi a cinza de casca de arroz. O mesmo aconteceu com o índice de fluidez e com o teor de carga.

Estes resultados mostraram que o polipropileno com $20 \%$ de cinza de arroz tem um comportamento inferior em suas propriedades quando comparadas ao polipropileno com $20 \%$ de talco.

\subsection{Segunda Parte do Trabalho}

Nesta segunda parte do trabalho foram analisadas as amostras de polipropileno com $20 \%$ da cinza de casca de arroz que foram irradiadas.

Primeiramente foram realizadas as análises térmicas.

Na TAB. 5 e FIG. 13 são apresentados e mostrados os resultados de temperatura de deflexão térmica de amostras de PP submetidas a diferentes doses de radiação.

TABELA 5 - Resultados de temperatura de deflexão térmica de amostras de PP submetidas a diferentes doses de radiação

\begin{tabular}{cccccc}
\hline Dose (kGy) & $\begin{array}{c}\text { Amostra 1 } \\
\left({ }^{\circ} \mathrm{C}\right)\end{array}$ & $\begin{array}{c}\text { Amostra } 2 \\
\left({ }^{\circ} \mathrm{C}\right)\end{array}$ & $\begin{array}{c}\text { Amostra 3 } \\
\left({ }^{\circ} \mathrm{C}\right)\end{array}$ & Média & $\begin{array}{c}\text { Desvio } \\
\text { Padrão }\end{array}$ \\
\hline 0 & 123,2 & 125,7 & ---- & 124,4 & 1,8 \\
50 & 101,9 & ---- & 100,3 & 101,1 & 1,1 \\
100 & 120,7 & 115,1 & 103,5 & 117,9 & 3,9 \\
200 & 118,3 & 119,7 & ---- & 119,0 & 1,0 \\
300 & 110,0 & 110,4 & 101,6 & 110,2 & 0,3 \\
500 & 117,1 & 118,3 & ---- & 117,7 & 0,8 \\
\hline
\end{tabular}




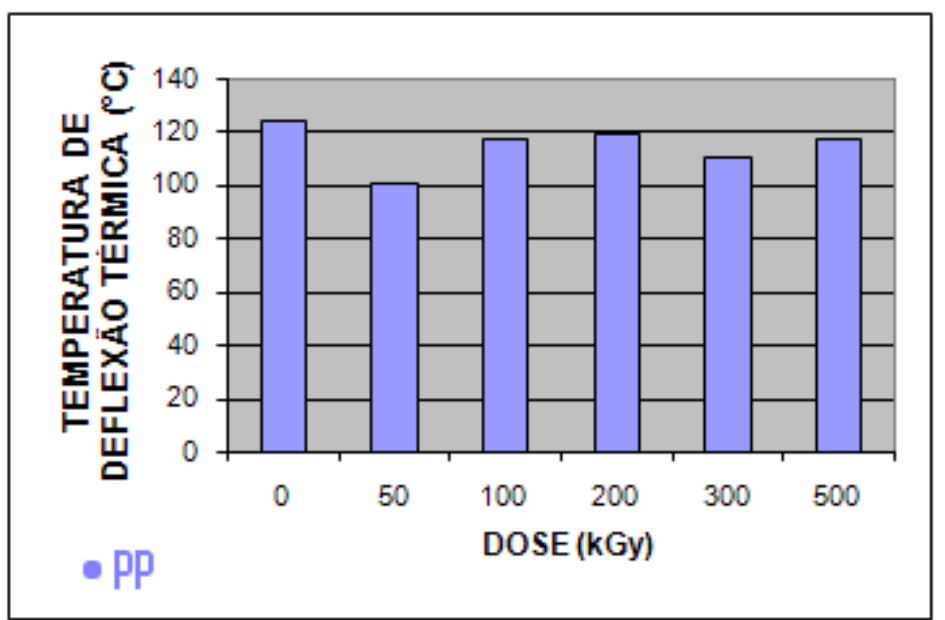

FIGURA 13 - Resultados de temperatura de deflexão térmica de amostras de PP submetidas a diferentes doses de radiação

Na TAB. 6 e FIG. 14 são apresentados e mostrados os resultados de temperatura de deflexão térmica de amostras de PP com cinza de casca de arroz submetidas a diferentes doses de radiação.

TABELA 6 - Resultados de temperatura de deflexão térmica de amostras de PP com cinza de casca de arroz submetidas a diferentes doses de radiação

\begin{tabular}{cccccc}
\hline Dose (kGy) & $\begin{array}{c}\text { Amostra } 1 \\
\left({ }^{\circ} \mathrm{C}\right)\end{array}$ & $\begin{array}{c}\text { Amostra } 2 \\
\left({ }^{\circ} \mathrm{C}\right)\end{array}$ & $\begin{array}{c}\text { Amostra 3 } \\
\left({ }^{\circ} \mathrm{C}\right)\end{array}$ & Média & $\begin{array}{c}\text { Desvio } \\
\text { Padrão }\end{array}$ \\
\hline 0 & 118,7 & 117,9 & ---- & 118,3 & 0,6 \\
50 & 111,7 & 115,0 & 120,1 & 115,6 & 2,3 \\
& & & & & \\
100 & 115,1 & 125,5 & 118,7 & 117,3 & 2,6 \\
200 & 117,3 & 121,1 & 120,4 & 119,6 & 2,0 \\
300 & 117,1 & 119,6 & 118,4 & 118,3 & 1,2 \\
500 & 116,5 & 114,8 & 111,7 & 114,3 & 2,4 \\
\hline
\end{tabular}




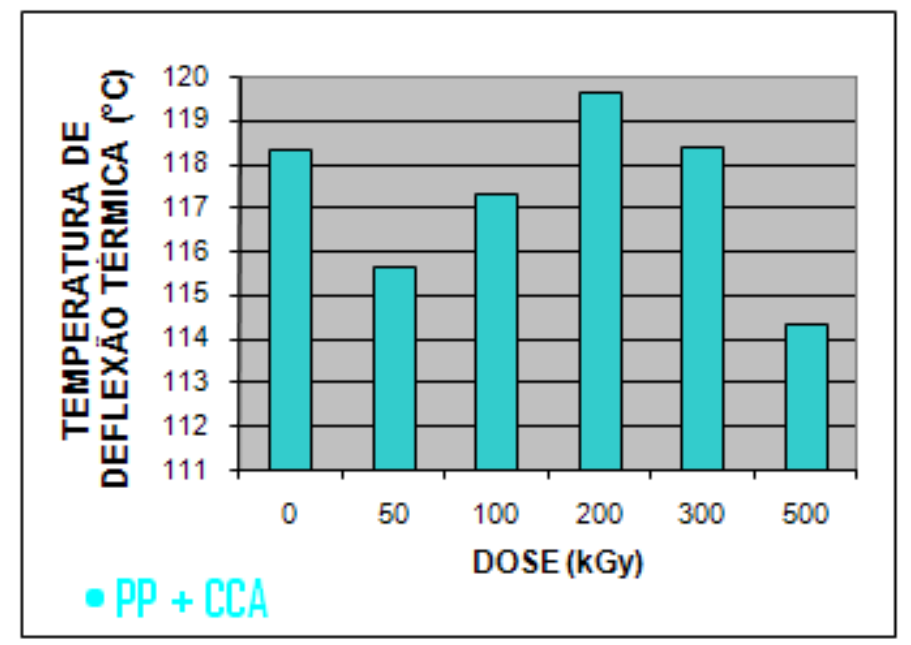

FIGURA 14 - Resultados de temperatura de deflexão térmica de amostras de PP com cinza de casca de arroz irradiadas e não irradiada

Observa-se pelos resultados apresentados nas TAB. 5 e 6 que a temperatura de deflexão térmica para as amostras de PP com cinza de casca de arroz é maior que as amostras de PP. De acordo com a FIG. 14 observa-se um pequeno aumento no HDT em 200 kGy diminuindo posteriormente quando as amostras são irradiadas a 300 e 500 kGy devido à cisão da cadeia polimérica. De acordo com os resultados ocorreram variações de $18,7 \%$ na amostra com dose de $50 \mathrm{kGy} ; 5,2 \%$ na amostra com dose de $100 \mathrm{kGy} ; 4,3 \%$ na amostra com dose de $200 \mathrm{kGy} ; 11,4 \%$ na amostra com dose de $300 \mathrm{kGy}$ e 5,3\% na amostra com dose de 500 kGy com relação ao PP. Quando se utilizou PP + CCA as variações foram as seguintes: $2,2 \%$ na amostra com dose de $50 \mathrm{kGy} ; 0,8 \%$ na amostra com dose de $100 \mathrm{kGy} ;-1,0 \%$ na amostra com dose de $200 \mathrm{kGy}$ e 3,3\% na amostra com dose de $500 \mathrm{kGy}$.

Na FIG. 15 são mostrados resultados de temperatura de deflexão térmica de amostras de PP e de PP com cinza da casca de arroz irradiadas e não irradiadas. 


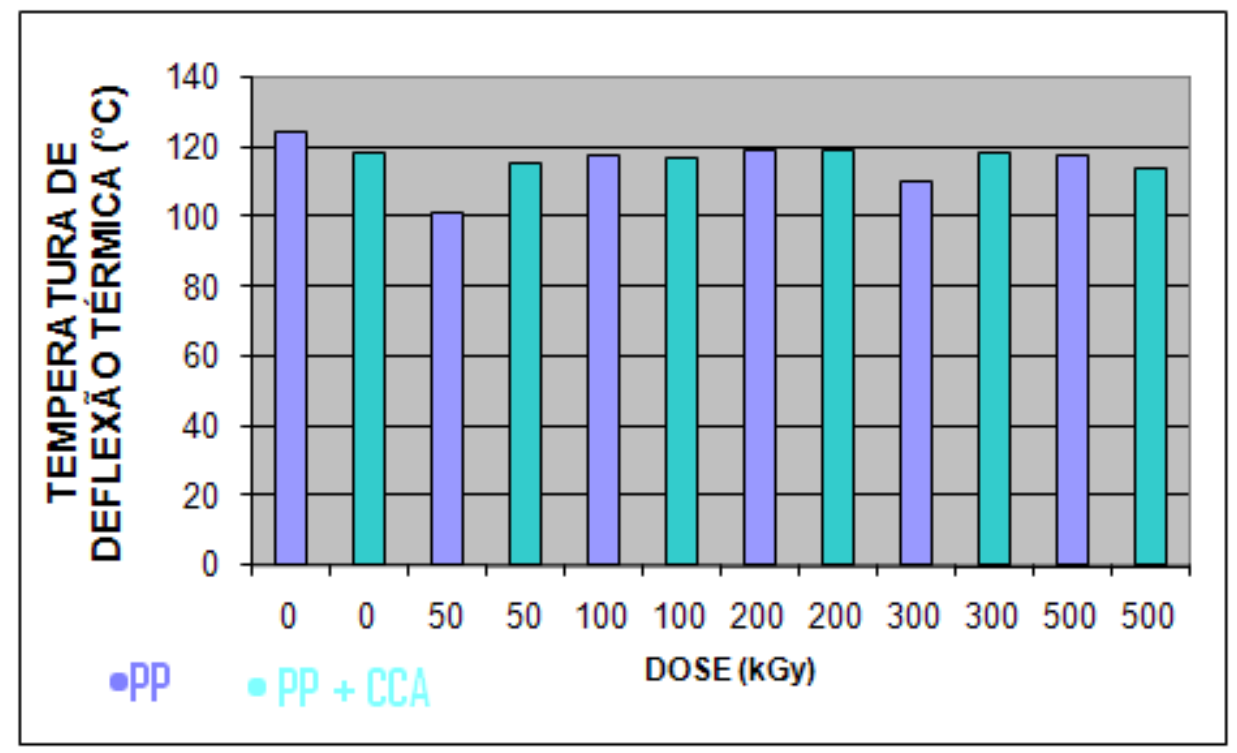

FIGURA 15 - Resultados de temperatura de deflexão térmica de amostras de PP e de PP com cinza de casca de arroz em amostras irradiadas e não irradiadas a diferentes doses

Observa-se que houve uma estabilização na temperatura de deflexão térmica para o PP entre 100 e $200 \mathrm{kGy}$, com diminuição a 300 kGy e também um pequeno aumento a 500 kGy. No caso do PP + CCA ocorreu uma estabilização entre 50 e 200 kGy com pequena diminuição entre 300 e 500 kGy. Pode-se dizer que não houve variação significativa entre os dois tipos de amostras estudadas em relação a HDT. Quando se utilizou a dose de $50 \mathrm{kGy}$, observou-se uma diferença de aproximadamente $20^{\circ} \mathrm{C}$ entre as temperaturas das amostras de PP e de PP + CCA devido à cisão da cadeia polimérica. As variações observadas, quando se utilizou amostras de PP e de PP + CCA, foram as seguintes: 4,9\% na amostra com dose de $0 \mathrm{kGy} ;-14,3 \%$ na amostra com dose de $50 \mathrm{kGy}$; 0,5\% na amostra com dose de $100 \mathrm{kGy} ;-0,5$ na amostra com dose de $200 \mathrm{kGy} ;-7,3 \%$ na amostra com dose de $300 \mathrm{kGy}$ e $2,8 \%$ na amostra com dose de $500 \mathrm{kGy}$.

Na TAB. 7 e FIG. 16 são apresentados e mostrados os resultados de temperatura de deflexão térmica de amostras de PP com cinza de casca de arroz e agente de acoplagem submetidas a diferentes doses de radiação. 
TABELA 7 - Resultados de temperatura de deflexão térmica de amostras de PP com cinza de casca de arroz e agente de acoplagem submetidas a diferentes doses de radiação

\begin{tabular}{ccccc}
\hline Dose $(\mathrm{kGy})$ & Amostra $1\left({ }^{\circ} \mathrm{C}\right)$ & Amostra $2\left({ }^{\circ} \mathrm{C}\right)$ & Média & Desvio Padrão \\
\hline 0 & 119,7 & 120,2 & 120,0 & 0,3 \\
50 & 112,2 & 121,1 & 116,6 & 6,3 \\
100 & 117,0 & 112,4 & 114,7 & 3,2 \\
200 & 113,8 & 114,4 & 114,9 & 0,4 \\
300 & 116,2 & 115,5 & 115,8 & 0,4 \\
500 & 115,3 & 116,1 & 115,7 & 0,5 \\
\hline
\end{tabular}

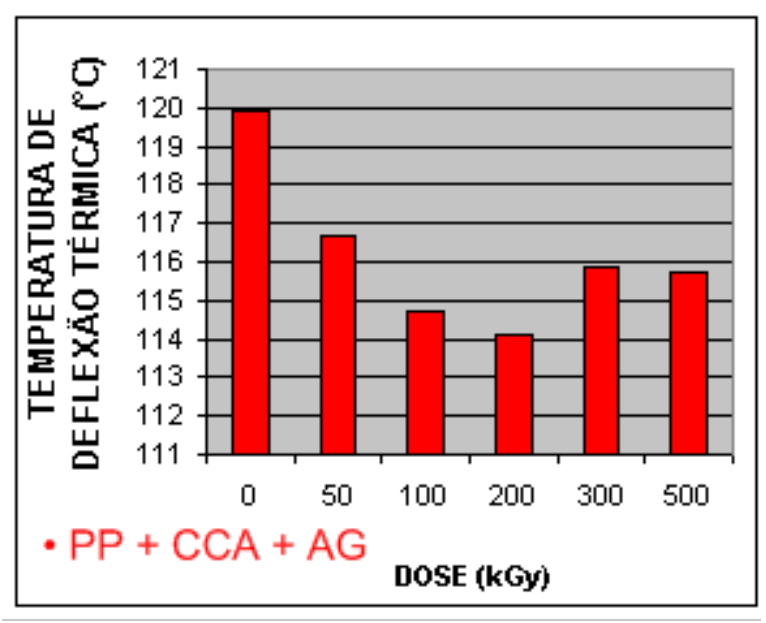

FIGURA 16 - Resultados de temperatura de deflexão térmica de amostras de PP com cinza de casca de arroz e agente de acoplagem submetidas a diferentes doses de radiação

Observa-se que a temperatura de deflexão térmica, a exemplo do que aconteceu com as amostras de PP e de PP com cinza de casca de arroz, continuou diminuindo quando se usou PP com agente de acoplagem (anidrido maleico a 1\%), havendo uma estabilização em doses de 300 e $500 \mathrm{kGy}$.

Na FIG. 17 tem-se resultados de temperatura de deflexão térmica de amostras de PP com cinza de casca de arroz e de PP com cinza de casca de arroz e agente de acoplagem em amostras irradiadas e não irradiadas. 


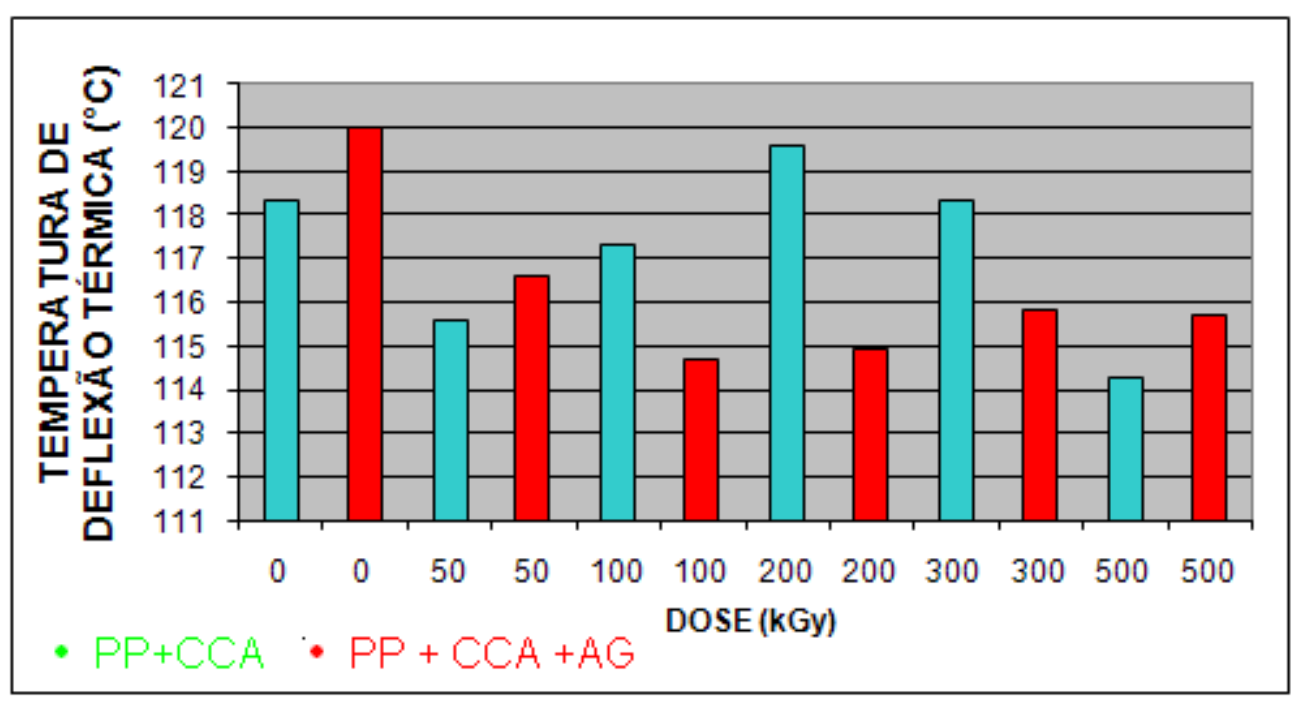

FIGURA 17 - Resultados de temperatura de deflexão térmica de amostras de PP com cinza de casca de arroz e de PP com cinza de casca de arroz e agente de acoplagem submetidas a diferentes doses de radiação

No que diz respeito à temperatura de deflexão térmica para as amostras de PP + CCA nota-se que a mesma diminui entre 0 e $50 \mathrm{kGy}$ e , também, 300 e 500 kGy. Observa-se um aumento entre 50 e $200 \mathrm{kGy}$. Em termos de resultados para amostras de PP + CCA observaram-se as seguintes variações: 2,8\% na amostra com dose de $50 \mathrm{kGy} ; 4,4 \%$ na amostra com dose de $100 \mathrm{kGy} ; 4,2 \%$ na amostra com dose de $200 \mathrm{kGy} ; 3,5 \%$ na amostra com dose de $300 \mathrm{kGy}$ e 3,5\% na amostra com dose de $500 \mathrm{kGy}$. Sobre as amostras de PP + CCA + AG, observou-se que a temperatura de deflexão térmica diminuiu de 0 a 100 kGy, aumentou entre 100 e 300 kGy e praticamente estabilizou a 500 kGy.

Analisando os resultados apresentados nas TAB. 5, 6 e 7 observou-se que houve um decréscimo na temperatura de deflexão térmica dos compósitos contendo cinza de casca de arroz em relação ao PP puro. Quando as amostras de PP, PP + CCA e PP $+\mathrm{CCA}+\mathrm{AG}$ foram irradiadas, os valores de temperatura de deflexão térmica tiveram uma variação não significativa podendo-se dizer que praticamente foram constantes. O agente de acoplagem melhorou o desempenho das amostras com relação a temperatura de deflexão térmica em doses acima de $100 \mathrm{kGy}$ devido a cisão da cadeia polimérica. Em termos de variações, nas amostras de PP + CCA e de PP + CCA + AG, observaram-se os seguintes resultados: $-14,3 \%$ na amostra com dose de $0 \mathrm{kGy} ;-0,8 \%$ na amostra com dose 
de $50 \mathrm{kGy} ; 2,2 \%$ na amostra com dose de $100 \mathrm{kGy} ; 4,5 \%$ na amostra com dose de 200 kGy; 2,1\% na amostra com dose de $300 \mathrm{kGy}$ e -1,2\% na amostra com dose de $500 \mathrm{kGy}$.

Na TAB. 8 e FIG. 18 são apresentados e mostrados os resultados de temperatura de amolecimento Vicat de amostras de PP submetidas a diferentes doses de radiação.

TABELA 8 - Resultados de temperatura de amolecimento Vicat de amostras de PP submetidas a diferentes doses de radiação

\begin{tabular}{cccccc}
\hline $\begin{array}{c}\text { Dose } \\
(\mathrm{kGy})\end{array}$ & $\begin{array}{c}\text { Amostra 1 } \\
\left({ }^{\circ} \mathrm{C}\right)\end{array}$ & $\begin{array}{c}\text { Amostra 2 } \\
\left({ }^{\circ} \mathrm{C}\right)\end{array}$ & $\begin{array}{c}\text { Amostra 3 } \\
\left({ }^{\circ} \mathrm{C}\right)\end{array}$ & $\begin{array}{c}\text { Média } \\
\left({ }^{\circ} \mathrm{C}\right)\end{array}$ & $\begin{array}{c}\text { Desvio } \\
\text { Padrão }\end{array}$ \\
\hline 0 & 150,3 & 150,6 & ---- & 150,4 & 0,2 \\
50 & 148,1 & 147,7 & 148,1 & 147,9 & 0,2 \\
100 & 145,4 & 145,6 & 145,7 & 145,5 & 0,1 \\
200 & 146,3 & 146,1 & ---- & 146,2 & 0,2 \\
300 & 137,7 & 137,8 & 138,0 & 137,8 & 0,1 \\
500 & 147,8 & 148,0 & ---- & 147,9 & 0,1 \\
\hline
\end{tabular}

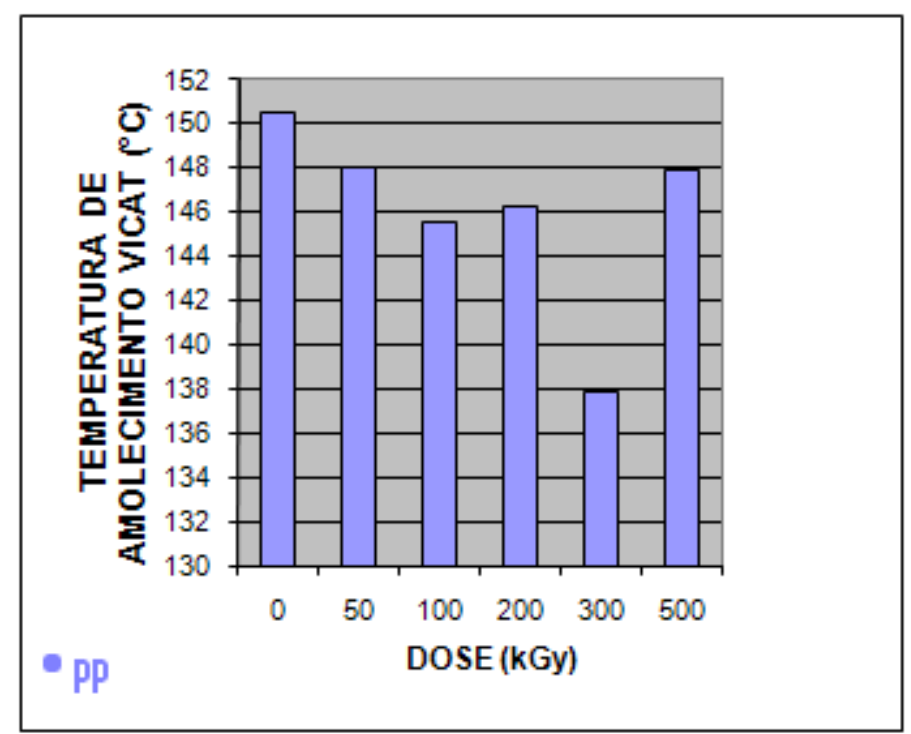

FIGURA 18 - Resultados de temperatura de amolecimento Vicat de amostras de PP submetidas a diferentes doses de radiação

Na TAB. 9 e FIG. 19 são apresentados e mostrados os resultados de temperatura de amolecimento Vicat de amostras de PP com cinza de casca de arroz submetidas a diferentes doses de radiação.

TABELA 9 - Resultados de temperatura de amolecimento Vicat de amostras de PP com cinza de casca de arroz submetidas a diferentes doses de radiação 


\begin{tabular}{cccccc}
\hline $\begin{array}{c}\text { Dose } \\
(\mathrm{kGy})\end{array}$ & $\begin{array}{c}\text { Amostra 1 } \\
\left({ }^{\circ} \mathrm{C}\right)\end{array}$ & $\begin{array}{c}\text { Amostra 2 } \\
\left({ }^{\circ} \mathrm{C}\right)\end{array}$ & $\begin{array}{c}\text { Amostra 3 } \\
\left({ }^{\circ} \mathrm{C}\right)\end{array}$ & $\begin{array}{c}\text { Média } \\
\left({ }^{\circ} \mathrm{C}\right)\end{array}$ & $\begin{array}{c}\text { Desvio } \\
\text { Padrão }\end{array}$ \\
\hline 0 & 147,2 & 147,3 & ---- & 147,2 & 0,1 \\
50 & 147,7 & 147,8 & 147,9 & 147,8 & 0,1 \\
100 & 146,0 & 145,9 & 145,9 & 145,9 & 0,1 \\
200 & 141,3 & 141,5 & 140,8 & 141,2 & 0,3 \\
300 & 138,8 & 138,8 & 138,7 & 138,7 & 0,1 \\
500 & 132,3 & 132,1 & 133,1 & 132,5 & 0,5 \\
\hline
\end{tabular}

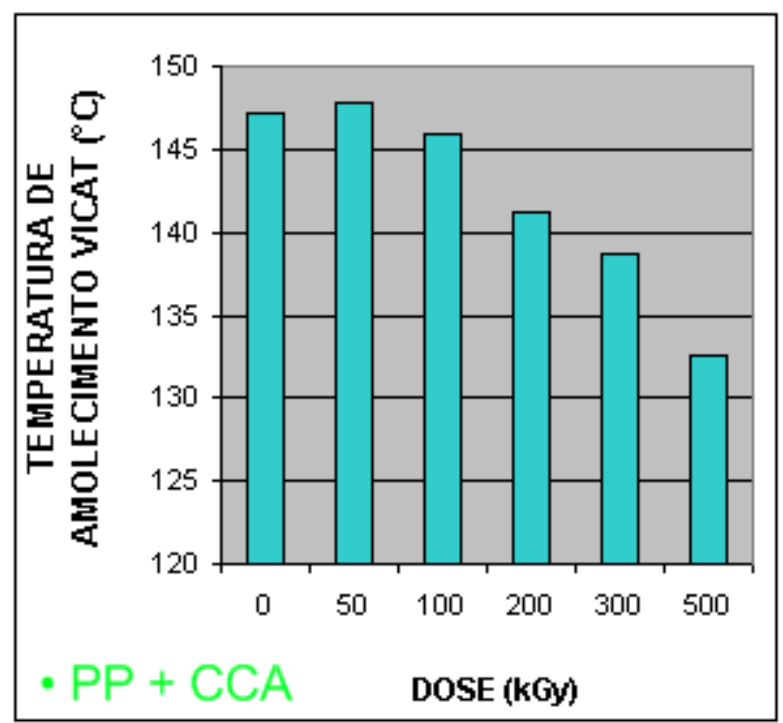

FIGURA 19 - Resultados de temperatura de amolecimento Vicat de amostras de PP com cinza de casca de arroz submetidas a diferentes doses de radiação

Analisando os resultados apresentados na TAB. 8 e FIG. 18 nota-se que a medida que a dose de radiação aumentou a temperatura de amolecimento Vicat, para amostras de PP, diminuiu de 0 a 100 kGy e entre 200 e 300 kGy aumentando quando a dose aplicada foi de 500 kGy. Na TAB. 9 e FIG. 18 observa-se que houve uma diminuição nos resultados de temperatura de amolecimento Vicat de amostras de PP + CCA a medida que a dose aumentou. Em termos de variações nos resultados, para amostras de PP, obteve-se os seguintes resultados para temperatura de amolecimento Vicat : 1,6\% para amostra com dose de $50 \mathrm{kGy} ; 3,2 \%$ para amostra com dose de $100 \mathrm{kGy} ; 2,7 \%$ para amostra com dose de $200 \mathrm{kGy} ; 8,3 \%$ para amostra com dose de $300 \mathrm{kGy}$ e 1,6\% para amostra com dose de $500 \mathrm{kGy}$.

Na FIG.20 são mostrados os resultados de temperatura de amolecimento Vicat para amostras irradiadas e não irradiadas de PP e de PP com a cinza de casca de arroz. 


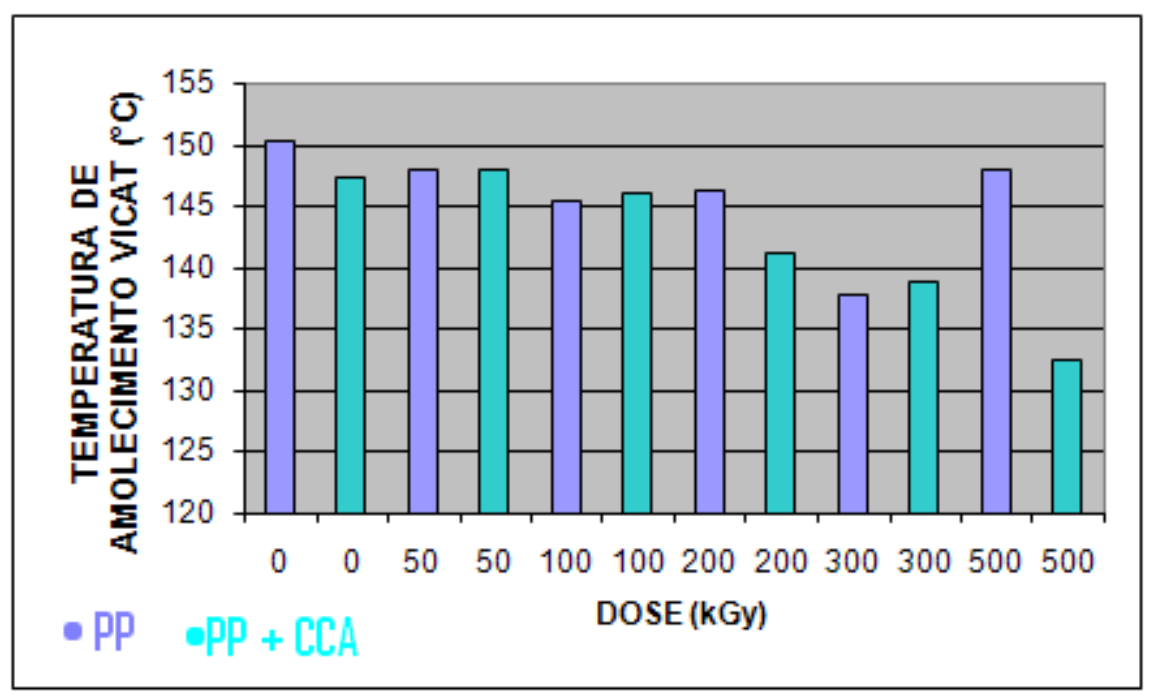

FIGURA 20 - Resultados de temperatura de amolecimento Vicat de amostras de PP e de PP com cinza de casca de arroz em amostras irradiadas e não irradiadas

A temperatura de amolecimento Vicat para as amostras de PP, diminuiu entre 0 e $100 \mathrm{kGy}$; na faixa compreendida de 100 a $200 \mathrm{kGy}$ houve uma pequena estabilização diminuindo a $300 \mathrm{kGy}$ e notou-se um aumento a $500 \mathrm{kGy}$. No que diz respeito às amostras de $\mathrm{PP}+\mathrm{CCA}$ observou-se que houve uma estabilização entre 0 e 50 kGy, com diminuição de 50 a 500 kGy. Em termos de variações nos resultados, para amostras de PP + CCA, obteve-se os seguintes resultados : $-0,4 \%$ na amostra com dose de $50 \mathrm{kGy} ; 0,8 \%$ para amostra com dose de $100 \mathrm{kGy} ; 4,0 \%$ para amostra com dose de 200 kGy; 5,7 para amostra de $300 \mathrm{kGy}$ e 9,9\% para amostra de $500 \mathrm{kGy}$. Em se falando de amostras combinadas de PP e de PP + CCA obteve-se os seguintes resultados: 2,1\% para amostra com dose de $0 \mathrm{kGy} ; 0,06 \%$ na amostra com de $50 \mathrm{kGy} ;-0,2 \%$ na amostra com dose de $100 \mathrm{kGy} ; 3,4 \%$ na amostra de $200 \mathrm{kGy} ;-0,6 \%$ na amostra de $300 \mathrm{kGy}$ e $10,4 \%$ na amostra de $500 \mathrm{kGy}$.

Na TAB. 10 são apresentados os resultados de temperatura de amolecimento Vicat de amostras de PP com cinza de casca de arroz e agente de acoplagem submetidas a diferentes doses de radiação.

TABELA 10 - Resultados de temperatura de amolecimento Vicat de amostras de PP com cinza de casca de arroz e agente de acoplagem submetidas a diferentes doses de radiação 


\begin{tabular}{ccccc}
\hline Dose $(\mathrm{kGy})$ & Amostra $1\left({ }^{\circ} \mathrm{C}\right)$ & Amostra $2\left({ }^{\circ} \mathrm{C}\right)$ & Média $\left({ }^{\circ} \mathrm{C}\right)$ & Desvio Padrão \\
\hline 0 & 148,3 & 148,5 & 148,4 & 0,1 \\
50 & 148,2 & 148,4 & 148,3 & 0,1 \\
100 & 144,4 & 144,5 & 144,4 & 0,7 \\
200 & 141,5 & 141,5 & 141,5 & -- \\
300 & 138,7 & 138,4 & 138,5 & 0,2 \\
500 & 138,7 & 138,5 & 138,6 & 0,1 \\
\hline
\end{tabular}

Na FIG. 21 são mostrados resultados de temperatura de amolecimento Vicat para amostras de PP com cinza de casca de arroz e agente de acoplagem em amostras irradiadas e não irradiada.

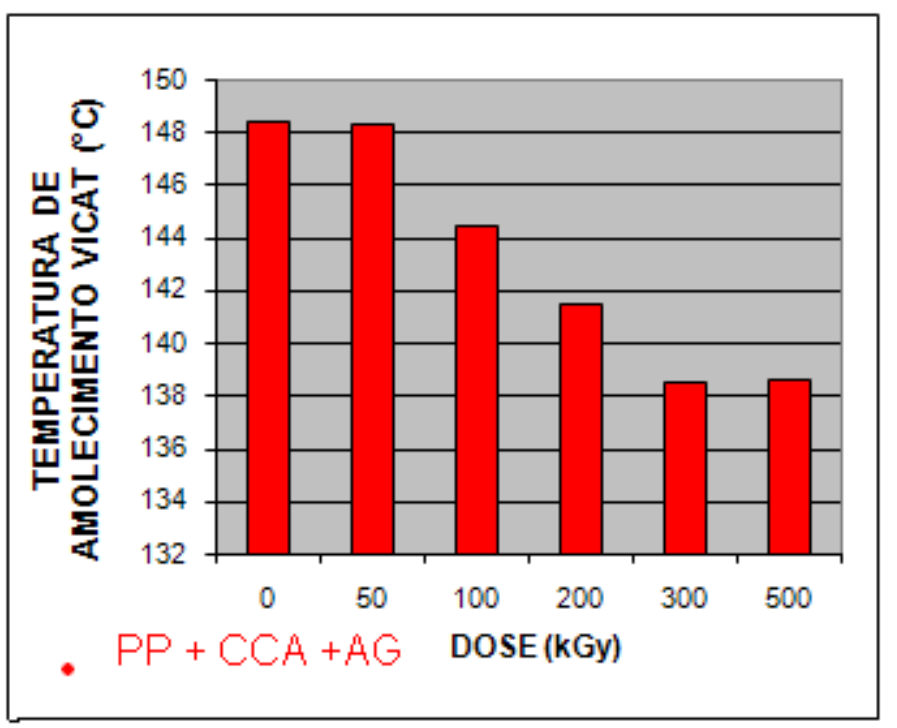

FIGURA 21 - Resultados de temperatura de amolecimento Vicat de amostras de PP com cinza de casca de arroz e agente de acoplagem em amostras irradiadas e não irradiada

Nota-se que para as amostras de PP + CCA ocorreu, primeiramente, uma estabilização na temperatura de amolecimento Vicat entre 0 e 50 kGy . Observou-se uma diminuição na mesma à medida que se aumentou a dose de radiação, entre 50 e 300 kGy, 
estabilizando-se entre 300 e 500 kGy, este comportamento deve-se à cisão das cadeias do polímero.

Na FIG. 22 encontram-se resultados de temperatura de amolecimento Vicat para amostras de PP com cinza de casca de arroz e de PP com cinza de casca de arroz e agente de acoplagem em amostras irradiadas e não irradiadas.

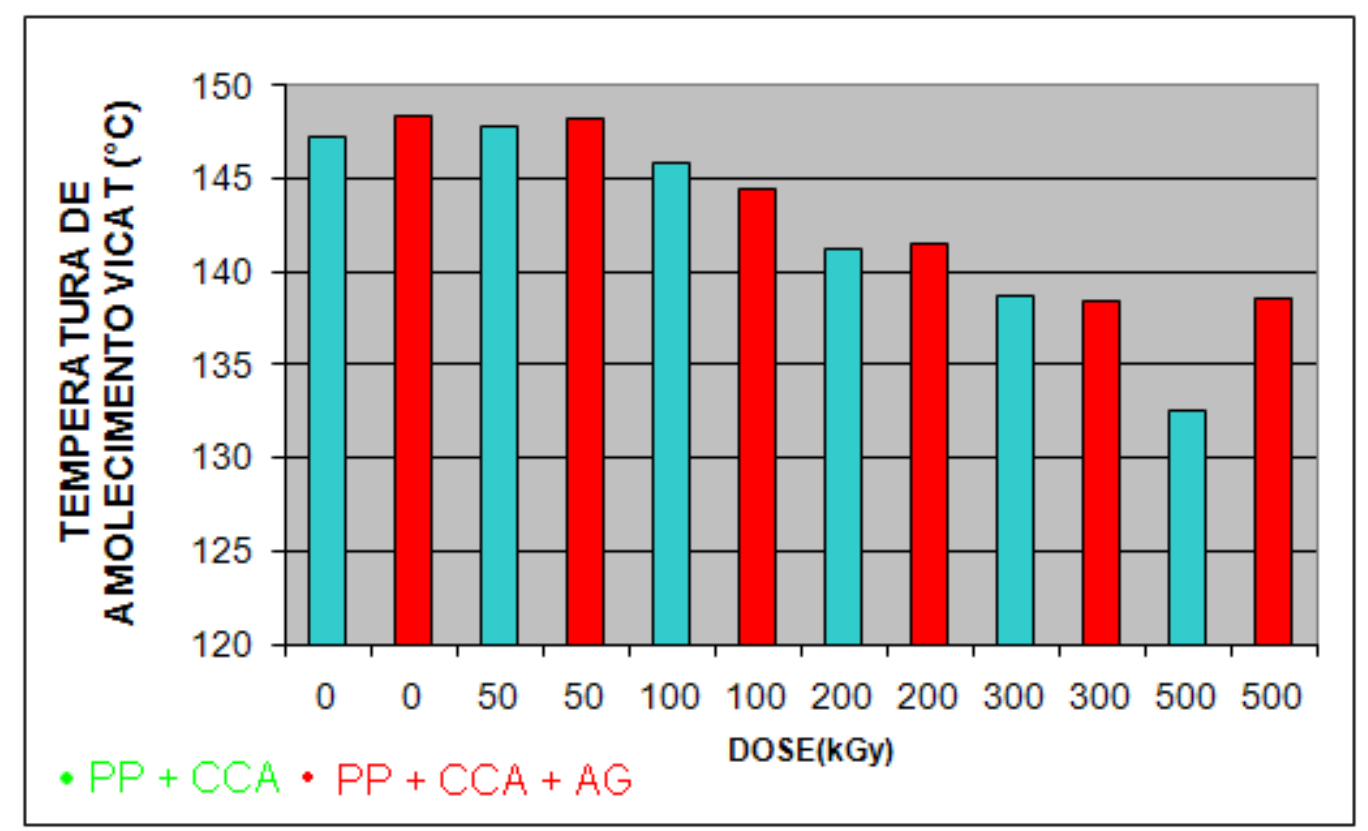

FIGURA 22 - Resultados de temperatura de amolecimento Vicat de amostras de PP com cinza de casca de arroz e de PP com cinza de casca de arroz e agente de acoplagem em amostras irradiadas e não irradiadas

No que diz respeito aos resultados de temperatura de amolecimento Vicat, para amostras de PP + CCA notou-se que houve uma estabilização entre 0 e 50 kGy e diminuição na mesma entre 50 e 500 kGy. Para as amostras de PP + CCA + AG, ocorreu, em doses de 0 a 50 kGy, a mesma estabilização que aconteceu para as amostras de PP + CCA, com posterior diminuição entre 50 e 300 kGy estabilizando-se no intervalo de 300 a $500 \mathrm{kGy}$. O agente de acoplagem atuou de maneira eficiente pois melhorou os resultados de temperatura de amolecimento Vicat para amostras de 100 a 500 kGy devido a cisão da cadeia polimérica. Para amostras de $\mathrm{PP}+\mathrm{CCA}+\mathrm{AG}$, em termos de temperatura de amolecimento Vicat, obteve-se os seguintes resultados: 0,06\% na amostra com dose de 50 kGy; 2,6\% na amostra com dose de $100 \mathrm{kGy} ; 4,6 \%$ na amostra com dose de $200 \mathrm{kGy}$; $6,6 \%$ na amostra com dose de $300 \mathrm{kGy}$ e $6,6 \%$ na amostra com dose de $500 \mathrm{kGy}$. Com 
relação as amostras combinadas de PP + CCA e de PP + CCA + AG, obteve-se os seguintes resultados: $-0,8 \%$ para amostra com dose de $0 \mathrm{kGy} ;-0,5 \%$ para amostra com dose de $50 \mathrm{kGy} ; 1,0 \%$ para amostra com dose de $100 \mathrm{kGy} ;-0,2 \%$ para amostra com dose de $200 \mathrm{kGy} ; 0,1 \%$ para amostra com dose de $300 \mathrm{kGy}$ e $-4,6 \%$ para amostra com dose de $500 \mathrm{kGy}$.

$\mathrm{Na}$ medida em que a dose de radiação aumentou, a temperatura de amolecimento Vicat para os compósitos de PP + CCA diminuiu com o aumento da dose de radiação. Os valores obtidos eram similares ao do PP puro indicando que a CCA não contribuiu para esta diminuição, uma vez que a proporção de PP utilizada é bem maior que a da CCA prevalecendo às propriedades térmicas da matriz polimérica.

Nas TAB. 11, 12 e 13 são apresentados os resultados de análises de DSC de amostras de PP, PP com cinza de casca de arroz e de PP com cinza de casca de arroz e agente de acoplagem submetidas a diferentes doses de radiação.

TABELA 11 - Resultados de análises DSC de amostras de PP submetidas a diferentes doses de radiação

\begin{tabular}{cccc}
\hline Amostra & Dose $(\mathrm{kGy})$ & Pto início fusão $\left({ }^{\circ} \mathrm{C}\right)$ & $\begin{array}{c}\text { Entalpia }(\Delta \mathrm{H}) \\
\mathrm{cal} / \mathrm{g}\end{array}$ \\
\hline PP & 0 & & $-27,5$ \\
PP & 50 & 152,7 & $-23,5$ \\
PP & 100 & 148,5 & $-26,0$ \\
PP & 200 & 144,0 & $-15,0$ \\
PP & 300 & 140,0 & $-19,0$ \\
PP & 500 & 133,4 & $-13,0$ \\
\hline
\end{tabular}

TABELA 12 - Resultados de análises DSC de amostras de PP com cinza de casca de arroz submetidas a diferentes doses de radiação

\begin{tabular}{cccc}
\hline Amostra & Dose (kGy) & Pto início fusão $\left({ }^{\circ} \mathrm{C}\right)$ & $\begin{array}{c}\text { Entalpia }(\Delta \mathrm{H}) \\
\mathrm{cal} / \mathrm{g}\end{array}$ \\
\hline $\mathrm{PP}+\mathrm{CCA}$ & 0 & 165,3 & $-22,2$
\end{tabular}




$\begin{array}{lccc}\text { PP+CCA } & 50 & 148,5 & -24,0 \\ \text { PP+CCA } & 100 & 141,0 & -21,0 \\ \text { PP+CCA } & 200 & 139,2 & -18,0 \\ \text { PP+CCA } & 300 & 137,0 & -13,1 \\ \text { PP+CCA } & 500 & 127,6 & -10,2\end{array}$

TABELA 13 - Resultados de análises DSC de amostras de PP com cinza de casca de arroz e agente de acoplagem submetidas a diferentes doses de radiação

\begin{tabular}{cccc}
\hline Amostra & Dose (kGy) & Pto início fusão $\left({ }^{\circ} \mathrm{C}\right)$ & $\begin{array}{c}\text { Entalpia }(\Delta \mathrm{H}) \\
\text { cal } / \mathrm{g}\end{array}$ \\
\hline PP+CCA+AG & 0 & 148,5 & $-13,0$ \\
PP+CCA+AG & 50 & 145,1 & $-16,1$ \\
PP+CCA+AG & 100 & 140,5 & $-16,1$ \\
PP+CCA+AG & 200 & 130,4 & $-11,3$ \\
PP+CCA+AG & 300 & 128,4 & $-15,0$ \\
PP+CCA+AG & 500 & 128,1 & $-8,2$ \\
\hline
\end{tabular}

De acordo com os resultados de calorimetria exploratória diferencial (DSC) apresentados nas TAB. 11, 12 e 13, os pontos de fusões tanto das amostras de PP, de PP $+\mathrm{CCA}$ e de $\mathrm{PP}+\mathrm{CCA}+\mathrm{AG}$ diminuem à medida que aumentou a dose de radiação em razão da cisão das moléculas de PP, o que induziu a redução da massa molar do polímero.

O valor da entalpia de fusão $(\Delta \mathrm{H})$ para o PP $100 \%$ cristalino é de $209 \mathrm{~J}$. De acordo com os dados apresentados nas TAB. 11, 12 e 13 pode 0 , indicar um decréscimo no grau de cristalinidade do PP com o aumento da dose de radiação.

Na TAB. 14 são apresentados os resultados de análises TG de amostras de PP.

TABELA 14 - Resultados de análises TG de amostras de PP submetidas a diferentes doses de radiação

\begin{tabular}{cccc}
\hline Amostras & Dose $(\mathrm{kGy})$ & $\begin{array}{c}\text { Pto. início } \\
\text { decomposição }\left({ }^{\circ} \mathrm{C}\right)\end{array}$ & Perda de massa \% \\
\hline PP & 0 & 322,1 & 97,3 \\
PP & 50 & 319,1 & 97,4 \\
PP & 100 & 310,5 & 97,7 \\
PP & 200 & 287,5 & 89,7 \\
PP & 300 & 250,5 & 97,2
\end{tabular}




\begin{tabular}{llll}
\hline PP & 500 & 274,2 & 94,7 \\
\hline
\end{tabular}

Na TAB. 15 são apresentados os resultados de análises TG de amostras de PP com cinza de casca de arroz submetidas a diferentes doses de radiação.

TABELA 15 - Resultados de análises TG de amostras de PP com cinza de casca de arroz submetidas a diferentes doses de radiação

\begin{tabular}{cccc}
\hline Amostras & Dose (kGy) & $\begin{array}{c}\text { Pto. início } \\
\text { decomposição }\left({ }^{\circ} \mathrm{C}\right)\end{array}$ & Perda de massa \% \\
\hline PP+CCA & 0 & 359,9 & 80,9 \\
PP+CCA & 50 & 319,7 & 82,6 \\
PP+CCA & 100 & 309,5 & 81,1 \\
PP+CCA & 200 & 307,1 & 81,4 \\
PP+CCA & 300 & 300,7 & 72,4 \\
PP+CCA & 500 & 314,3 & 76,4 \\
\hline
\end{tabular}

Na TAB. 16 são apresentados os resultados de análises TG de amostras de PP com cinza de casca de arroz e agente de acoplagem submetidas a diferentes doses de radiação.

TABELA 16 - Resultados de análises TG de amostras de PP com cinza de casca de arroz e agente de acoplagem submetidas a diferentes doses de radiação

\begin{tabular}{cccc}
\hline Amostras & Dose (kGy) & $\begin{array}{c}\text { Pto. início } \\
\text { decomposição }\left({ }^{\circ} \mathrm{C}\right)\end{array}$ & Perda de massa \% \\
\hline PP+CCA+AG & 0 & 325,8 & 77,7 \\
PP+CCA+AG & 50 & 398,4 & 74,6 \\
PP+CCA+AG & 100 & 326,1 & 78,9 \\
PP+CCA+AG & 200 & 323,8 & 81,3 \\
PP+CCA+AG & 300 & 318,7 & 75,3 \\
PP+CCA+AG & 500 & 323,7 & 78,5 \\
\hline
\end{tabular}

Estes resultados em relação à perda de massa estão coerentes, pois no caso do PP ele perdeu aproximadamente $100 \%$ e no caso do PP + CCA ele perde a parte correspondente ao PP que é de $80 \%$ restando $20 \%$ de massa correspondente a CCA. 
Observa-se também que tanto nas amostras de PP puro como de PP + CCA ocorre cisão do material irradiado quando comparado com o não irradiado. No caso do PP + CCA, com doses a partir de $200 \mathrm{kGy}$, o material apresenta maior estabilidade térmica quando comparado com o PP puro. Isto também é verificado com o PP puro e PP + CCA, não irradiados. O PP + CCA apresenta maior estabilidade térmica. A CCA aumentou tanto os resultados de termogravimetria quanto resultados os de temperatura de degradação.

Na TAB. 17 são apresentados os resultados de dureza Shore D de amostras de PP, PP + CCA e de PP + CCA + AG submetidas a diferentes doses de radiação.

TABELA 17 - Resultados de testes de dureza Shore D de amostras de PP, PP + CCA e de $\mathrm{PP}+\mathrm{CCA}+\mathrm{AG}$ submetidas a diferentes doses de radiação

\begin{tabular}{ccccccc}
\hline Amostra & $0 \mathrm{kGy}$ & $50 \mathrm{kGy}$ & $100 \mathrm{kGy}$ & $200 \mathrm{kGy}$ & $300 \mathrm{kGy}$ & $500 \mathrm{kGy}$ \\
\hline PP & $72,3 \pm 1,3$ & $73,3 \pm 1,2$ & $74,7 \pm 0,7$ & $69,3 \pm 1,3$ & $74,3 \pm 1,4$ & $72,4 \pm 0,7$ \\
PP + CCA & $80,9 \pm 1,4$ & $82,0 \pm 1,6$ & $82,1 \pm 1,2$ & $82,6 \pm 1,2$ & $81,8 \pm 1,4$ & $82,1 \pm 1,0$ \\
PP + CCA+AG & $75,6 \pm 0,6$ & $77,0 \pm 1,5$ & $76,0 \pm 1,3$ & $77,4 \pm 0,7$ & $77,0 \pm 0,9$ & $76,0 \pm 0,8$ \\
\hline
\end{tabular}

De acordo com os resultados apresentados na TAB 17, observa-se que não houve variação significativa nos valores de dureza à medida que se aumenta a dose de radiação. Comparando os resultados de dureza entre as amostras de PP com as de PP + $\mathrm{CCA}$ e PP + CCA + AG observou-se que os resultados de PP+ CCA + AG indicaram uma maior homogeneização entre o PP e a CCA. A CCA aumentou a TG e a temperatura de degradação.

Na FIG. 23 são mostrados os resultados de dureza Shore D para amostras de PP em amostras irradiadas e não irradiada. 


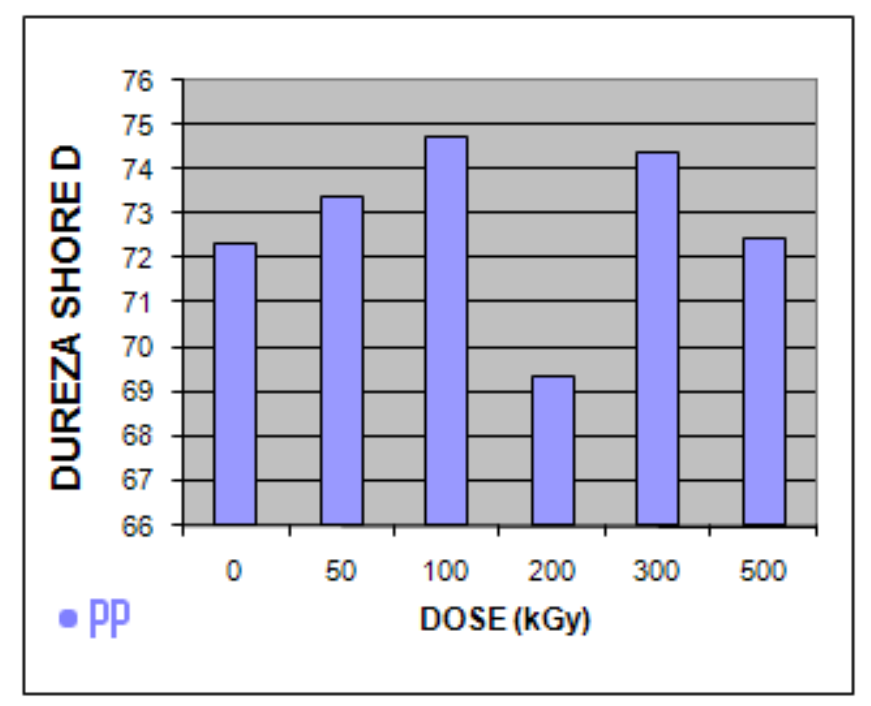

FIGURA 23 - Resultados de dureza Shore D de amostras de PP em amostras irradiadas e não irradiada

Em termos de variações nos resultados, para amostras de PP, nos ensaios de dureza Shore D, obteve-se os seguintes resultados: $-1,3 \%$ para amostra na dose de $50 \mathrm{kGy}$; $-3,3 \%$ para amostra na dose de $100 \mathrm{kGy} ; 4,9 \%$ para amostra na dose de $200 \mathrm{kGy} ;-2,7 \%$ para amostra na dose de 300 kGy e $-0,1 \%$ para amostra na dose de 500 kGy.

Na FIG.24 são mostrados os resultados de dureza Shore D para amostras de PP com cinza de casca de arroz em amostras irradiadas e não irradiada.

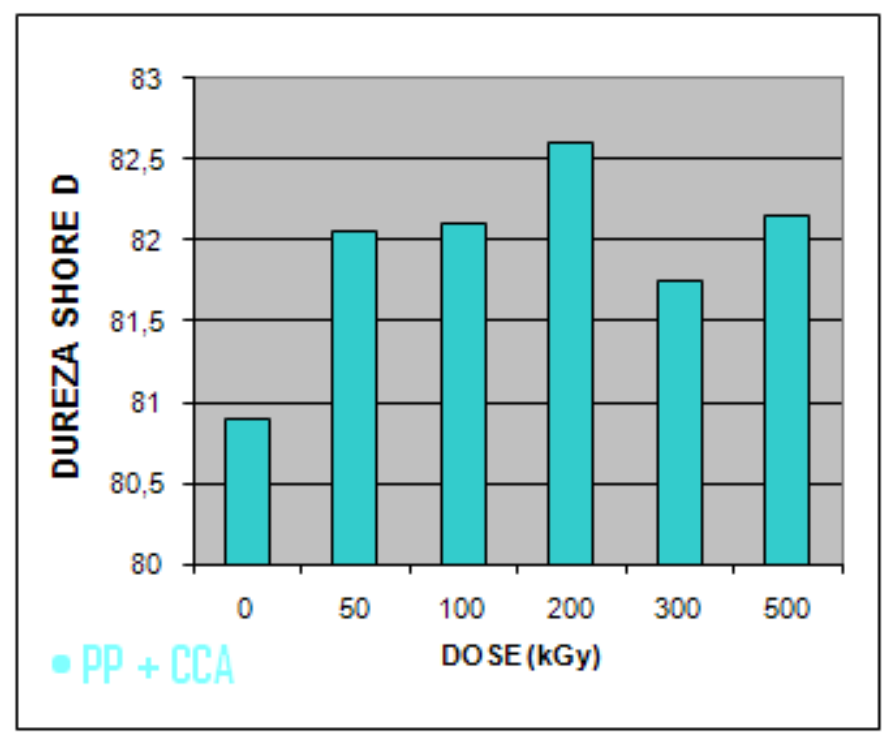

FIGURA 24 - Resultados de dureza Shore D de amostras de PP com cinza de 
casca de arroz em amostras irradiadas e não irradiada

Com relação às amostras de $\mathrm{PP}+\mathrm{CCA}$, nos ensaios de dureza Shore $\mathrm{D}$, obteve-se as seguintes variações: $-1,3 \%$ para amostra na dose de $50 \mathrm{kGy} ;-1,4 \%$ para amostra na dose de $100 \mathrm{kGy} ;-2,1 \%$ para amostra de $200 \mathrm{kGy} ;-1,1 \%$ para amostra de 300 kGy e $-1,2 \%$ para amostra de 500 kGy.

Na FIG.25 encontram-se resultados de dureza Shore D de amostras irradiadas e não irradiadas de PP e de PP com cinza de casca de arroz em diferentes doses de radiação. 


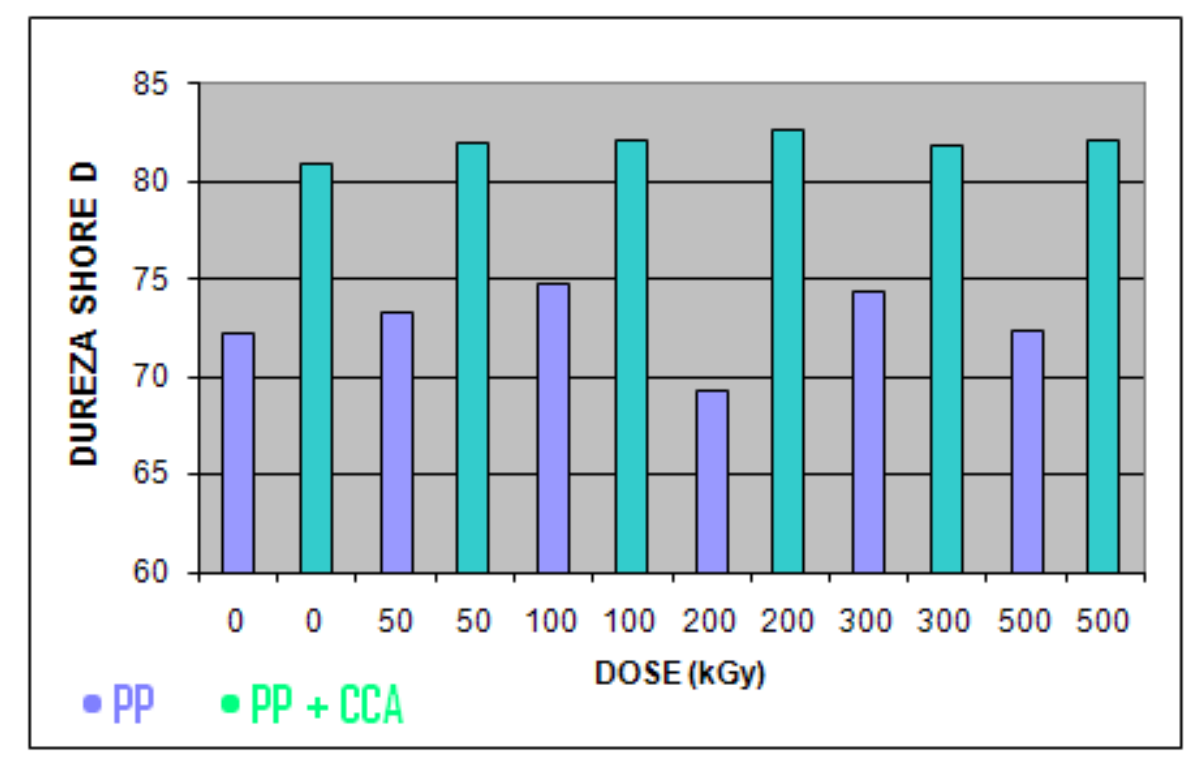

FIGURA 25 - Resultados de dureza Shore D de amostras de PP e de PP com cinza de casca de arroz em amostras irradiadas e não irradiadas

No que diz respeito às amostras de PP e de PP + CCA, nos ensaios de dureza Shore D, obteve-se os seguintes resultados: $-11,8 \%$ para amostra nas doses de 0 e $50 \mathrm{kGy}$; $-9,9 \%$ para amostra na dose de $100 \mathrm{kGy} ;-19,1 \%$ para amostra na dose de $200 \mathrm{kGy} ;-10 \%$ para amostra na dose de $300 \mathrm{kGy}$ e $-13,3 \%$ para amostra na dose de $500 \mathrm{kGy}$.

Na FIG. 26 são apresentados resultados de dureza Shore D para amostras de PP com cinza de casca de arroz e agente de acoplagem submetidas a diferentes doses de radiação.

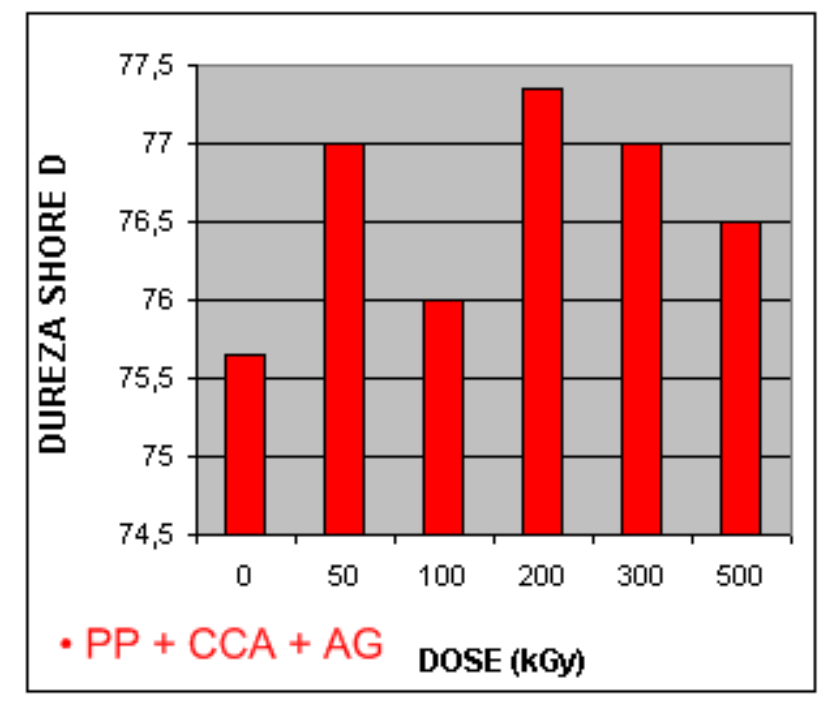

FIGURA 26 - Resultados de dureza Shore D de amostras de PP com cinza de casca de arroz e agente de acoplagem em amostras irradiadas e não irradiada 
Nota-se que houve um aumento na dureza Shore D entre 0 e 50 kGy e de 100 a 200 kGy, uma diminuição entre 50 e 100 kGy e de 200 a 500 kGy nas amostras de PP + $\mathrm{CCA}+\mathrm{AG}$ em doses devido a presença da CCA e aos processos de cisão da molécula de PP. Em termos de variações nos resultados para amostras de PP $+\mathrm{CCA}+\mathrm{AG}$, nos ensaios de dureza Shore $\mathrm{D}$, obteve-se os seguintes resultados: $-1,8 \%$ para amostra na dose de 50 $\mathrm{kGy} ;-0,5 \%$ para amostra na dose de $100 \mathrm{kGy} ;-2,3 \%$ para amostra na dose de $200 \mathrm{kGy}$; $-1,8 \%$ para amostra na dose de $300 \mathrm{kGy}$ e $-0,5 \%$ para amostra na dose de $500 \mathrm{kGy}$.

Na FIG. 27 encontram-se valores de dureza Shore D de amostras de PP com cinza de casca de arroz e de PP com cinza de casca de arroz e agente de acoplagem de amostras irradiadas e não irradiadas.

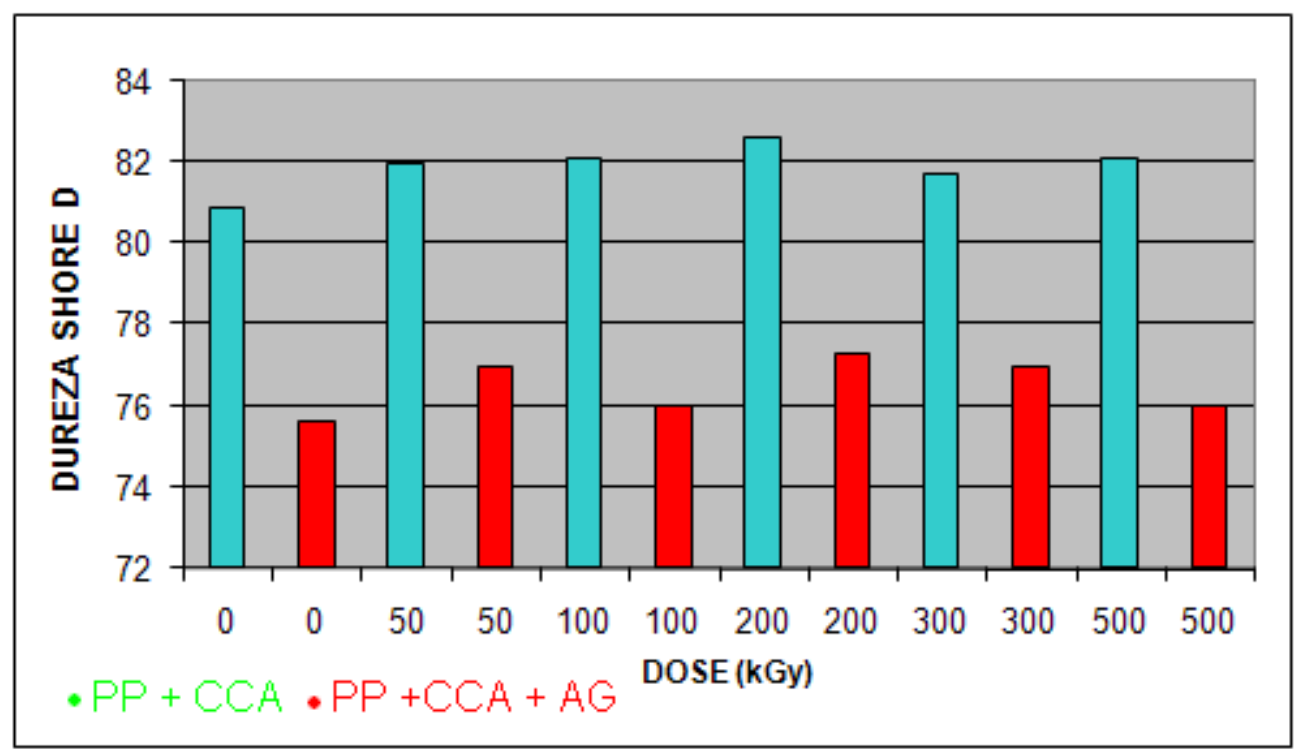

FIGURA 27 - Resultados de dureza Shore D de amostras irradiadas e não irradiadas de PP com cinza de casca de arroz e de PP com cinza de casca de arroz e agente de acoplagem

Em termos de resultados de dureza Shore D para as amostras de PP + CCA observaram-se aumentos entre 0 e $200 \mathrm{kGy}$ e também de 300 e $500 \mathrm{kGy}$; ocorreu uma diminuição no intervalo de 200 a 300 kGy em razão da cisão das moléculas de PP. Observaram-se pequenos aumentos na dureza Shore D para as amostras de PP+ CCA + AG de 0 a 50 kGy e de 100 a 200 kGy em razão da presença da cinza de casca de arroz e do agente de acoplagem. Notou-se uma diminuição entre 300 e 500 kGy em virtude da cisão das moléculas de PP. Em termos de variações percentuais, nas amostras de PP + CCA e de PP + CCA + AG, no ensaio de dureza Shore D, obteve-se os seguintes resultados: 6,5\% para amostra na dose de $0 \mathrm{kGy} ; 6,0 \%$ para amostra na dose de $50 \mathrm{kGy}$; 
7,4\% para amostra na dose de $100 \mathrm{kGy} ; 6,2 \%$ para amostra na dose de $200 \mathrm{kGy} ; 5,8 \%$ para amostra na dose de $300 \mathrm{kGy}$ e 7,4\% para amostra na dose de $500 \mathrm{kGy}$.

Na TAB. 18, são apresentados os resultados de testes de impacto Izod com PP, $\mathrm{PP}+\mathrm{CCA}$ e PP + CCA + AG nas doses de 0 a $500 \mathrm{kGy}$.

TABELA 18 - Resultados de testes de impacto Izod com PP, PP + CCA e PP + CCA + AG para amostras submetidas a diferentes doses de radiação

\begin{tabular}{ccccccc}
\hline Amostra & $0 \mathrm{kGy}$ & $50 \mathrm{kGy}$ & $100 \mathrm{kGy}$ & $200 \mathrm{kGy}$ & $300 \mathrm{kGy}$ & $500 \mathrm{kGy}$ \\
\hline PP & $371,0 \pm 7,0$ & $237,8 \pm 154,4$ & $72,9 \pm 21,8$ & $35,2 \pm 5,8$ & $29,2 \pm 4,6$ & $14,2 \pm 1,9$ \\
PP+CCA & $276,4 \pm 15,9$ & $192,8 \pm 15,7$ & $110,2 \pm 13,1$ & $75,3 \pm 8,2$ & $55,5 \pm 10,4$ & $27,4 \pm 4,0$ \\
PP+CCA+AG & $274,8 \pm 14,8$ & $182,9 \pm 24,9$ & $129,2 \pm 2,9$ & $81,6 \pm 4,9$ & $55,4 \pm 3,8$ & $34,7 \pm 0,8$ \\
\hline
\end{tabular}

Nas FIG. 28 e 29 são apresentados os resultados de resistência ao impacto Izod em amostras irradiadas e não irradiadas de PP e de PP + CCA nas doses de 0 a 500 kGy .

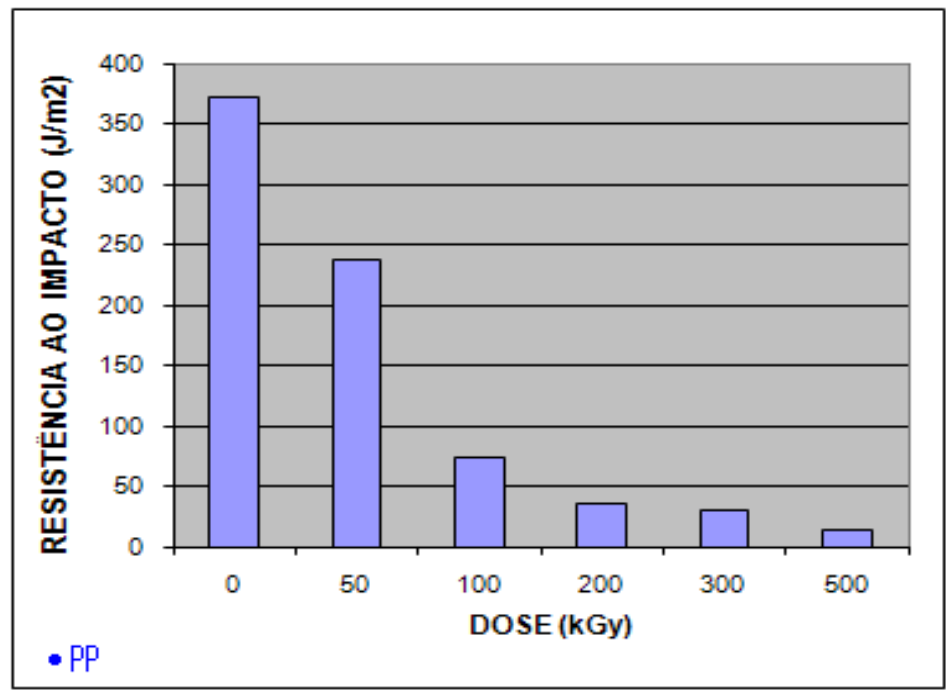

FIGURA 28 - Resultados de resistência ao impacto Izod de amostras de PP em amostras irradiadas e não irradiada 


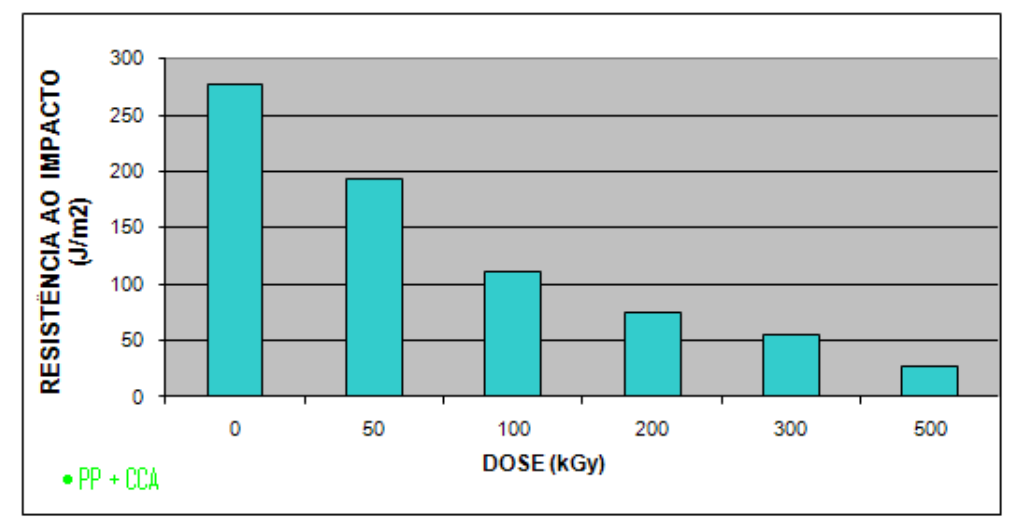

FIGURA 29 - Resultados de resistência ao impacto Izod de amostras de PP com cinza de casca de arroz em amostras irradiadas e não irradiada

Para amostras de PP, no ensaio de impacto Izod, obteve-se os seguintes resultados percentuais: 35,9\% para amostra na dose de $50 \mathrm{kGy} ; 80,3 \%$ para amostra na dose de $100 \mathrm{kGy}$; 90,5\% para amostra na dose de $200 \mathrm{kGy}$; 92,1\% para amostra na dose de 300 kGy e 96,1\% para amostra na dose de $500 \mathrm{kGy}$. Em se falando de variações percentuais, na amostra de PP + CCA, do ensaio de impacto Izod, obteve-se os seguintes resultados : 30,2\% para amostra na dose de $50 \mathrm{kGy} ; 60,1 \%$ para amostra na dose de 100 kGy; 72,7\% para amostra na dose de $200 \mathrm{kGy}$; 79,9\% para amostra na dose de $300 \mathrm{kGy}$ e $90 \%$ para amostra na dose de $500 \mathrm{kGy}$.

Na FIG. 30 são mostrados resultados de resistência a impacto Izod para amostras de PP e de PP com cinza de casca de arroz em amostras irradiadas e não irradiadas. 


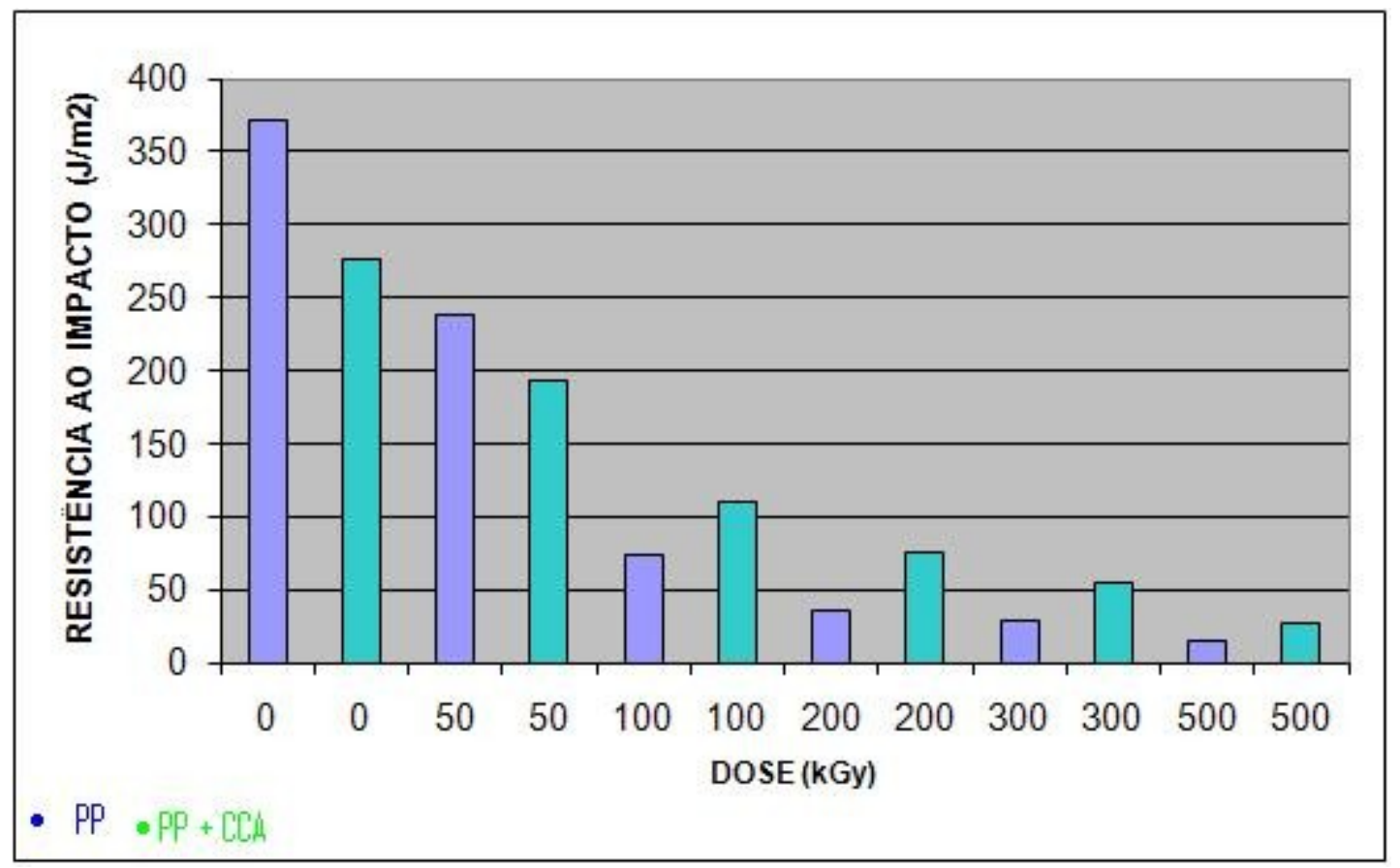

FIGURA 30 - Resultados de impacto Izod de amostras irradiadas e não irradiadas de PP e de PP com cinza de casca de arroz

Em termos de variações percentuais, nas amostras de PP e de PP + CCA, no ensaio de resistência ao impacto Izod, obteve-se os seguintes resultados : 25,4\% para amostra na dose de $0 \mathrm{kGy} ; 18,9 \%$ para amostra na dose de $50 \mathrm{kGy} ;-51,1 \%$ para amostra na dose de $100 \mathrm{kGy} ;-113,9 \%$ para amostra na dose de $200 \mathrm{kGy}$; $-90 \%$ para amostra na dose de 300 kGy e $-92,9 \%$ para amostra na dose de $500 \mathrm{kGy}$.

Na FIG.31 são mostrados os resultados de resistência ao impacto Izod para amostras de PP com cinza de casca de arroz e agente de acoplagem em amostras irradiadas e não irradiada. 


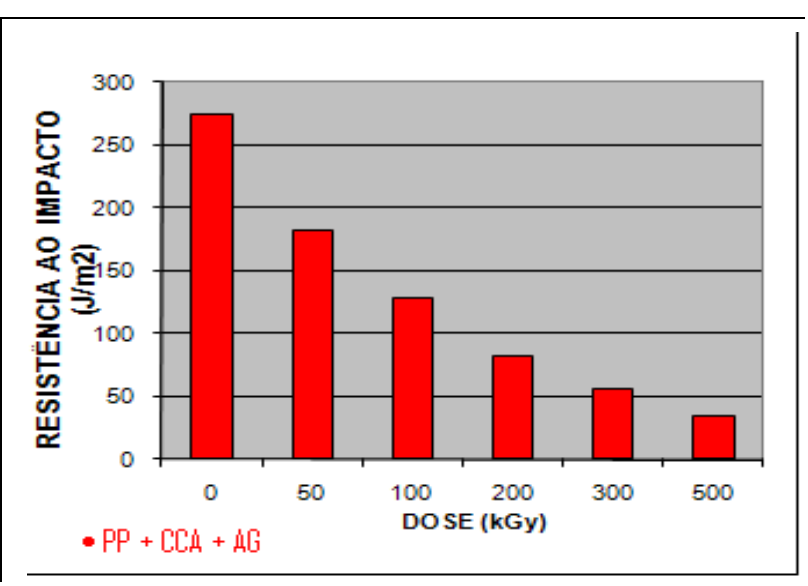

FIGURA 31 - Resultados de resistência ao impacto Izod de amostras de PP com cinza de casca de arroz e agente de acoplagem em amostras irradiadas e não irradiada

Comparando-se os dados das TAB. 18, em termos de resultados, conclui-se que houve uma diminuição no impacto Izod à medida que aumentava-se a dose o que pode ser justificado pelo processo de cisão das cadeias do PP . Observando os dados dos resultados, com agente de acoplagem (anidrido maleico a 1\%), notou-se que os resultados eram bem similares aos do PP + CCA. Em termos de variações percentuais, para amostras de PP + $\mathrm{CCA}+\mathrm{AG}$, no ensaio de resistência ao impacto Izod, obteve-se os seguintes resultados : $32,9 \%$ para amostra na dose de $50 \mathrm{kGy} ; 52,9 \%$ para amostra na dose de $100 \mathrm{kGy} ; 70,3 \%$ para amostra na dose de $200 \mathrm{kGy} ; 79,8 \%$ para amostra na dose de $300 \mathrm{kGy}$ e 87,3\% para amostra na dose de $500 \mathrm{kGy}$.

Na FIG. 32 são mostrados os resultados de resistência ao impacto Izod para amostras de PP com cinza de casca de arroz e de PP com cinza de casca de arroz e agente de acoplagem em amostras irradiadas e não irradiadas. 


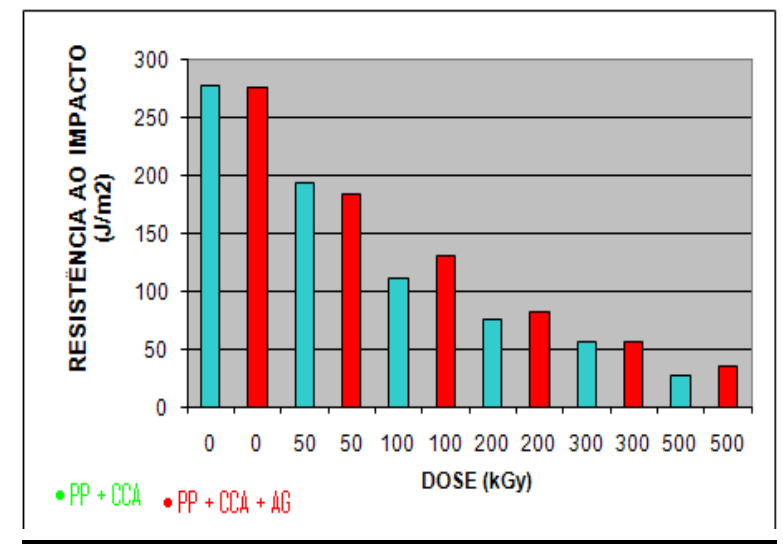

FIGURA 32-Resultados de resistência ao impacto Izod de amostras de PP com cinza de casca de arroz e de PP com cinza de casca de arroz e agente de acoplagem em amostras irradiadas e não irradiadas

À medida que se aumentou a dose de radiação observou-se que ocorreu uma diminuição na resistência ao impacto Izod indicando que a energia absorvida diminuiu, ou seja, ocorreu uma redução da tenacidade do material. A tenacidade está, provavelmente, associada à cisão das cadeias, pois com as cadeias mais curtas o processo de rearranjo molecular não é capaz de absorver a carga aplicada. Ao comparar os resultados das amostras de PP puro com PP + CCA não irradiados observou-se que houve um aumento nos valores do impacto devido à presença da CCA. Em se falando de variações percentuais, para amostras de PP $+\mathrm{CCA}$ e de PP $+\mathrm{CCA}+\mathrm{AG}$, no ensaio de resistência ao impacto Izod, obteve-se os seguintes resultados: 0,5\% para amostra na dose de $0 \mathrm{kGy}$; $5,1 \%$ para amostra na dose de $50 \mathrm{kGy} ;-17,2 \%$ para amostra na dose de $100 \mathrm{kGy} ;-8,3 \%$ para amostra na dose de $200 \mathrm{kGy} ; 0,1 \%$ para amostra na dose de $300 \mathrm{kGy}$ e $-2,6 \%$ para amostra na dose de $500 \mathrm{kGy}$.

Na TAB. 19 e FIG. 33, 34 e 36 são apresentados e mostrados resultados de testes de tensão na ruptura com PP, PP + CCA e de PP + CCA + AG nas doses de 0 a 500 kGy. 
TABELA 19 - Resultados de testes de tensão na ruptura de amostras de PP, PP + CCA e de $\mathrm{PP}+\mathrm{CCA}+\mathrm{AG}$ submetidas a diferentes doses de radiação

\begin{tabular}{ccccccr}
\hline Amostra & $0 \mathrm{kGy}$ & $50 \mathrm{kGy}$ & $100 \mathrm{kGy}$ & $200 \mathrm{kGy}$ & $300 \mathrm{kGy}$ & $500 \mathrm{kGy}$ \\
\hline PP & $30,5 \pm 0,9$ & $30,3 \pm 0,8$ & $25,3 \pm 0,5$ & $19,0 \pm 0,9$ & $16,1 \pm 1,7$ & $14,8 \pm 1,2$ \\
PP+CCA & $24,5 \pm 0,4$ & $22,5 \pm 0,7$ & $18,4 \pm 0,2$ & $15,3 \pm 0,4$ & $14,0 \pm 0,7$ & $14,3 \pm 0,7$ \\
PP+CCA+AG & $24,0 \pm 0,4$ & $22,4 \pm 0,3$ & $19,6 \pm 0,5$ & $16,4 \pm 0,5$ & $15,5 \pm 0,5$ & $13,7 \pm 1,0$ \\
\hline
\end{tabular}

Nas FIG. 33, 34 e 35 encontram-se resultados de tensão máxima (MPa) na ruptura para amostras de PP, PP + CCA e de PP com PP + CCA nas doses de 0 a $500 \mathrm{kGy}$.

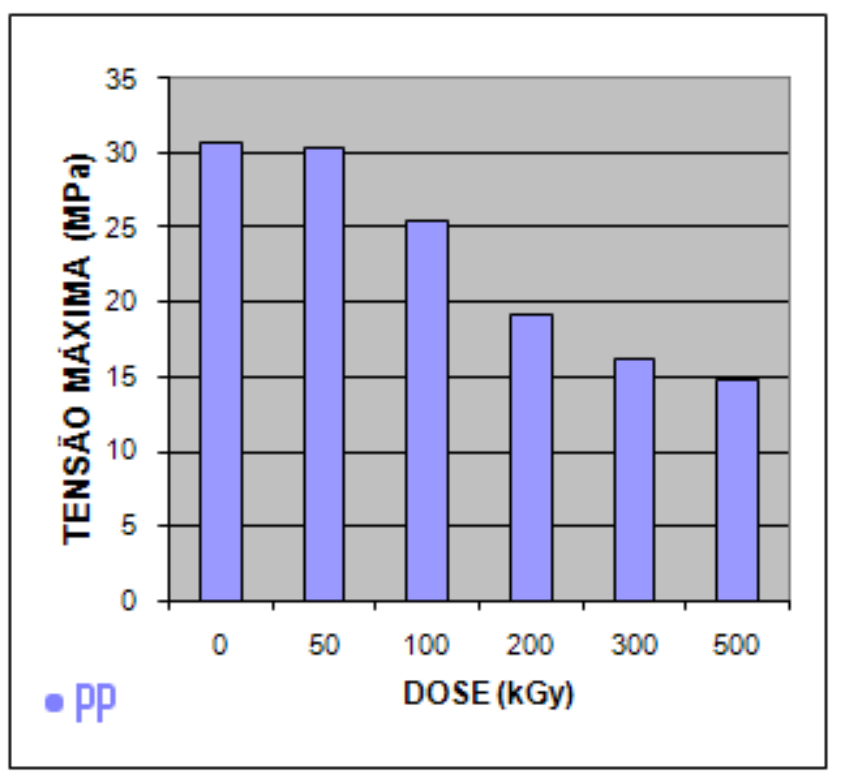

FIGURA 33 - Resultados de tensão máxima em amostras de PP irradiadas e não irradiada 


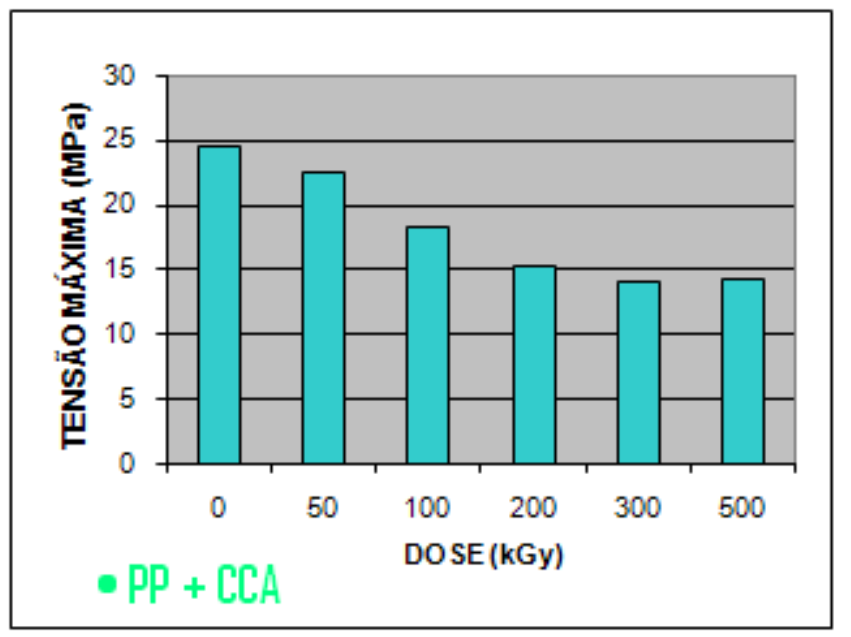

FIGURA 34 - Resultados de tensão máxima em amostras de PP irradiadas e não irradiada com cinza de casca de arroz

Em termos de variações percentuais, para amostra de PP, no ensaio de tensão na ruptura, obteve-se os seguintes resultados: $0,3 \%$ para amostra na dose de $50 \mathrm{kGy}$; $16,7 \%$ para amostra na dose de $100 \mathrm{kGy} ; 37,5 \%$ para amostra na dose de $200 \mathrm{kGy} ; 47 \%$ para amostra na dose de $300 \mathrm{kGy}$ e 51,3\% para amostra na dose de $500 \mathrm{kGy}$. Com as amostras de PP + CCA, com o mesmo tipo de ensaio, obteve-se os seguintes resultados: $8,1 \%$ para amostra na dose de $50 \mathrm{kGy} ; 24,8 \%$ para amostra na dose de $100 \mathrm{kGy} ; 37,5 \%$ para amostra na dose de $200 \mathrm{kGy}$; 42,8\% para amostra na dose de $300 \mathrm{kGy}$ e 41,6\% para amostra na dose de $500 \mathrm{kGy}$. 


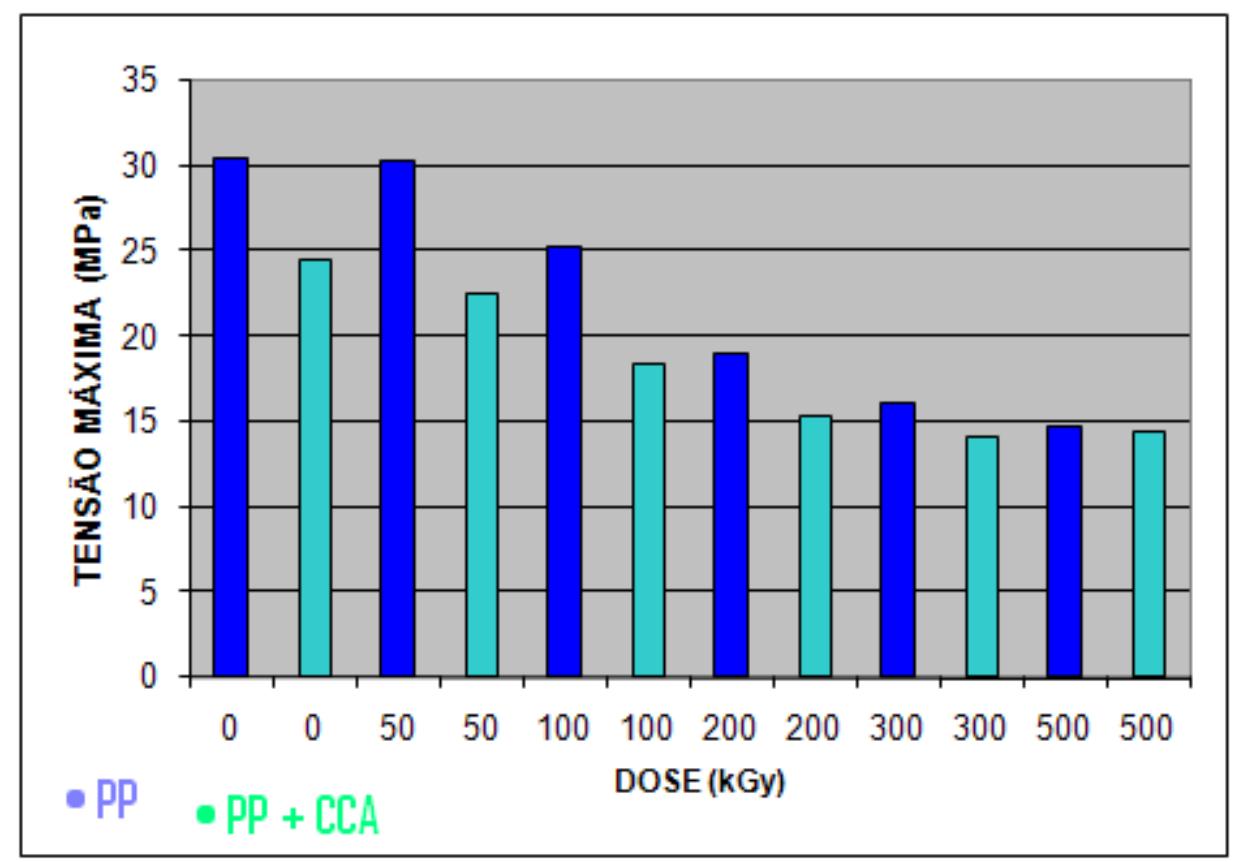

FIGURA 35 - Resultados de tensão máxima de amostras irradiadas e não irradiadas de PP e de PP com cinza de casca de arroz

No que diz respeito às variações percentuais, para amostras combinadas de PP e de PP + CCA, no ensaio de tensão na ruptura, obteve-se os seguintes resultados: 19,4\% para amostra na dose de $0 \mathrm{kGy} ; 25,7 \%$ para amostra na dose de $50 \mathrm{kGy} ; 2$,2\% para amostra na dose de $100 \mathrm{kGy} ; 19,4 \%$ para amostra na dose de $200 \mathrm{kGy} ; 13,0 \%$ para amostra na dose de 300 kGy e 3,3\% para amostra na dose de $500 \mathrm{kGy}$.

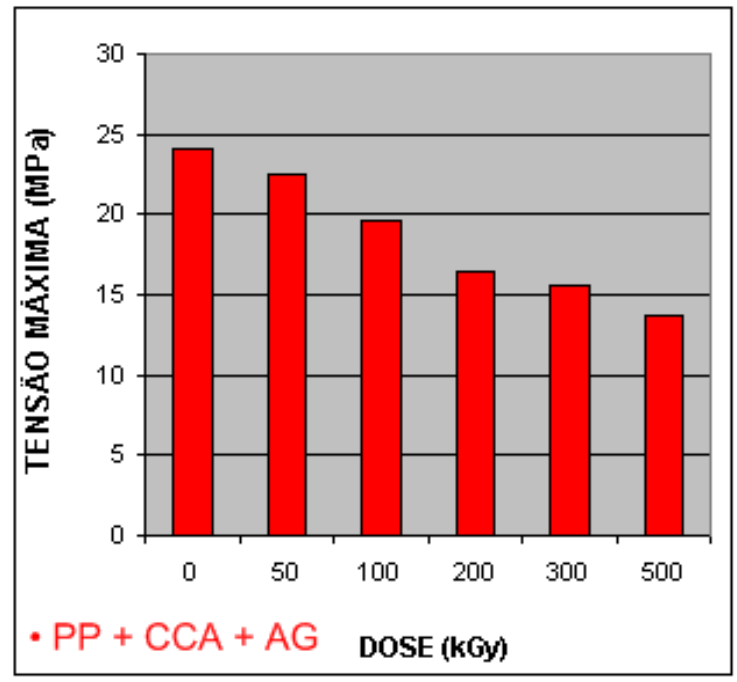

FIGURA 36 - Resultados de tensão máxima de amostras de PP com cinza de casca de arroz e agente de acoplagem em amostras irradiadas e não irradiada 
Em termos de resultados médios nos testes de tração, observa-se que à medida que a dose vai aumentando de 0 a 500 kGy, a tensão máxima ( $\mathrm{MPa}$ ) vai diminuindo, comparando-se o PP puro com o PP que continha cinza de casca de arroz, tal fato deve-se à cisão das moléculas de PP. O mesmo fato ocorreu também quando se utilizou o agente de acoplagem (anidrido maleico a 1\%). Com as amostras de PP $+\mathrm{CCA}+\mathrm{AG}$, no ensaio de tensão na ruptura, obteve-se os seguintes resultados com as respectivas variações percentuais: 6,6\% para amostra na dose de $50 \mathrm{kGy} ; 18,3 \%$ para amostra na dose de 100 kGy; 31,6\% para amostra na dose de $200 \mathrm{kGy}$; 35,4\% para amostra na dose de $300 \mathrm{kGy}$ e $42,9 \%$ para amostra na dose de $500 \mathrm{kGy}$.

Na FIG.37 são apresentados e mostrados resultados de tensão máxima de amostras de PP + CCA e de PP + CCA + AG em testes de tração.

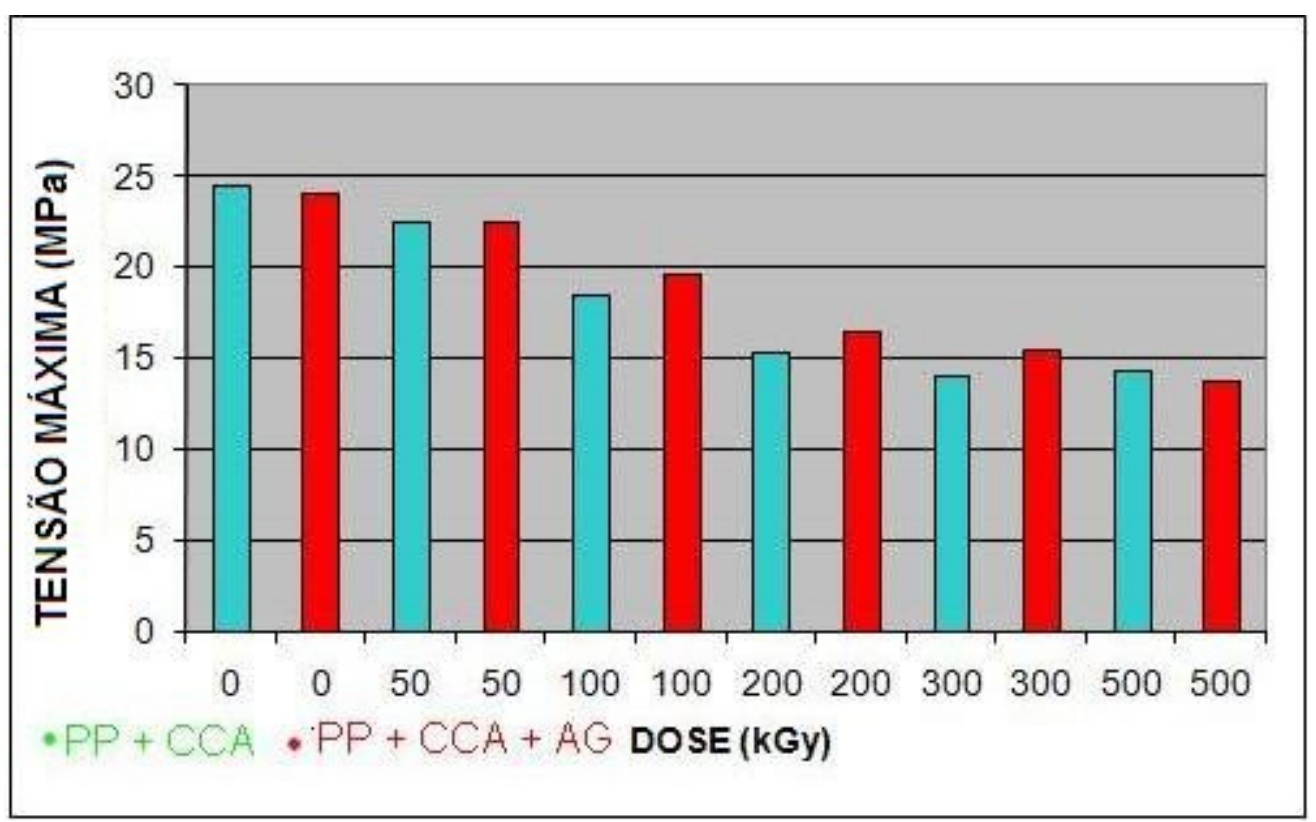

FIGURA 37 - Resultados de tensão máxima de amostras irradiadas e não irradiadas de PP com cinza de casca de arroz e de PP com cinza de casca de arroz e agente de acoplagem 
De acordo com os resultados apresentados na TAB. 19 observou-se que as tensões nas rupturas das amostras de PP, PP + CCA e PP + CCA + AG diminuíram. Este comportamento está de acordo com o observado no ensaio de impacto que mostraram também, uma diminuição com o aumento da dose de radiação. Estas duas propriedades são indicadoras da tenacidade do material e mostraram que o PP apresenta uma tendência à ocorrência de fratura frágil com o aumento da dose de radiação. No que diz respeito às amostras de PP + CCA e de PP + CCA + AG, no ensaio de tensão na ruptura, obteve-se as seguintes variações percentuais: 2,0\% para amostra na dose de $0 \mathrm{kGy} ; 0,4 \%$ para amostra na dose de $50 \mathrm{kGy} ;-6,5 \%$ para amostra na dose de $100 \mathrm{kGy} ;-7,1 \%$ para amostra na dose de $200 \mathrm{kGy} ;-10,7 \%$ para amostra na dose de $300 \mathrm{kGy}$ e $4,1 \%$ para amostra na dose de 500 $\mathrm{kGy}$.

Foram obtidas algumas micrografias do polímero em questão em amostras de polipropileno (PP) puro, polipropileno combinado com cinza da casca de arroz (PP + CCA) e, também, polipropileno com cinza da casca de arroz e agente de acoplagem (PP + CCA + anidrido maleico a 1 \%), conforme FIG. 38 a 43, nas doses de 0 e 200 kGy.

\section{PP puro O KGy(9)}

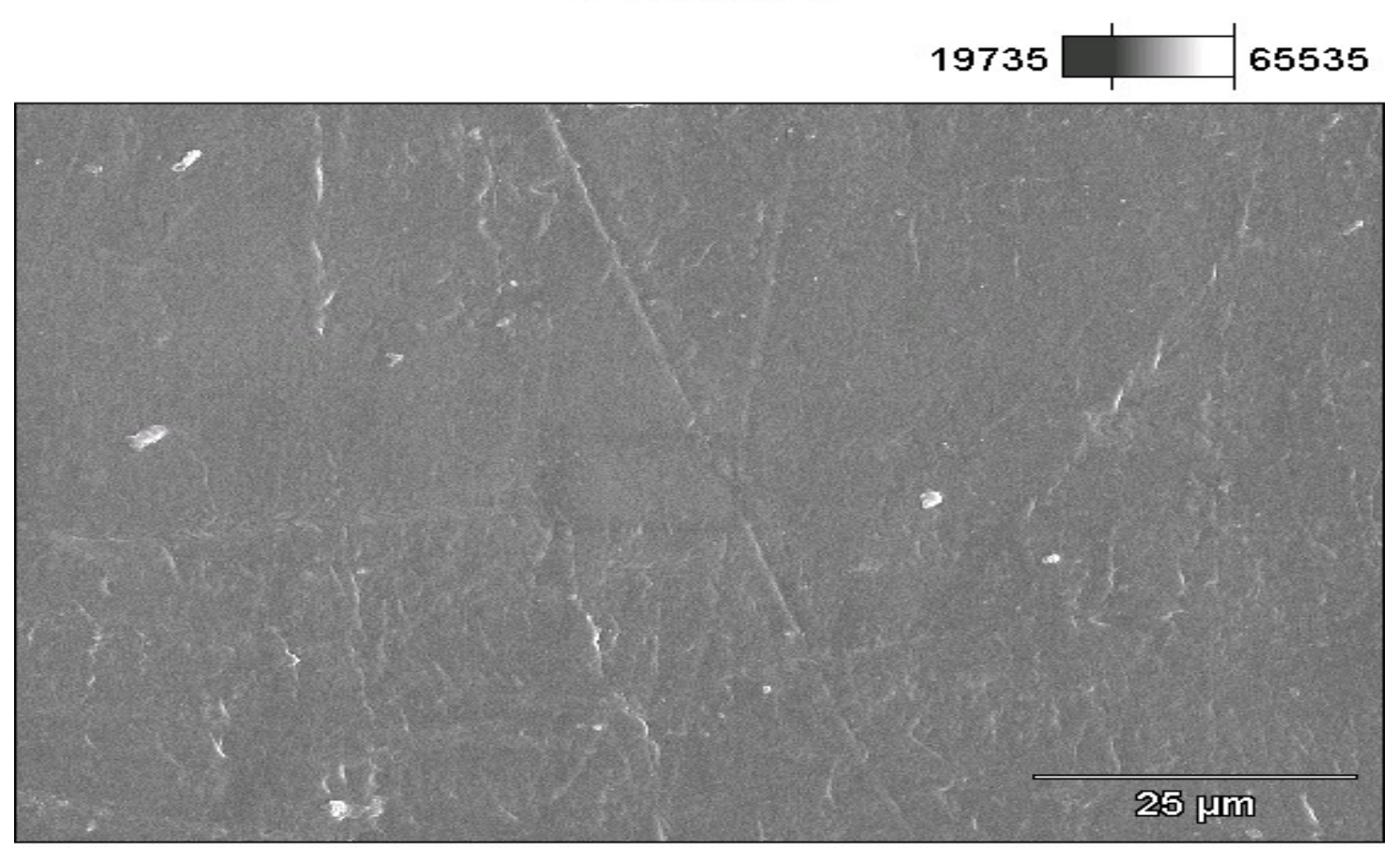

FIGURA 38 - Micrografia de amostra de PP a 0 kGy 


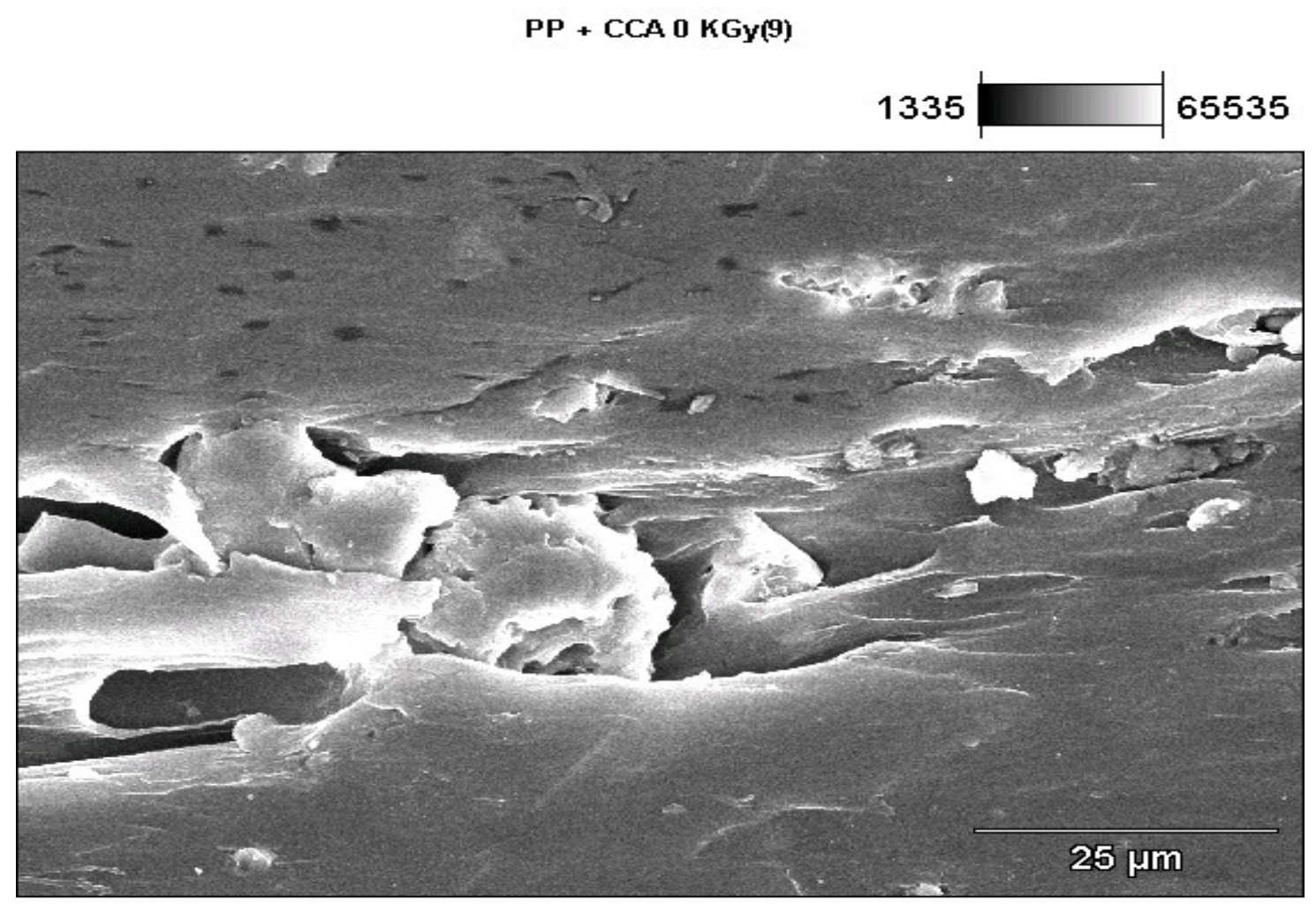

FIGURA 39 - Micrografia de amostra de PP com cinza de casca de arroz a 0 kGy $P P+C C A+A G$ AC O KGy(7)

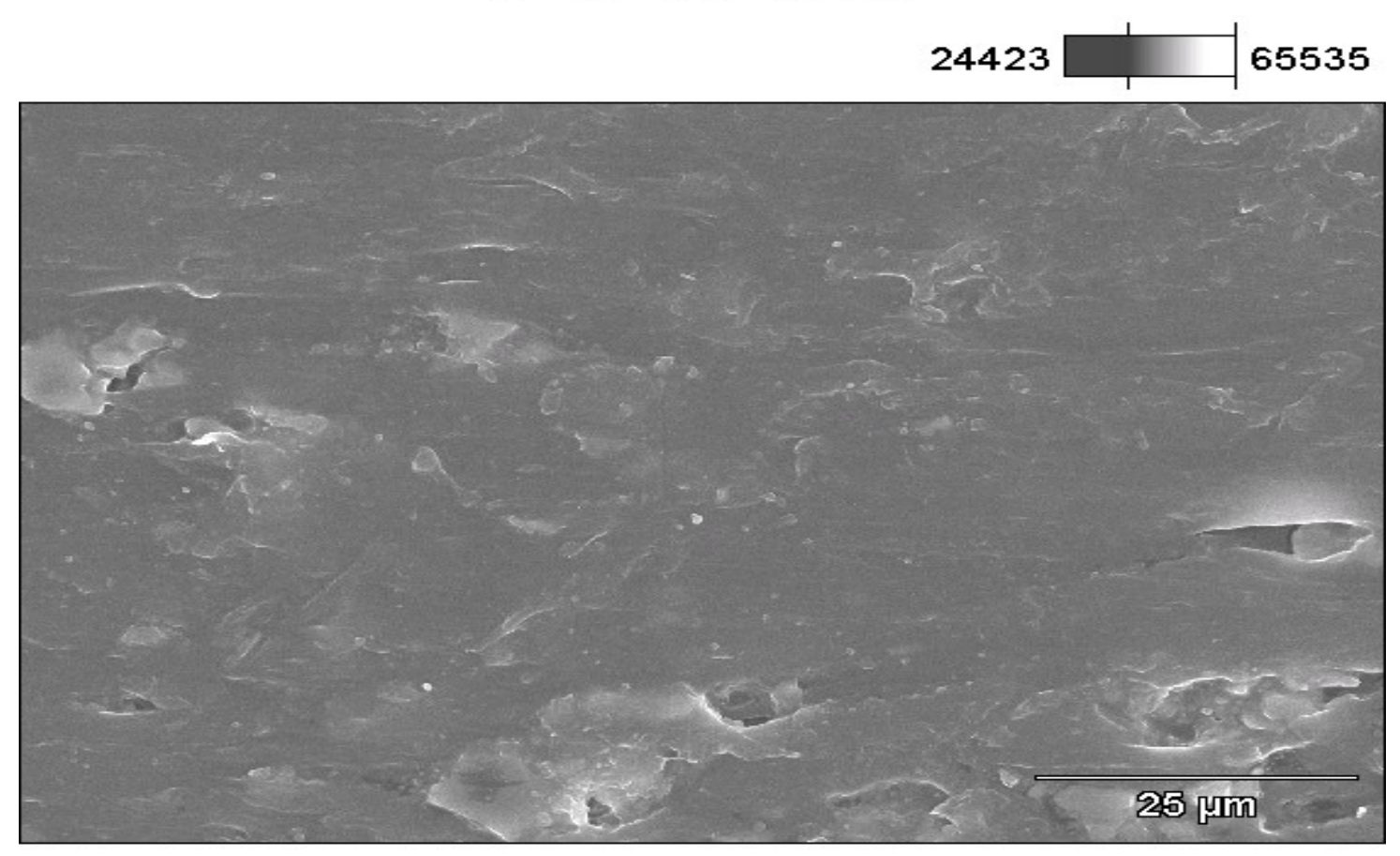

FIGURA 40 - Micrografia de amostra de PP com cinza de casca de arroz e agente de acoplagem a $0 \mathrm{kGy}$ 
PP puro 200 KGy(4)

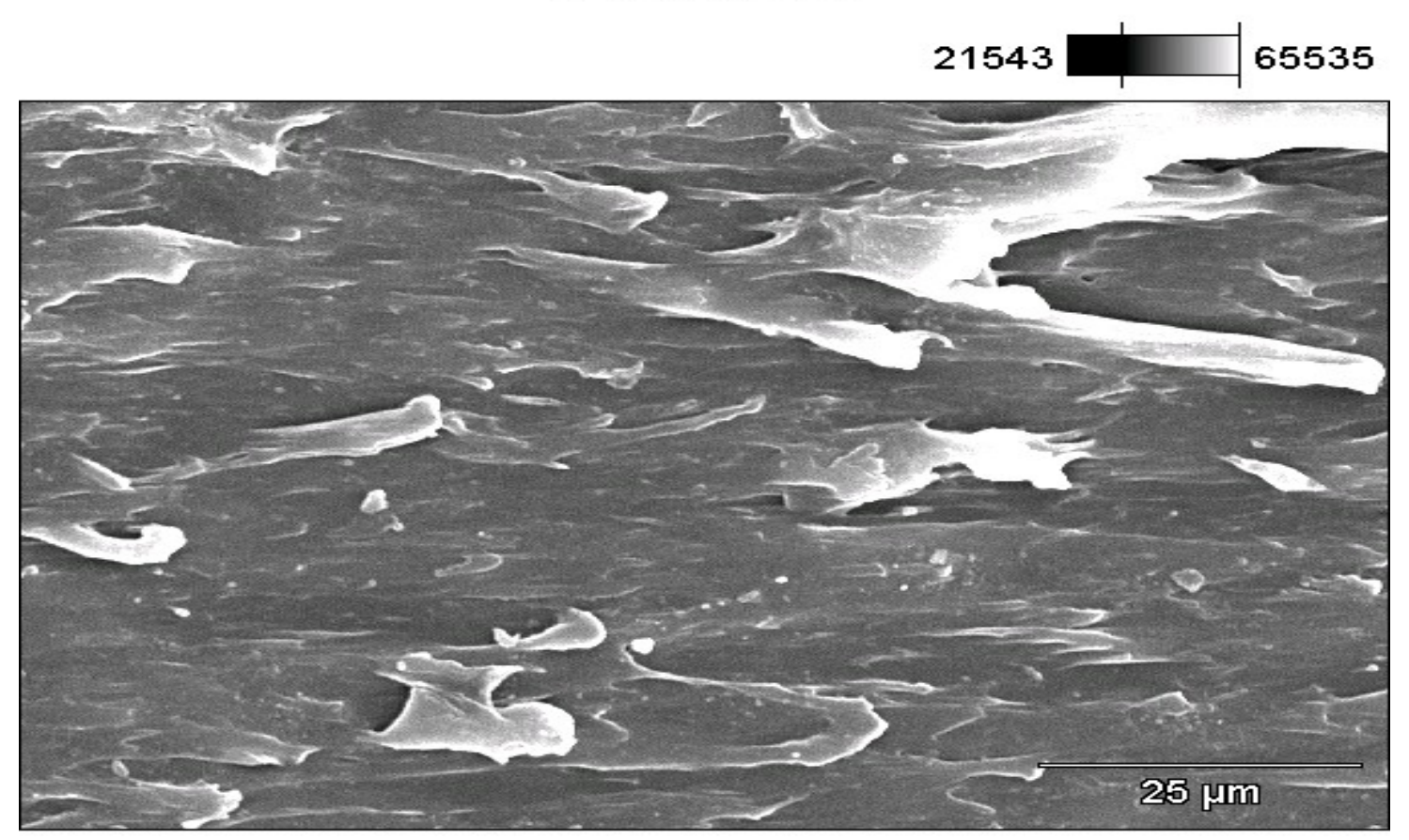

FIGURA 41 - Micrografia de amostra de PP a 200 kGy

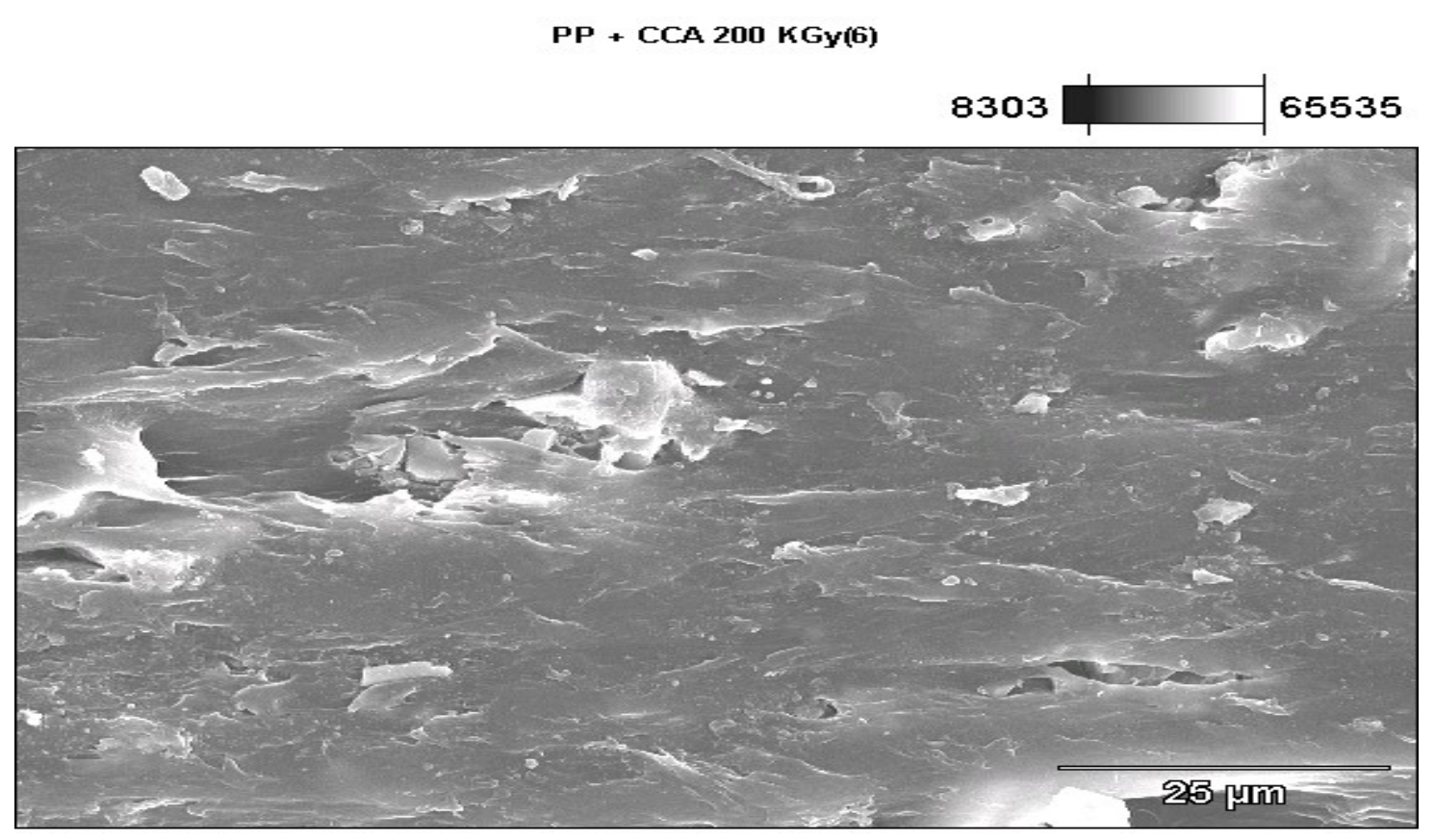

FIGURA 42 - Micrografia de amostra de PP com cinza de casca de arroz a 200 kGy 


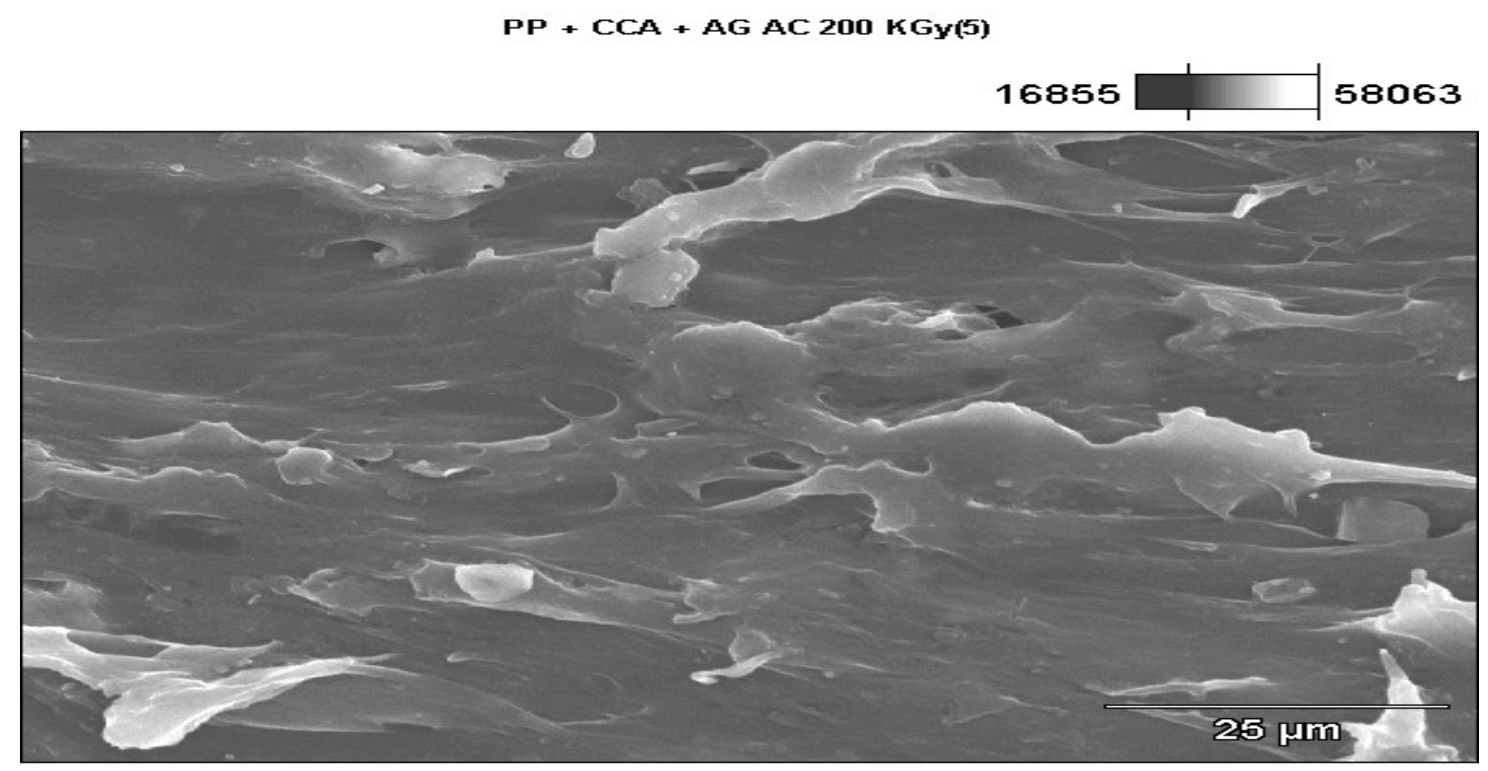

FIGURA 43 - Micrografia de amostra de PP com cinza de casca de arroz e agente de acoplagem a $200 \mathrm{kGy}$

De acordo com as micrografias pode-se concluir que o PP com a cinza da casca de arroz e agente de acoplagem, na amostra não irradiada, está mais homogêneo do que o PP com cinza da casca de arroz (CCA). Quando se irradiou o polipropileno com cinza de casca de arroz e agente de acoplagem a $200 \mathrm{kGy}$, houve uma melhor dispersão da carga (cinza da casca de arroz) e também uma melhor interação do PP com a cinza da casca de arroz em razão da presença do agente de acoplagem.

Nas FIG. 44 e 45 são apresentados os espectros de absorção na região do infravermelho correspondentes as amostras de PP e de PP + CCA não irradiadas e submetidas às doses de radiação de 200 e $500 \mathrm{kGy}$, respectivamente. 


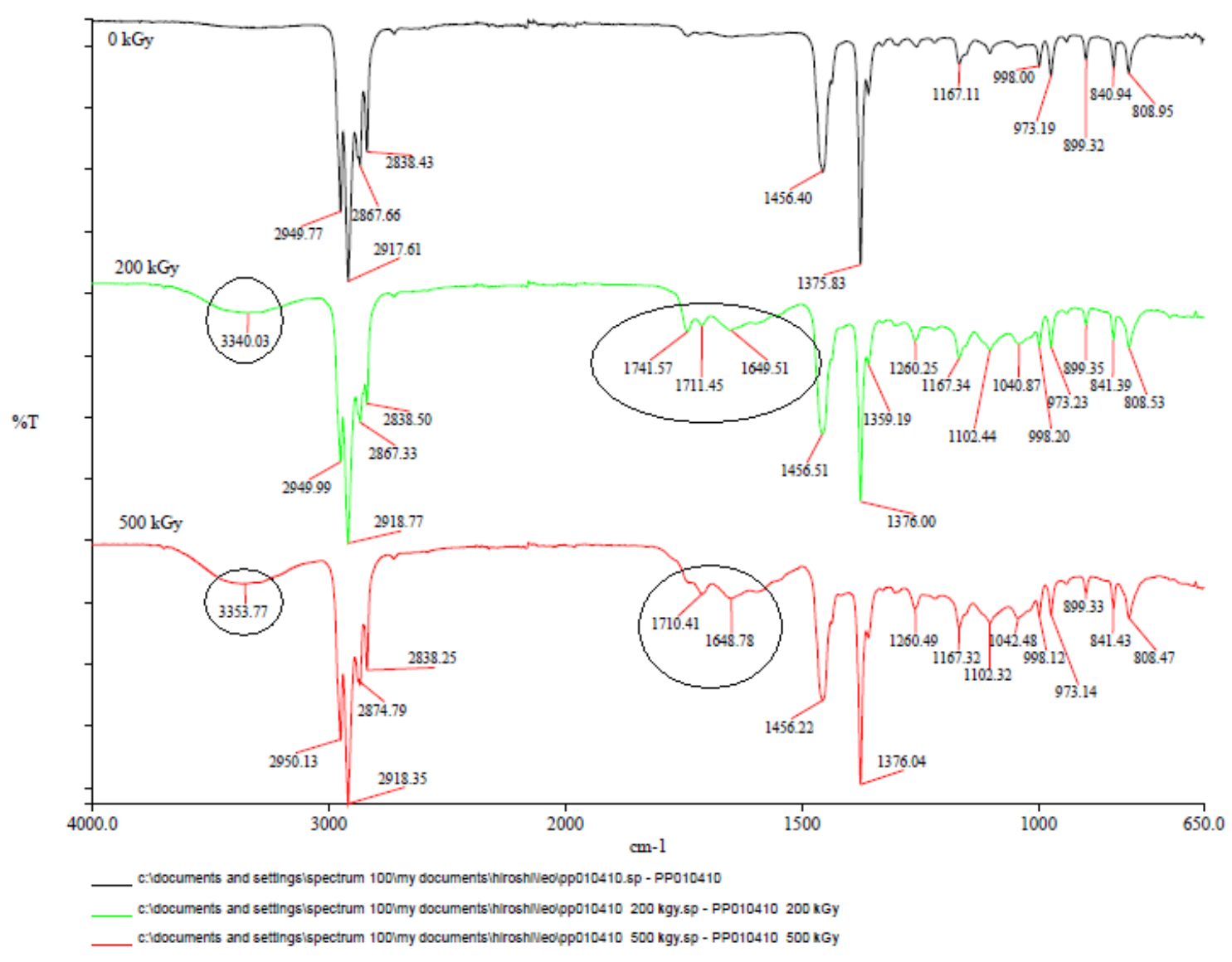

FIGURA 44 - Espectros de absorção na região do infravermelho das amostras de PP não irradiada e submetidas a doses de radiação de 200 e 500 kGy 


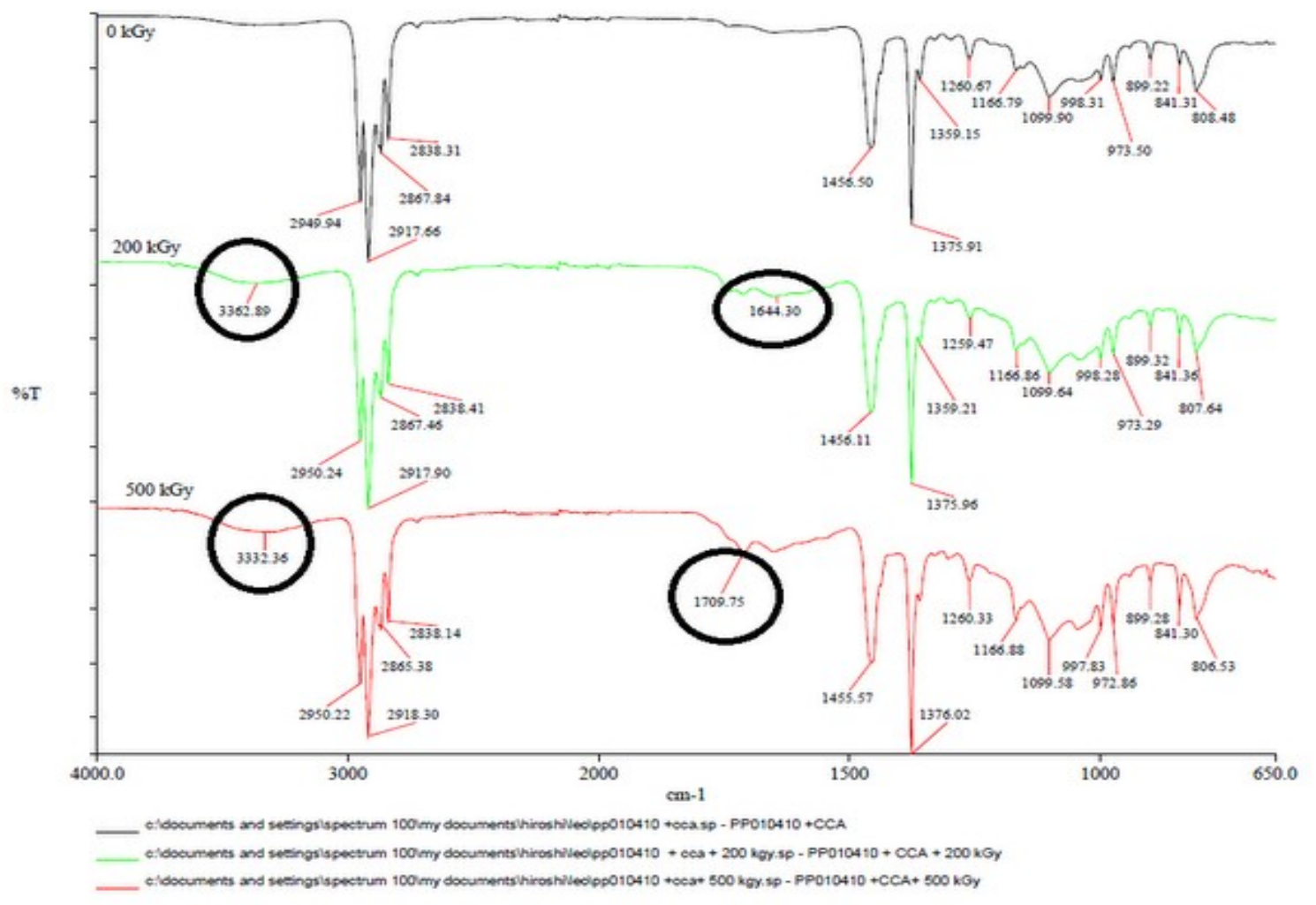

FIGURA 45 - Espectros de absorção na região do infravermelho das amostras de PP + CCA não irradiada e submetidas a doses de radiação de 200 e 500 kGy

De acordo com os espectros mostrados nas FIG. 44 e 45 quando as amostras de PP puro e de PP + CCA foram irradiadas observou-se o aparecimento das bandas na região de aproximadamente $3350 \mathrm{~cm}^{-1}$ o que correspondeu a absorção do grupo $\mathrm{OH}$ provavelmente devido a oxidação do PP que foi irradiado na presença de ar. Também, se observou o aparecimento de bandas entre 1600-1800 $\mathrm{cm}^{-1}$ correspondentes aos grupos carbonila subproduto da oxidação do PP o que está de acordo com a literatura (TERENCE, 2009). 


\section{CONCLUSÕES}

Da primeira etapa deste trabalho, em razão do fato das propriedades do composto de PP com a carga de $20 \%$ de cinza de casca de arroz terem apresentado resultados inferiores em relação àquelas quando se utilizou $20 \%$ de talco como carga, pode-se concluir que a cinza de casca de arroz pode ser usada como carga de enchimento para outros usos menos nobres do PP. Desta forma se está dando um destino para esse resíduo que hoje é descartado no meio ambiente contribuindo para a preservação do mesmo, além de reduzir o custo do produto.

De acordo com os resultados obtidos quando se irradiou as amostras de PP puro e PP + CCA pode-se dizer que o PP é um polímero semi-cristalino e portanto tem sua morfologia modificada quando exposto ao processo de irradiação. Este fato é atribuído aos mecanismos de cisão das cadeias poliméricas, fato que está de acordo com a literatura.

De acordo com as micrografias pode-se dizer que nas amostras não irradiadas de PP + CCA + AG ocorreu uma melhor homogeneização quando comparado com as amostras de PP + CCA. Quando as amostras foram irradiadas a $200 \mathrm{kGy}$, observou-se melhor dispersão da carga (CCA) e, também, uma melhor interação do PP com a CCA em razão da presença do agente de acoplagem.

Nos espectros de absorção na região do infravermelho quando as amostras de PP e de PP + CCA foram irradiadas notou-se o aparecimento de bandas de absorção na região de $3350 \mathrm{~cm}^{-1}$ (presença do grupo $\mathrm{OH}^{-}$) e, da mesma forma, entre $1600-1800 \mathrm{~cm}^{-1}$ (presença do grupo carbonila) correspondente a oxidação do PP, uma vez que as irradiações foram realizadas em presença de ar. 


\section{REFERÊNCIAS BIBLIOGRÁFICAS}

ALBUQUERQUE, J.A.C. O plástico na prática. Porto Alegre, RS: Editora Sagra, 1990, p. $46-49$ e 211.

AMERICAN SOCIETY FOR TESTING MATERIALS, Standard Test Method for tensile properties of plastics (ASTM D - 638-09).

AMERICAN SOCIETY FOR TESTING MATERIALS, Standard Test Method for Heat Distortion Temperature and Softening Point (ASTM D -.648-81).

AMERICAN SOCIETY FOR TESTING MATERIALS, Standard Test Method for Vicat Softening Temperature of plastics (ASTM D - 1525-81).

AMERICAN SOCIETY FOR TESTING MATERIALS, Standard Test Method for rubber property - Durometer Hardness (ASTM D - 2240 ).

AMERICAN SOCIETY FOR TESTING MATERIALS, Standard Test Method for determining the Izod pendulum impact resistance of plastics (ASTM D $256-06 \mathrm{ae} 1$ ).

ASCIUTTI, S. A. Apostila poliamida 6 e 6.6, produção e transformação, Petronyl, 1997.

BAKER ,D.F..; WEBER, K.E. Introduction to fillers. In: Modern Plastics Encyclopedia, N.Y.: New York, McGraw Hill, 1989.

BERA, J ; KALE,D.D. Effect of particle size of chemically treated rice husk powder on the properties of filled polypropylene .J. Polym. Mat., v. 23, n. 2, p. 203-209, 2006.

BERA, J.; KALE, D.D. . Properties of polypropylene filled with the chemically treated rice husk. J. Appl. Polym. Sci., v. 110, n. 2, p.1271-1279, 2008.

BILLMEYER, F.W. Textbook of polymer science. 3.ed. New York, N.Y.:Wiley, 1986, p.369.

BONDIOLI, F.; ANDREOLA, F.; BARBIERI, L.; MANFREDINI, T.; FERRARI, A.M. . Effect of rice husk ash (RHA) in the synthesis of $(\mathrm{Pr}, \mathrm{Zr}) \mathrm{SiO}_{4}$ ceramic pigment. Journal of European Ceramic Society, v.27, n. 12, p.3483-3488, 2007.

BRYDSON, J.A. Plastics materials. London: Butterworth \& Co Ltd, 1975, p.182-247.

BUI, D.D.; HU, J.; STROEVEN, P. Particle size effect on the strength of rice husk ash blended gap-graded Portland cement concrete. Cem. Concr. Compos., v.27, n. 3, p.357$366,2005$.

CHAPIRO,A. Radiation-induced reactions In: Encyclopedia of Polymer Science and Technology, NewYork, N.Y.: John Wiley, v. 11, p. 702-760, 1969. 
CHARlesby, A.. Atomic Radiation and Polymers. Oxford: Pergamon, 1960.

CLEGG, D.W. ;COLLYER, A.A. Irradiation effects on Polymers. New York, N.Y.: Elsevier Science, 1991.

DELLA, V.P. Processamento e caracterização de sílica ativa obtida a partir da cinza de casca de arroz. 2001. Dissertação (Mestrado) - Universidade Federal de Santa Catarina, Santa Catarina.

FELISBERTI, M.I.; SILVA, M.A. Síntese e Reatividade de Macromoléculas. QG 952 Processamento de polímeros - Cap. 4, 2007. Disponível em: $<$ http//www.www.gppol.iqm.unicamp.br/QG\%2095220\%cap\%20iv.pdf $>$ Acesso em :14 out .2007 .

FERRO, S. Commodities - Preço e Consumo revertem queda no segundo semestre. Editora QD Ltda, Revista Plástico Moderno, n. 369, 2005.

FERRO, W.P.; WIEBECK, H.; SILVA, L.G.A. Uso da cinza da casca de arroz como carga em matrizes de poliamida 6 e poliamida 6.6. Polímeros, v. 17, n.3 , p. 240-243, 2007.

FICHA DE INFORMAÇÃO DE SEGURANÇA DE PRODUTO QUÍMICO- FISPQ. Produto: polipropilenos, Revisão: 02, datada de 13/10/2004, item 9. Disponível em: http//www2.braskem.com.br/ori-tec/fispq/pdf/FISPQ_PP_BRASKEM.pdf. Acesso em 02 out 2007 .

FROUCHI, M.; DABDIN, S. Composites of rice husk/wheat straw with PMDI resin and polypropylene composites. Polym. Polym. Compos., v. 15, n. 8, p. 619-625, 2007.

FUAD, M.Y.A.; YAKOB, J.; ISHAK, Z.A.M.; OMAR, A.K.M. Density measurement of rice husk ash filler particles in polypropylene composites. Polym. Test., v.12, n.2, p. 107$112,1993$.

FUAD, M.Y.A.; ISMAIL, Z.; ISHAK, Z.A.M.; OMAR, A.K.M. Application of rice husk ash in polypropylene : Effect of titanate, zirconate and silane coupling agents . European Polym. Journal, v.31, n.9, p.885-893, 1995.

FUNDAÇÃO DE AMPARO À PESQUISA DO ESTADO DA BAHIA Relatório técnico final - Desenvolvimento de Compósitos de polipropileno com sisal - PP/ sisal, item 2.1.1, Salvador, 2005. Disponível em: $<$ http www.fabesp.gov.br/ fabesp/ programas/ projetos_estrategicos/rele_apl/2006-12>. Acesso em :19 jun. 2007.

GODLEWSKI, R.E.; HEGGS, R.P. Coupling agents In: Thermoplastic Polymer Additives, Lutz Jr., J. T. (ed). New York, N.Y.: Marcel Dekker Inc, 1989.

GORNI, A.A. Introdução aos plásticos. 2004. Disponível em:< http//www.gorni.eng.br $>$. Acesso em : 09 fev. 2007. 
GOULAS, A.E. ; RIGHANAKOS, K.A. ; KONTOMINAS, M.G. Effect of ionizing radiation on physicochemical and mechanical of commercial coextrude flexible plastics packaging materials. Radiat.Phys. Chem., v. 68, p. 865-872, 2003.

GULMINE et al., 2002; apud OZZETTI, 2004 apud TERENCE, M.C.. Estudo da formação e das propriedades de blendas poliméricas de polipropileno e de polietileno submetidas à radiação gama. 2009. Tese (Pós Doutorado) - Instituto de Pesquisas Energéticas e Nucleares, São Paulo.

HESS, R.; HERRMANN, H. Ceras/Polímeros feitos sob medida por catálise metalocênica. Editora QD Ltda, Revista Plástico Moderno, n. 368, 2005.

INSTITUTO DE QUÍMICA DA UNIVERSIDADE FEDERAL DO RIO GRANDE DO SUL Poliolefinas ufrgs prorext tecpol. Disponível em: $<$ http//www.iq.ufrgs.br/solid/poliolefinas.doc $>$. Acesso em: 14 out .2007.

INTERNATIONAL ORGANIZATION FOR STANDARDIZATION , Plastics Determination of flexural properties ( ISO $178: 2001$ ).

INTERNATIONAL ORGANIZATION FOR STANDARDIZATION , Plastics Determination of tensile properties Part 1 : General principles ( ISO 527-1 : 1993).

INTERNATIONAL ORGANIZATION FOR STANDARDIZATION , Plastics Determination of tensile impact strength ( ISO $179: 2004$, alterada pela norma ISO $8256: 2004)$.

INTERNATIONAL ORGANIZATION FOR STANDARDIZATION , Plastics Determination of the melt mass-flow rate ( MFR ) and the melt volume -flow rate (MVR ) of thermoplastics ( ISO 1133: 2005 ).

INTERNATIONAL ORGANIZATION FOR STANDARDIZATION , Plastics Determination of temperature of deflection under load Part 2 : Plastics and ebonite ( ISO 75-2 A : 1993 , revisada pela norma ISO 75-2 : 2004 ).

INTERNATIONAL ORGANIZATION FOR STANDARDIZATION , Plastics Determination of ash - Part 1 : General methods ( ISO 3451-1 : 1997 , revisada pela norma ISO 3451-1:2008).

ISMAIL, H. ; OSMAN, H..; JAAFAR,M. Hybrid-filler filled polypropylene (natural rubber) composites. Effect of natural weathering on mechanical and thermal properties and morphology. J. Vinyl Addit Technol., v, 14, n.3, p.142-151, 2008.

JANOWITZER, M. Propileno clarificado oferece ampla variedade de aplicações. Editora QD, Revista Plástico Moderno, n. 363, 2005.

JAUBERTHIE, R.; RENDELL, F.; TAMBA, S.; CISSE, J. Origin of the pozzolanic effect of rice husks. Construction and Building Materials, v. 14, n.8, p.419-423, 2000.

LORIS, L.Z; BERALDO, A. Efeito da adição da cinza da casca de arroz. Engenharia Agrícola, v. 28, n .2, p. 217-226, 2008. 
MACHADO, L.D.B.; MATOS, J.R. Análise térmica diferencial e calorimetria exploratória diferencial. In: CANEVAROLO JR., S.V. (Ed.). Técnicas de Caracterização de Polímeros. São Paulo, S.P.: Artliber Editora, 2004 p. 229-261.

MANO, E.B; MENDES, L.C. Introdução a polímeros. 2.ed. São Paulo, S.P.: Editora Edgard Blucher, 1999, p.54-55 e 94.

MANO. E.B, Polímeros como materiais de engenharia. São Paulo, S.P., Editora Edgard Blucher, 1991, p.4.

MATOS, J.R., MACHADO, L.D.B. Análise térmica - Termogravimetria. In: CANeVarolo JR., S.V. (Ed.). Técnicas de Caracterização de Polímeros. São Paulo, S.P.: Artliber Editora, 2004. p.209-228.

MIRANDA, L.F. Estudo de parâmetros de processo para a síntese de membranas hidrofilicas a base de poli(n-vinil-2-pirrolidona). 1999. Tese (Doutorado) - Instituto de Pesquisas Energéticas e Nucleares, São Paulo.

MORRISON, T.R.;; BOYD,.R.N. Química Orgânica. 7.ed., Lisboa.: Fundação Calouste Gulbenkian, 1973, p. 1232-1233.

O'DONNELl, J.H. \& SANGSTER, D.F. Principles of Radiation Chemistry, New York, N.Y., Arnold E, 1970.

PLÁSTICOS CARONE LTDA. A história do plástico - Os primórdios do plástico. 1997. Disponível em : <http://www.plasticoscarone.com.br/siscarone/lenoticia.asp $>$ Acesso em: $12 \mathrm{fev}$. 2007.

PLATZER, N.A.J. Irradiation of Polymers. Washington. American Chemical Society, 1967.

RAZAVI-NOURI, M.; JAFARZADEH-DOGOURI, F.; OROMIEHIE, A. Mechanical properties and water absorption behaviour of chopped rice husk filled polypropylene composites . Iranian Polym. J., v.15, n. 9, p. 757-766,2006.

RIONIL COMPOSTOS VINÍLICOS LTDA. 2007. Disponível em:< http//www.rionil.com.br/plásticos.htm.>. Acesso em : 21 fev. 2007.

SAECHTLING, H. Manuale delle materie plastiche, Milano: Tecniche Nuove, Edizione Italiana, 1996.

SAE-OUI, P.; RAKDEE, C.; THANMATHORN, P. Use of hice husk ash in natural rubber vulcanizates: in comparison with other commercial fillers. J. Appl Polym. Sci, v. 83, n. 11, p. $2485-2493,2002$.

SALMAH , H.; ISMAIL,H. The effect of filler loading and maleated polypropylene on properties of rubberwood filled polypropylene. J. Reinf. Plast. Compos, v. 27, n.16-17, p.1867-1876, 2008. 
SANTOS, F.L. Polímeros condutores. 2000. Disponível em $<\mathrm{http} / /$ www.unicap.br/Chico/polimeros1.htm>. Acesso em: 17 fev. 2007.

SERAS,S.M.; SULTANA, S.; NARAYAN SWAMY, R. Potential of indigenously produced rice ash in concrete. Copyright 2006 INIST- CNRS . Disponível em: < http// www.cat.inist.fr/?aModele $>$ Acesso em: 23 maio 2007.

SEREDA, L.; LÓPEZ-GONZALEZ, M.M. ; VISCONTE, L.L.Y.; NUNES, R.C.; FURTADO, C.R.G.; RIANDE, E. Influence of sílica and black husk ash fillers on the diffusivity and solubility of gases in silicone rubbers. Polymer, v. 44, n.10, p.3085-3093, 2003.

SIRIWARDENA,S.; ISMAIL, H.; ISHIAKU, U.S. White rice husk ash filled ethylenepropylene-diene terpolymer/polypropylene blends: effect of dinamic vulcanization and filler loading . Polym.- Plast. Technol Eng., v.40, n. 4, p. 519-538, 2001.

SOLOMONS, T.W.G. Química Orgânica. Rio de Janeiro, R.J., Livros Técnicos e Científicos Editora, 1982, p. 52-53, 280 e 286.

SOUZA, M.F.; BATISTA, P.S.; LIBORIO, J.B.L. Processo de Extração da Sílica Amorfa Contida na Casca e na Planta do Arroz .Privilégio de Inovação BR PI Pat. 9903208, 30 jun. 1999 (Depósito).

STEVENS, M.P. Polymer chemistry - an introduction . 2.ed. New York, N.Y.: Oxford University Press, 1990, p. 31, 33 e 34.

SUZANO PETROQUÍMICA Sobre o polipropileno.2007. Disponivel. em $<$ :http www.suzanopetroquimica.com.br/ website / home / Produtos/ sobreopp.cfm>. Acesso em: 05 jun. 2007.

TORO, P.; QUIJADA, R.; MURILLO, O. Study of morphology and mechanical properties of polypropylene composites with silica or rice husk. Polym.Int. ,v. 54, n. 4, p. 730-734, 2005.

VICK polipropileno -VICK . 2007 . Disponivel em: $<$ http www.vick.com.br / vick / produtos /polipropileno/ polipropileno.htm> . Acesso em: 05 jun. 2007.

WIEBECK, H.; BORRELlY, D. F.; XAVIER, C.; SANTOS, P. S.; ASCIUTTI, S. A.; CORRÊA, M. P. The effect of silane coupling agents on a composite polyamide $6 /$ talc J. Chem. Eng., v. 15, p. 406 - 409, 1998.

YANG, H.S.; KIM, H.J. Effect of compatibilizing on rice husk flour reinforced polypropylene composites. Composites Structures , v.77, n. 1, p. 45-55, 2007. 
